$$
\begin{gathered}
\text { Aus dem Fachbereich Medizin } \\
\text { der Johann Wolfgang Goethe-Universität } \\
\text { Frankfurt am Main }
\end{gathered}
$$

betreut am

Zentrum der Kinder- und Jugendmedizin

Institut für experimentelle Tumorforschung in der Pädiatrie

Direktorin: Prof. Dr. Simone Fulda

\title{
Evaluation of $\mathrm{BH} 3$ mimetics as a novel therapeutic strategy in acute myeloid leukemia
}

\author{
Dissertation \\ zur Erlangung des Doktorgrades der Medizin \\ des Fachbereichs Medizin \\ der Johann Wolfgang Goethe-Universität \\ Frankfurt am Main
}

vorgelegt von

Larissa Ewald

aus Frankfurt am Main

Frankfurt am Main, 2020 



$$
\begin{gathered}
\text { Aus dem Fachbereich Medizin } \\
\text { der Johann Wolfgang Goethe-Universität } \\
\text { Frankfurt am Main }
\end{gathered}
$$

betreut am

Zentrum der Kinder- und Jugendmedizin

Institut für experimentelle Tumorforschung in der Pädiatrie

Direktorin: Prof. Dr. Simone Fulda

\title{
Evaluation of $\mathrm{BH} 3$ mimetics as a novel therapeutic strategy in acute myeloid leukemia
}

\author{
Dissertation \\ zur Erlangung des Doktorgrades der Medizin \\ des Fachbereichs Medizin \\ der Johann Wolfgang Goethe-Universität \\ Frankfurt am Main
}

vorgelegt von

Larissa Ewald

aus Frankfurt am Main

Frankfurt am Main, 2020 
Dekan:

Referentin:

Korreferent:

2. Korreferentin:
Prof. Dr. Stefan Zeuzem

Prof. Dr. Simone Fulda

Prof. Dr. Thomas Oellerich

Prof. Dr. Daniela Krause

04.08.2021 


\section{Table of contents}

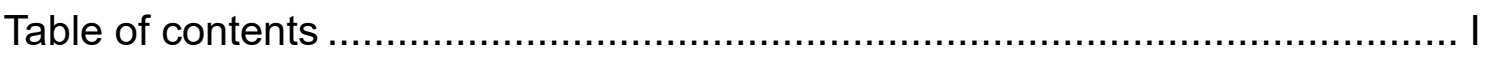

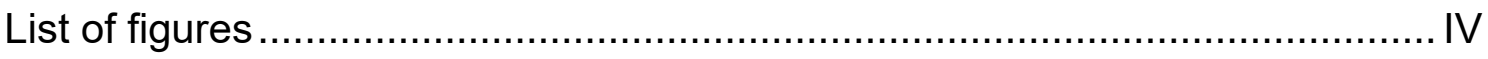

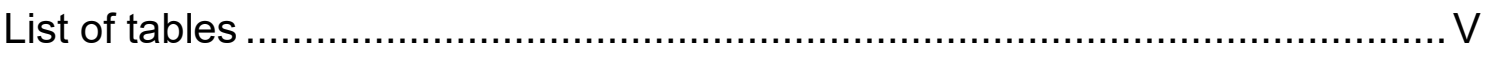

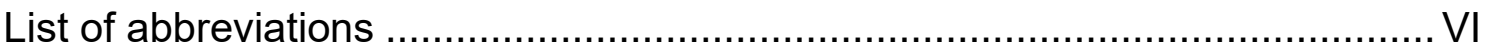

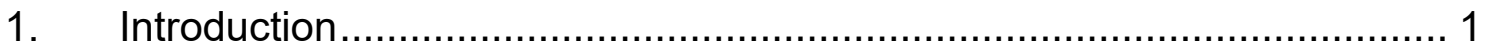

1.1 Acute myeloid leukemia ............................................................ 1

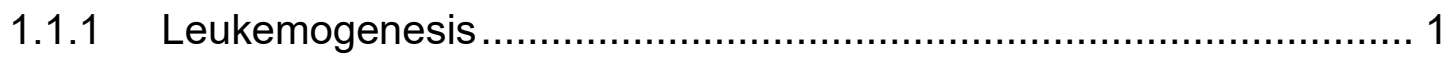

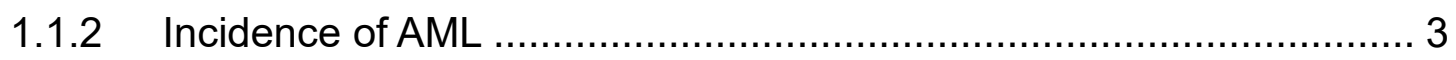

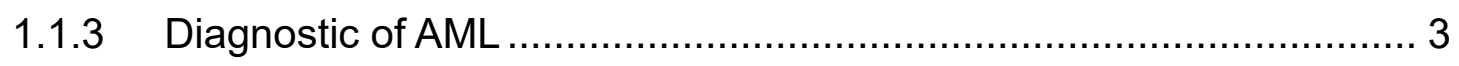

1.1.4 Standard therapeutic strategy against AML .................................. 7

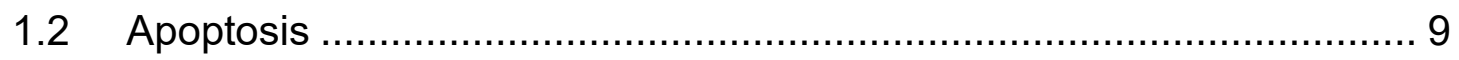

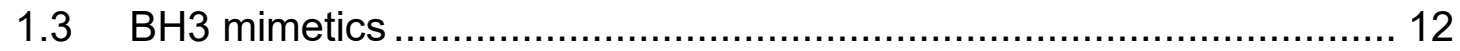

1.3.1 Steps towards the development of selective $\mathrm{BH} 3$ mimetics ............ 12

1.3.2 Selective BCL-2 inhibitors: ABT-199 and S55746 ........................ 12

1.3.3 Selective BCL-XL inhibitor: A-1331852 ...................................... 13

1.3.4 Selective MCL-1 inhibitor: S63845 ............................................... 14

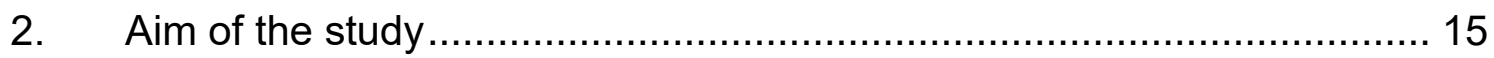

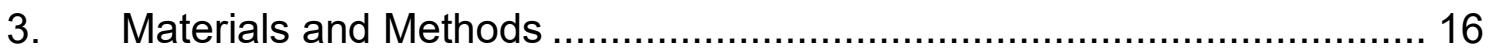

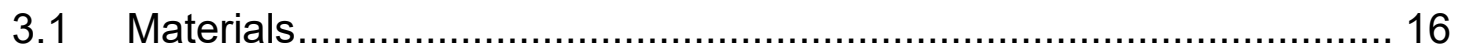

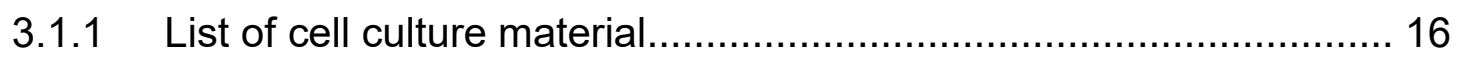

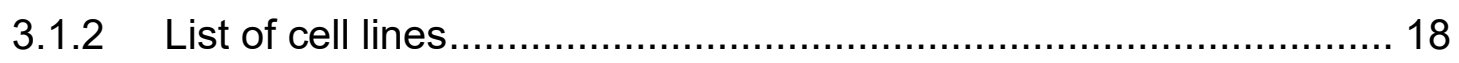

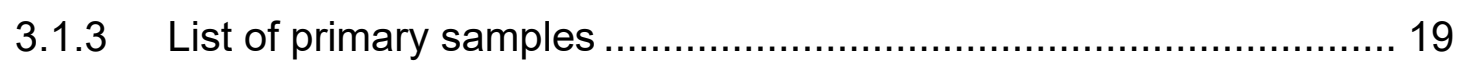

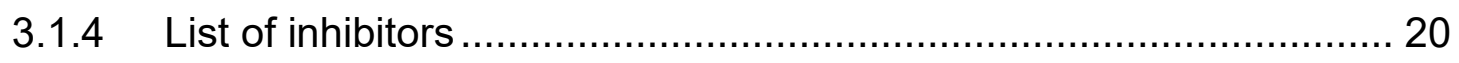

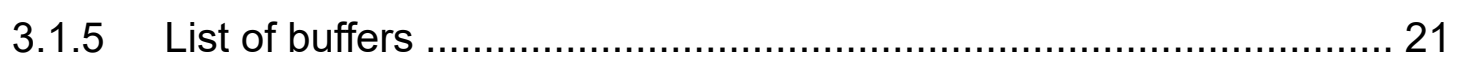

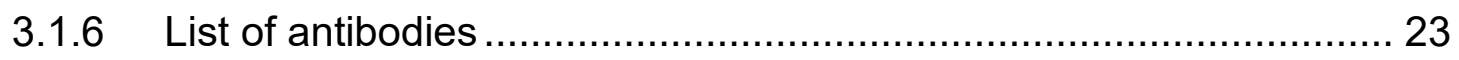

3.1.6.1 Primary antibodies for Western blotting ….............................. 23

3.1.6.2 Secondary antibodies for Western blotting ................................ 24

3.1.6.3 Primary antibodies for immunoprecipitation (IP) ......................... 24

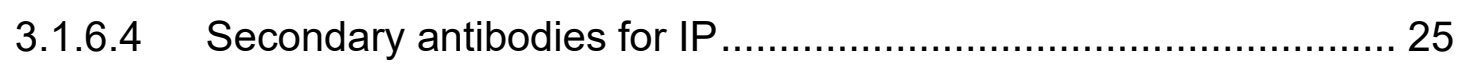




\subsubsection{Antibodies for fluorescence-activated cell sorting (FACS)}

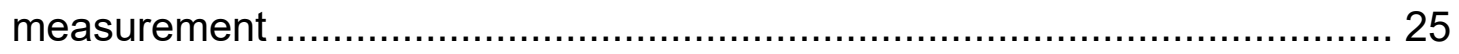

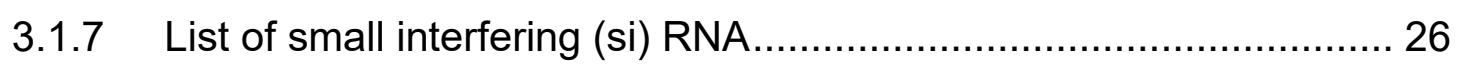

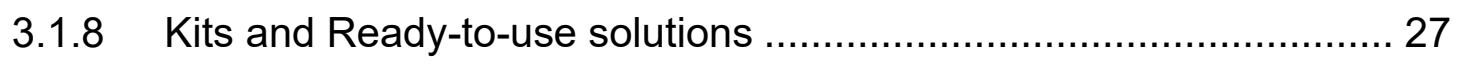

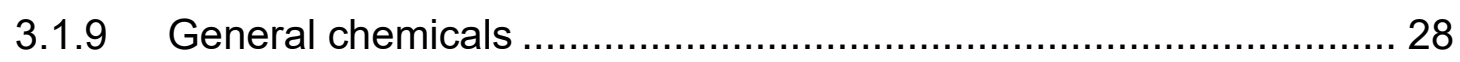

3.1.10 Consumable materials ......................................................... 30

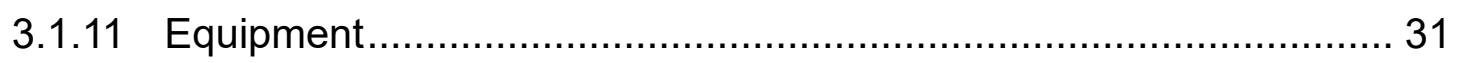

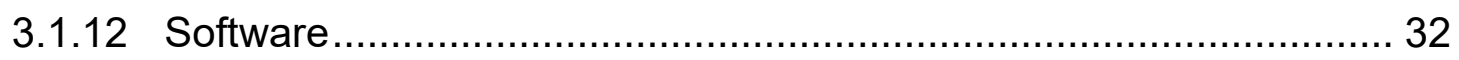

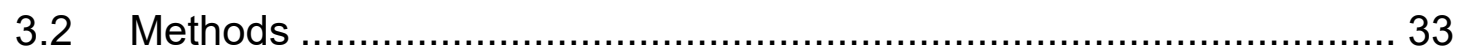

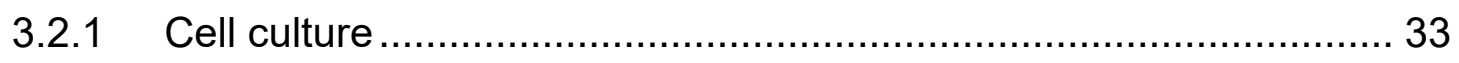

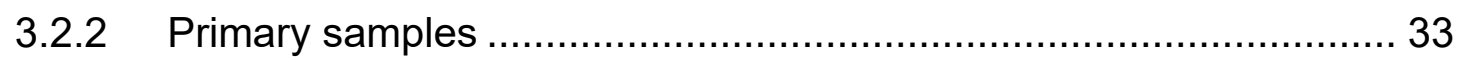

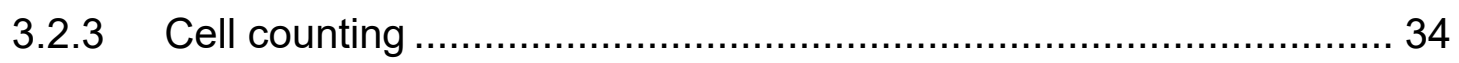

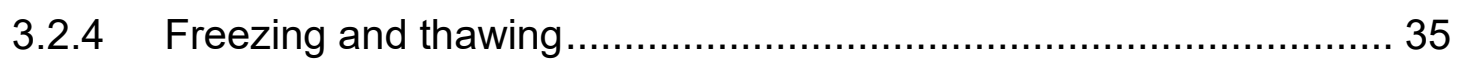

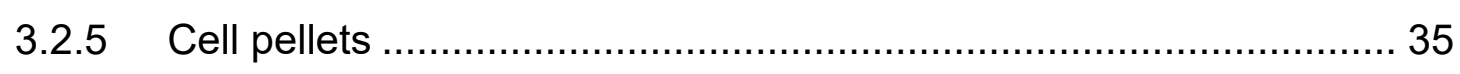

3.2.6 CellTiter-Glo viability assay ........................................................ 36

3.2.7 Cell death analysis with Annexin V-FITC staining .......................... 36

3.2.8 Cell death analysis of primary samples........................................ 37

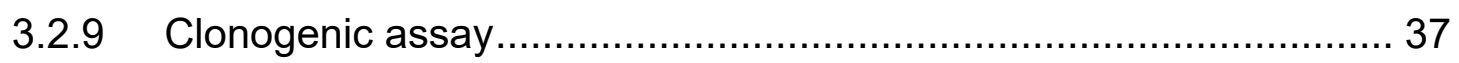

3.2.10 Determination of loss of mitochondrial membrane potential (MMP). 38

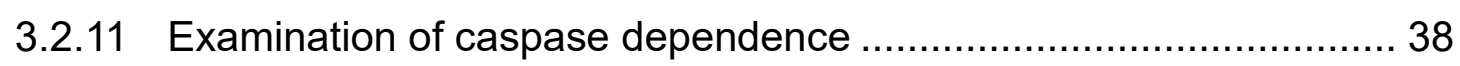

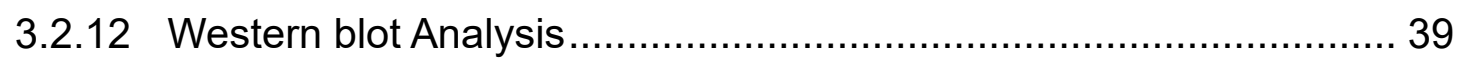

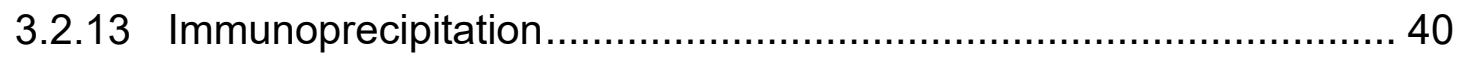

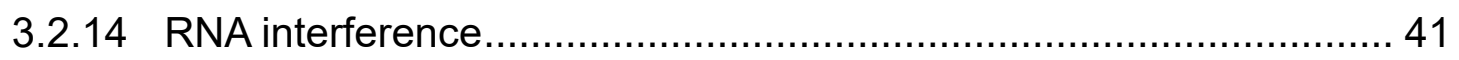

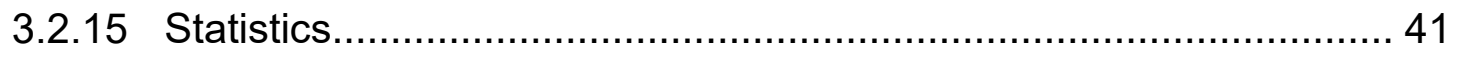

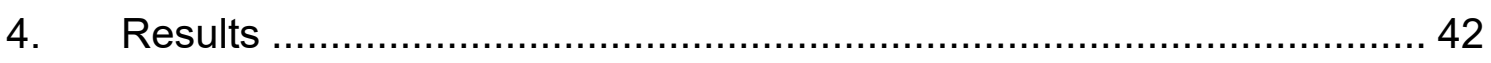

4.1 MCL-1 as well as BCL-2 inhibition decreases viability of AML cells .... 42

4.2 The sensitivity of AML cell lines towards $\mathrm{BH} 3$ mimetics does not correlate with the basal expression levels of BCL-2 proteins ....................... 47

4.3 MCL-1 expression is essential for the survival of AML cell lines.......... 49

4.4 $\mathrm{BH} 3$ mimetics induce cell death primarily via caspase-dependent

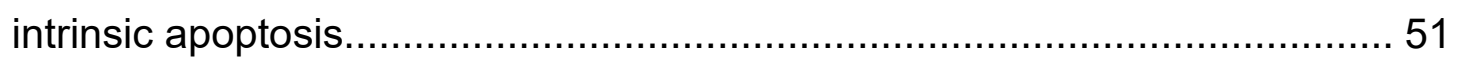

4.5 S63845 displaces BIMs and NOXA from MCL-1 ............................. 54

4.6 Primary $\mathrm{AML}$ samples show a wide range of responses to $\mathrm{BH} 3$ mimetics. 
4.7 $\mathrm{BH} 3$ mimetics show moderate to high toxicity in normal $\mathrm{CD} 34^{+}$cells while their clonogenic growth is differently impacted................................. 57

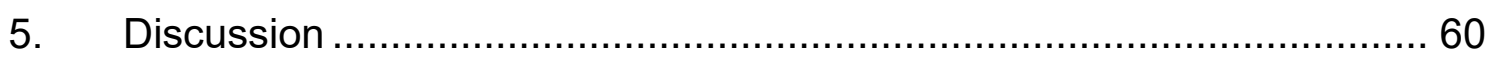

5.1 MCL-1 is a key therapeutic target for AML treatment ......................... 60

5.2 ABT-199 is more potent than 555746 while having the same mode of

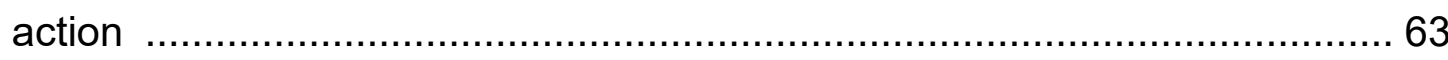

5.3 BCL-2 protein expression levels could not serve as a prediction marker of sensitivity towards $\mathrm{BH} 3$ mimetics. 64

5.4 BH3 mimetics induced apoptosis occurs by the displacement of $\mathrm{BH} 3-$ only proteins from anti-apoptotic $\mathrm{BCL}-2$ proteins 67 5.5 S63845 and ABT-199 are translational more relevant than S55746 and

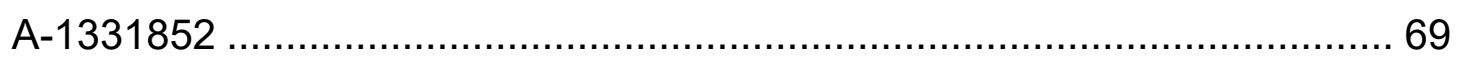

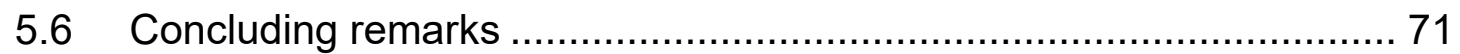

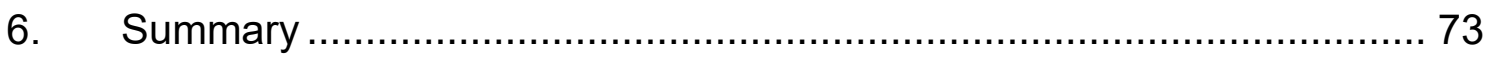

6.1 Deutsche Zusammenfassung ....................................................... 73

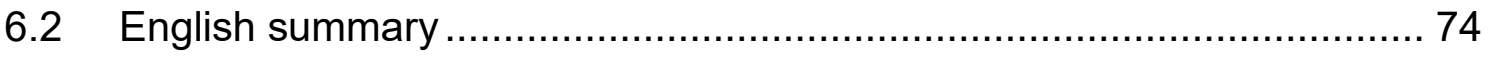

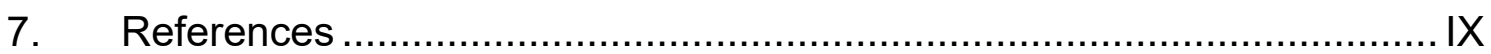

8. Related publications ......................................................................II

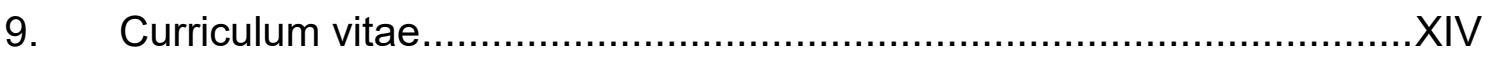

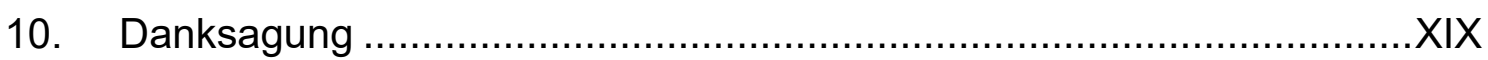

11. Schriftliche Erklärung.................................................................. 


\section{List of figures}

Figure 1: Hematopoiesis.

Figure 2: The intrinsic apoptotic pathway.

Figure 3: Intervention of $\mathrm{BH} 3$ mimetics in the interactions of BCL-2 proteins... 14 Figure 4: MCL-1 constitutes the most promising anti-apoptotic therapeutic target in AML.

Figure 5: Comparison of $\mathrm{EC}_{50}$ values from $\mathrm{S} 63845$ with those from ABT-199.. 44 Figure 6: Results of CellTiter-Glo viability assay can be confirmed by flow cytometry.

Figure 7: BCL-2 protein expression levels do not predict susceptibility to $\mathrm{BH} 3$ mimetics 48

Figure 8: AML cell lines depend on MCL-1 for their survival. 50

Figure 9: $\mathrm{BH} 3$ mimetics induce cell death in a time-dependent manner. 51

Figure 10: $\mathrm{BH} 3$ mimetics induced cell death comprises MOMP with loss of mitochondrial membrane potential.

Figure 11: The cleavage and activation of caspase-3 is necessary for $\mathrm{BH} 3$ mimetics to induce cell death.

Figure 12: BH3 mimetics induced cell death is caspase dependent. 53

Figure 13: S63845 displaces BIMs and NOXA from MCL-1.

Figure 14: Primary AML samples show heterogeneous sensitivity towards $\mathrm{BH} 3$ mimetics.

Figure 15: In comparison to BCL-2 and BCL- $\mathrm{X}_{\mathrm{L}}$ inhibitors, the $\mathrm{MCL}-1$ inhibitor shows less induction of cell death and less inhibition of colony formation of CD $34^{+}$cells. 


\section{List of tables}

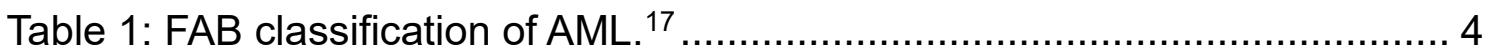

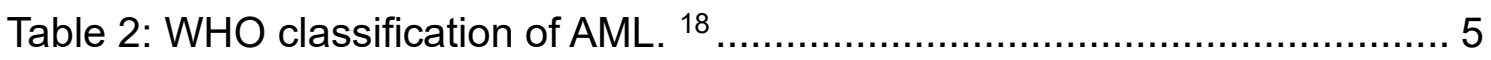

Table 3: European Leukemia Net risk stratification by genetics. Table adapted

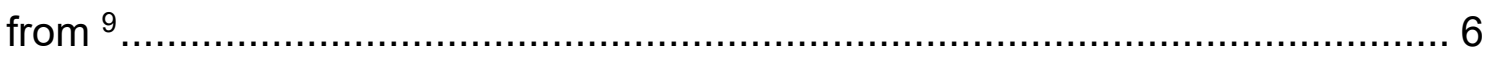

Table 4: List of cell culture material. ....................................................... 16

Table 5: List of cell lines. ..................................................................... 18

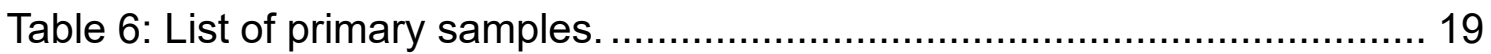

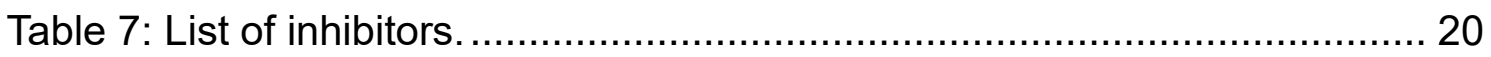

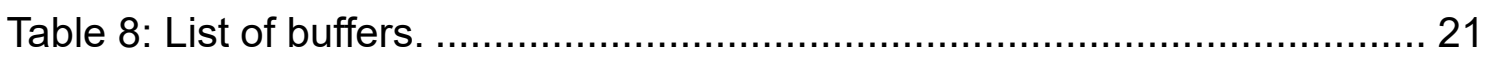

Table 9: Primary antibodies for Western blotting. .................................... 23

Table 10: Secondary antibodies for Western blotting. ............................... 24

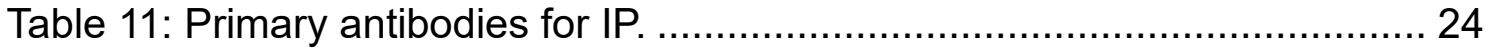

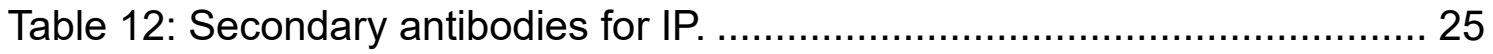

Table 13: Antibodies for FACS measurement. .......................................... 25

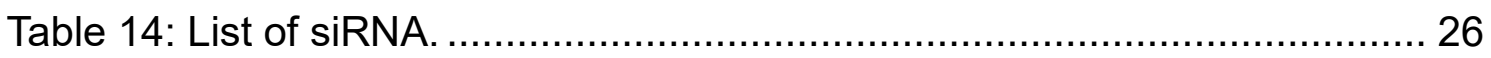

Table 15: Kits and Ready-to-use solutions .......................................... 27

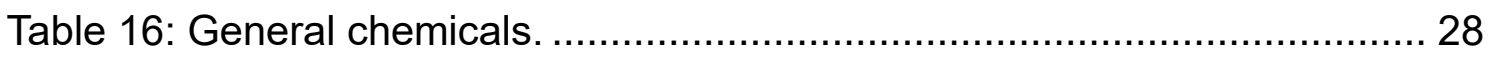

Table 17: Consumable materials. .............................................................. 30

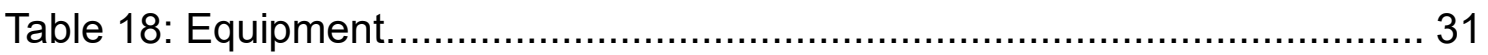

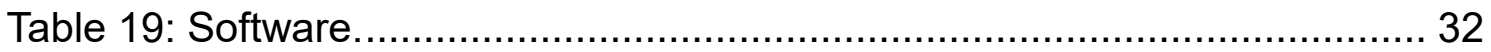

Table 20: $\mathrm{EC}_{50}$ values of $\mathrm{AML}$ cell lines to $\mathrm{BH} 3$ mimetics. ............................ 44

Table 21: EC 50 values of Primary AML samples to $\mathrm{BH} 3$ mimetics. .................. 56 


\section{List of abbreviations}

\begin{tabular}{ll}
\hline Abbreviation & Complete designation \\
\hline 2-HG & (R)-2-hydroxyglutarate \\
ALL & Acute lymphoid leukemia \\
AML & Acute myeloid leukemia \\
Apaf-1 & Apoptotic peptidase activating factor 1 \\
APL & Acute promyelocytic leukemia \\
APS & Ammonium persulfate \\
Ara-C & Cytarabine \\
BAK & BCL-2-antagonist/killer \\
BAX & BCL-2 associated X protein \\
BCA & Bicinchoninic acid \\
BCL-2 & B-Cell Lymphoma-2 \\
BCL-XL & B-Cell Lymphoma-Extra Large \\
BFU-E & Burst forming unit - erythroid \\
BM & Bone marrow \\
BSA & Bovine serum albumin \\
Casp. & Caspase \\
CFU-GEMM & Colony forming unit - granulocyte, macrophage, \\
& megakaryocyte \\
CFU-GM & Colony forming unit - granulocyte, macrophage \\
CHAPS & 3-[(3-Cholamidopropyl)dimethylammonio]-1-propanesulfonate \\
CLL & Chronic lymphatic leukemia \\
CLP & Common lymphoid progenitor \\
CMP & Common myeloid progenitor \\
CTG & CellTiter-Glo \\
Cyt. C & Cytochrome C \\
DMP & Dimethyl pimelimidate \\
DMSO & Dimethyl sulfoxide \\
DPBS & Dulbecco's phosphate buffered saline \\
DSMZ & German collection of microorganisms and cell cultures \\
\end{tabular}


DTT Dithiothreitol

E.g. For example

$\mathrm{EC}_{50} \quad$ Half maximal effective concentration

ECL Enhanced chemiluminescence

EDTA Ethylene diamine tetraacetic acid

FAB French american british

FACS Fluorescence-activated cell sorting

FCS Fetal calf serum

FDA Food and drug administration

FITC Fluorescein isothiocyanate

FLT3 Fms-like tyrosine kinase 3

GM-CSF Granulocyte-macrophage colony-stimulating factor

GMP Granulocyte/macrophage progenitor

$\mathrm{HCl} \quad$ Hydrochloric acid

HEPES 2-(4-(2-Hydroxyethyl)-1-piperazinyl)- ethanesulfonic acid

HLA Human leukocyte antigen

HPC Hematopoietic progenitor cell

HSC Hematopoietic stem cells

IDH Isocitrate dehydrogenases

IL-3 Interleukin-3

IMDM Iscove's modified Dulbecco's medium

IP Immunoprecipitation

LT-HSC Long-term hematopoietic stem cell

MCL Mantle cell lymphoma

MCL-1 Myeloid cell leukemia sequence 1

MDS Myelodysplastic syndrome

MEM Minimum essential medium

MEP Megakaryocyte/erythroid progenitor

Min Minute

MMP Mitochondrial membrane potential

MNC Mononuclear cell

MOMP Mitochondrial outer membrane permeabilization

$\mathrm{NaOH} \quad$ Sodium hydroxide 


\begin{tabular}{ll} 
NOS & not otherwise specified \\
PARP & Poly (ADP-ribose) polymerase \\
PB & Peripheral blood \\
PBS & Phosphate buffer saline \\
PI & Propidium iodide \\
PIC & Protease inhibitor cocktail \\
PMSF & Phenylmethylsulfonylfluorid \\
PS & Phosphatidylserine \\
RBC & Red blood cell \\
Rh & Recombinant human \\
Rh-SCF & Rh stem cell factor \\
RT & Room temperature \\
SDS & Sodium dodecyl sulfate \\
Sec & Secondary \\
Si & Small interfering \\
SiCtrl & Non-targeting control siRNA \\
SLL & Small lymphocytic lymphoma \\
SSC & Side scatter \\
ST-HSC & Short-term hematopoietic stem cell \\
TAM & Transient abnormal myelopoiesis \\
TEA & Triethanolamine \\
TEMED & Tetramethylethylenediamine \\
TMRM & Tetramethylrhodamine methylester \\
WHO & World health organization \\
zVAD & zVAD.fmk \\
zVAD.fmk & N-benzyloxy-carbonyl-Val-Asp-fluoromethylketon \\
& \\
\hline
\end{tabular}




\section{Introduction}

\subsection{Acute myeloid leukemia}

\subsubsection{Leukemogenesis}

Hematopoiesis physiologically takes place in human bone marrow and guarantees a constant provision of novel blood cells. It is characterized by the development of a pluripotent hematopoietic stem cell either to a myeloid or a lymphatic progenitor cell (Figure 1). After developing to progenitor cells, these cells differentiate to mature blood cells like erythrocytes, thrombocytes and leukocytes from myeloid progenitors and lymphocytes starting from lymphatic progenitors. Those mature blood cells execute important functions for normal life. Accordingly, oxygen transport is ensured by the erythrocytes, immune defense by leukocytes as well as lymphocytes and blood coagulation by thrombocytes. ${ }^{1,2}$ 


\section{Introduction}

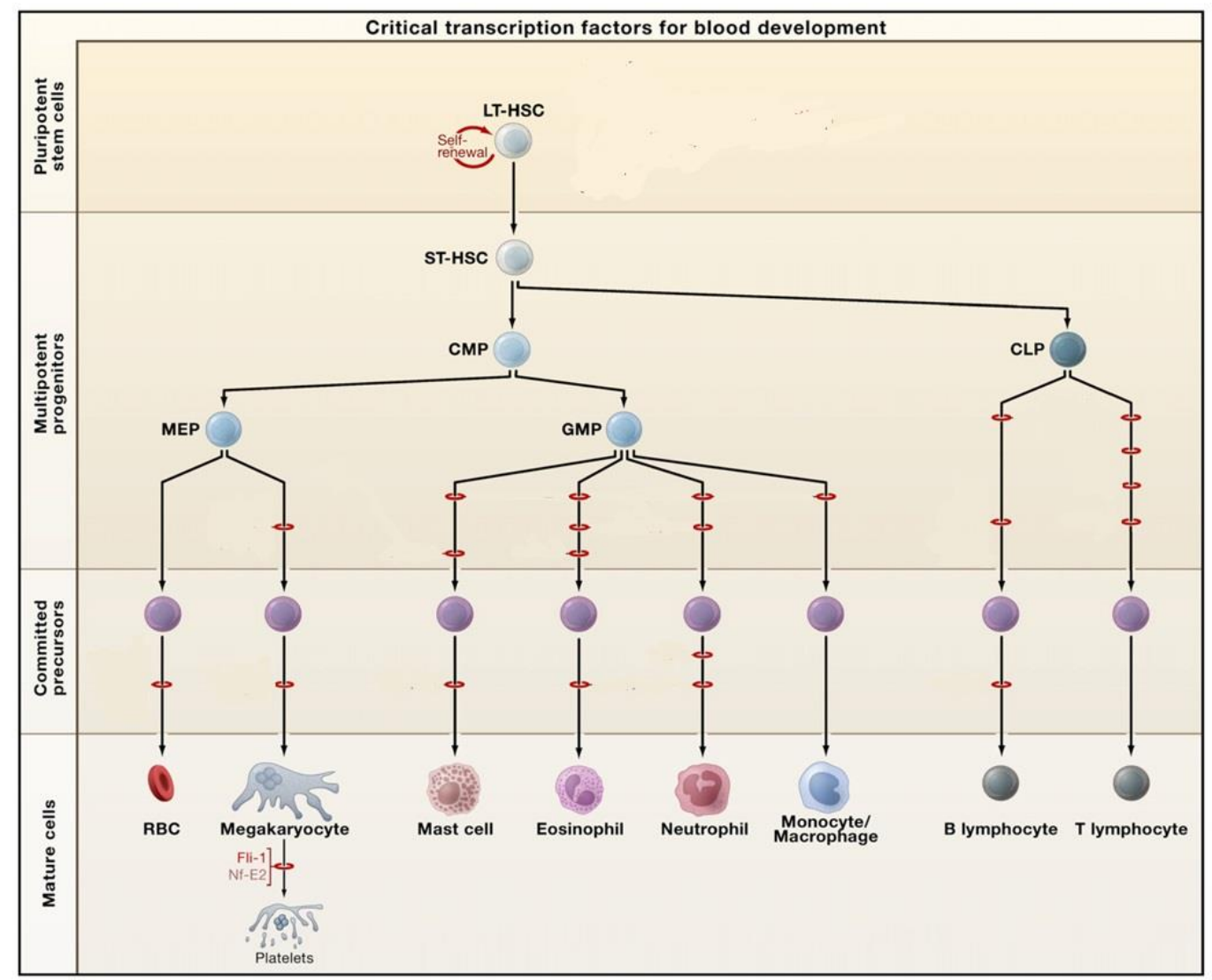

Figure 1: Hematopoiesis.

Normal hematopoiesis in human starts from pluripotent long-term hematopoietic stem cells (LT-HSC) which are self-renewing and mature into short-term hematopoietic stem cells (ST-HSC). This develops into either common myeloid progenitor (CMP) or common lymphoid progenitor (CLP) cells. CMP develop again into megakaryocyte/erythroid progenitor (MEP) or granulocyte/macrophage progenitor (GMP). In the end these cells evolve into mature peripheral blood cells like red blood cells (RBC) / erythrocytes, platelets, leukocytes and starting from CLPs into B- or T-lymphocytes. Figure modified from ${ }^{3}$

Leukemia develops from disordered hematopoiesis. In case of acute myeloid leukemia (AML), immature myeloid progenitors, so called blasts, undergo dysregulated proliferation. In combination with a differentiation block in hematopoiesis and evasion of cell death, these malignant transformed progenitor cells accumulate in bone marrow and repress remaining functioning hematopoietic nests. ${ }^{4}$ Thus, there is a lack of mature cells like erythrocytes or thrombocytes in peripheral blood, which leads to typical symptoms (see Chapter 1.1.3). 


\subsubsection{Incidence of AML}

With approximately $30 \%$ of all leukemias in adults and 4.3 per 100.000 inhabitants 5 this cancer type belongs to the most frequently ${ }^{6,7}$ and with 2,8 deaths per 100.000 persons the most killing subtype of leukemia in United States. ${ }^{5}$ The incidence correlates with the age, with the majority of these patients being older than 65 years, and differs with race and gender. ${ }^{6}$

\subsubsection{Diagnostic of AML}

There are different methods for AML diagnostic. Indicative symptoms are for example (e.g.) fatigue and paleness as a sign for an anemia, petechiae and epistaxis as a sign for a thrombocytopenia or susceptibility for infections as a sign for a granulocytopenia. ${ }^{8}$ These symptoms may indicate an analysis of the blood with a differential blood count to investigate the amount of the respective blood cells. In case of anemia, thrombocytopenia and/or granulocytopenia, a blood smear and an aspiration of the bone marrow is useful. The analysis consists in counting of blood cells based on their morphology. To diagnose an AML, the amount of blasts in bone marrow must be higher than $20 \% .{ }^{9}$ In comparison for the diagnosis of a myelodysplastic syndrome (MDS), as a disease that can evolve into an $\mathrm{AML}^{10}$, the amount of blasts can be lower than $20 \% .{ }^{11} \mathrm{Next}$, the identification of the origin of those blasts is necessary. This is possible by either cytochemical analysis or immunophenotyping. ${ }^{9,12}$ Cytochemistry is based on staining methods with Myeloperoxidase or Sudan Black B, that identifies myeloid origin, or nonspecific esterase, which detects monoblastic or monocytic differentiation. ${ }^{12}$ Immunophenotyping using flow cytometry allows a quantification of surface or cytoplasmic antigens and the assignment to a lineage. Generally, when an antigen is exposed in more than $20 \%$ of blasts, then the AML applies to be positive for this marker. Cytogenetic analysis can be performed to detect chromosomal aberrations like translocations or inversions either with a karyogram or fluorescence in situ hybridization. Additionally, the investigation of the molecular genetics by reverse transcriptase-polymerase chain reaction 
allows the proof of gene fusions. These chromosomal aberrations and gene mutations influence the prognosis. ${ }^{9,12}$

On the basis of morphological and cytochemical features eight subtypes can be differentiated by the French-American-British (FAB) classification of AML (Table 1). ${ }^{13-16}$ M0 to M5 includes leukocytic progenitor cells, M6 refer to erythrocytic progenitor cells and M7 to thrombocytic progenitor cells.

Table 1: FAB classification of AML. ${ }^{17}$

\begin{tabular}{ll}
\hline FAB subtype & Designation \\
\hline M0 & Undifferentiated acute myeloblastic leukemia \\
M1 & Acute myeloblastic leukemia with minimal maturation \\
M2 & Acute myeloblastic leukemia with maturation \\
M3 & Acute promyelocytic leukemia (APL) \\
M4 & Acute myelomonocytic leukemia \\
M4eos & Acute myelomonocytic leukemia with eosinophilia \\
M5 & Acute monocytic leukemia \\
M6 & Acute erythroid leukemia \\
M7 & Acute megakaryoblastic leukemia \\
\hline
\end{tabular}

Today, this classification is largely displaced by the World Health Organization (WHO) classification (Table 2) which is based on cytogenetic and molecular genetic characteristics of the blast cells. ${ }^{18}$ 
Table 2: WHO classification of AML. ${ }^{18}$
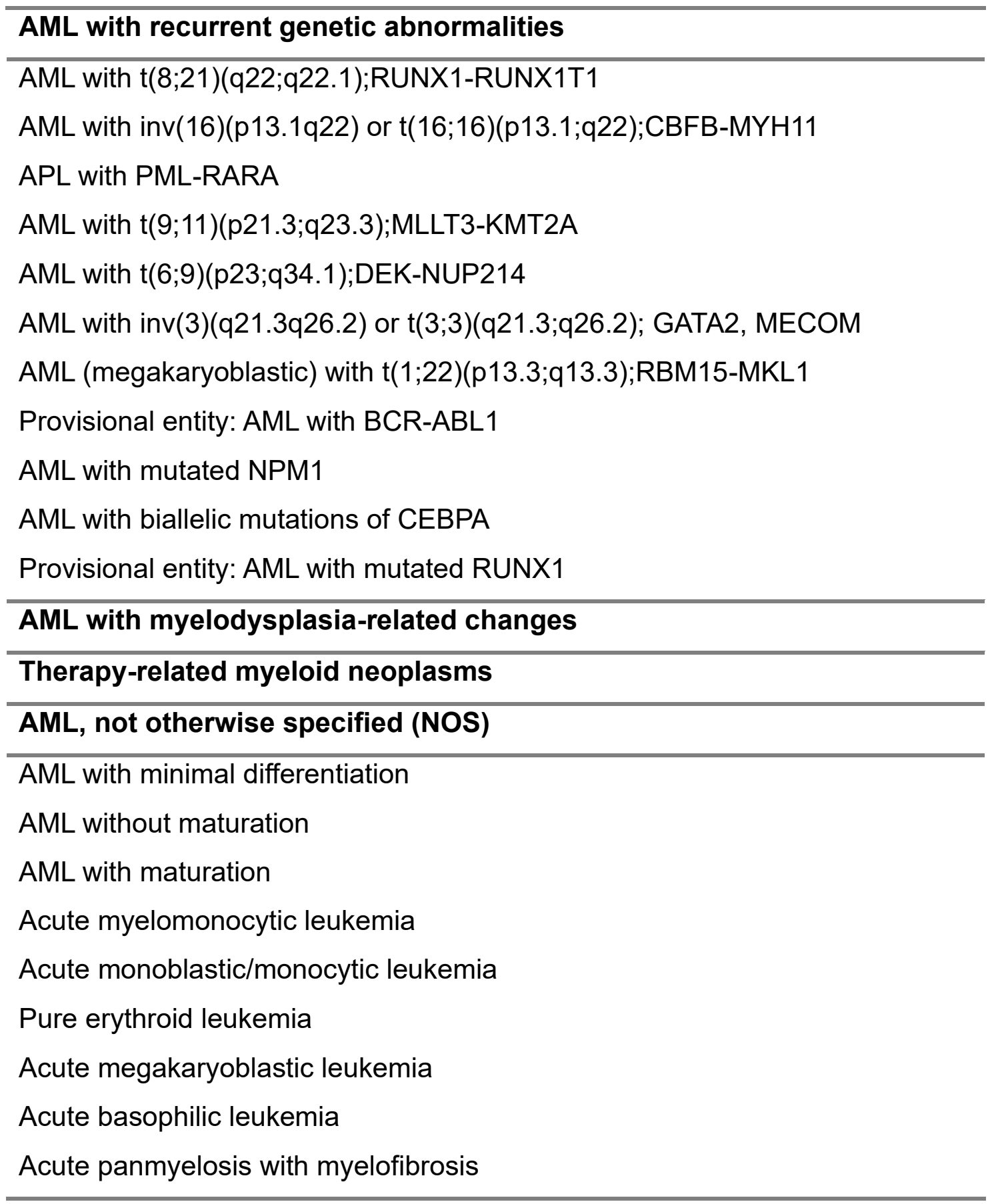

There are different features that influence the patient's prognosis. Individual therapeutic strategy depends on patient-related and disease-related factors. Patient-related features are e.g. the age, general condition, comorbidities and former diseases that encourage resistance against chemotherapy like myelodysplastic or -proliferative diseases. Disease-related factors (Table 3) particularly are certain mutations of genes like RUNX1, ASLX1 or TP53. 
Furthermore, chromosomal translocations or inversions that are existent in up to $55 \%$ of adults are also unfavorable factors. ${ }^{9}$

Table 3: European Leukemia Net risk stratification by genetics. Table adapted from ${ }^{9}$

\begin{tabular}{|c|c|}
\hline Risk category & Genetic abnormality \\
\hline \multirow[t]{4}{*}{ Favorable } & $\mathrm{t}(8 ; 21)(\mathrm{q} 22 ; \mathrm{q} 22.1) ; \mathrm{RUNX1-RUNX1T1}$ \\
\hline & $\operatorname{inv}(16)(p 13.1 q 22)$ or $t(16 ; 16)(p 13.1 ; q 22) ; C B F B-M Y H 11$ \\
\hline & Mutated NPM1 without FLT3-ITD or with FLT3-ITDlow† \\
\hline & Biallelic mutated CEBPA \\
\hline \multirow[t]{5}{*}{ Intermediate } & Mutated NPM1 and FLT3-ITDhigh† \\
\hline & Wild-type NPM1 without FLT3-ITD or with FLT3- \\
\hline & ITDlow† (without adverse-risk genetic lesions) \\
\hline & $\mathrm{t}(9 ; 11)(\mathrm{p} 21.3 ; q 23.3) ;$ MLLT3-KMT2A \\
\hline & $\begin{array}{l}\text { Cytogenetic abnormalities not classified as favorable or } \\
\text { adverse }\end{array}$ \\
\hline \multirow[t]{10}{*}{ Adverse } & $\mathrm{t}(6 ; 9)(\mathrm{p} 23 ; \mathrm{q} 34.1) ;$ DEK-NUP214 \\
\hline & $\mathrm{t}(\mathrm{v} ; 11 \mathrm{q} 23.3) ; \mathrm{KMT} 2 \mathrm{~A}$ rearranged \\
\hline & $\mathrm{t}(9 ; 22)(\mathrm{q} 34.1 ; \mathrm{q} 11.2) ; \mathrm{BCR}-\mathrm{ABL} 1$ \\
\hline & $\operatorname{inv}(3)(q 21.3 q 26.2)$ or $t(3 ; 3)(q 21.3 ; q 26.2)$ \\
\hline & GATA2,MECOM(EVI1) 25 or del(5q); 27; 217/abn(17p) \\
\hline & Complex karyotype,§ monosomal karyotype $\|$ \\
\hline & Wild-type NPM1 and FLT3-ITDhigh† \\
\hline & Mutated RUNX1\{ \\
\hline & Mutated ASXL1\{ \\
\hline & Mutated TP53\# \\
\hline
\end{tabular}

Frequencies, response rates, and outcome measures should be reported by risk category, and, if sufficient numbers are available, by specific genetic lesions indicated.

*Prognostic impact of a marker is treatment-dependent and may change with new therapies.

†Low, low allelic ratio $(, 0.5)$; high, high allelic ratio (0.5); semiquantitative assessment of FLT3-ITD allelic ratio (using DNA fragment analysis) is determined as ratio of the area under the curve "FLT3-ITD" divided by area under the curve "FLT3wild type"; recent studies indicate that AML with NPM1 mutation and FLT3-ITD 
low allelic ratio may also have a more favorable prognosis and patients should not routinely be assigned to allogeneic HCT.

$\ddagger$ The presence of $\mathrm{t}(9 ; 11)(\mathrm{p} 21.3 ; \mathrm{q} 23.3)$ takes precedence over rare, concurrent adverse-risk gene mutations. $\S$ Three or more unrelated chromosome abnormalities in the absence of 1 of the WHO-designated recurring translocations or inversions, that is, $t(8 ; 21)$, inv(16) or $t(16 ; 16), t(9 ; 11), t(v ; 11)(v ; q 23.3), t(6 ; 9)$, inv(3) or $t(3 ; 3)$; AML with BCR-ABL1.

\|Defined by the presence of 1 single monosomy (excluding loss of $X$ or $Y$ ) in association with at least 1 additional monosomy or structural chromosome abnormality (excluding core-binding factor AML).

\{These markers should not be used as an adverse prognostic marker if they cooccur with favorable-risk AML subtypes.

\#TP53 mutations are significantly associated with AML with complex and monosomal karyotype.

\subsubsection{Standard therapeutic strategy against AML}

The main therapeutic strategy for the treatment of AML patients contains the induction and the consolidation therapy. ${ }^{19}$ The aim of the induction therapy is to attain a remission, which is characterized as an amount of blasts in bone marrow of less than $5 \%$. Therefore, cytarabine (Ara-C) is given intravenous for 7 days at intermediate doses and additionally, an anthracycline is applied for 3 days. ${ }^{19,20}$ Consolidation therapy includes high dose chemotherapy and stem cell transplantation with the aim of preservation of remission and cure. Patients at 60 years and younger with advantageous risk profile receive two to four cycles with Ara-C and own a cure rate up to $70 \%$. For patients older than 60 years and beneficial risk profile this is also the method of choice. But if they have an intermediate or disadvantageous risk profile, they will not benefit from this procedure because the cure rate is only up to $15 \%{ }^{19}$, so for these patients investigational therapies could be useful alternative therapeutic strategies.

Stem cell transplantation is applied to patients that do not respond with complete remission to the mentioned standard therapeutic strategy with chemotherapy. This is accomplished in three steps: conditioning, transplantation and regeneration. ${ }^{21}$ Conditioning is performed either with alkylating chemotherapeutics like Fludarabine plus Cyclophosphamide or with full-body radiation. ${ }^{19}$ The purpose of this is on the one hand, to eliminate the leukemic cells and on the other hand, to suppress the recipients bone marrow. This is followed by the transplantation of Human Leukocyte Antigen (HLA) matched 
hematopoietic donor stem cells. Thus, this leads to an aplasia, a condition with a lack of blood cells because the recipients stem cells cannot perform hematopoiesis anymore and the donors stem cells are not able yet. After one to two weeks the donors stem cells start performing hematopoiesis and the blood count regenerates. The aim of this is triggering the so called Graft-versus-Leukemia effect ${ }^{19}$ : leukocytes from the graft assume the function the recipient's cells could not accomplish and combat the leukemic cells.

Altogether, patients at 60 years and younger possess a cure rate of $35-40 \%$ and patients older than 60 years of 10 to $15 \%$. Cure rate and median survival with this standard therapy are especially unsatisfactory for patients with unfavorable risk profiles. Because this applies to a high proportion of AML patients, there is an urgent need to establish novel therapies. ${ }^{19}$ 


\subsection{Apoptosis}

As the balance between cell proliferation and death is an effective strategy to guarantee tissue homeostasis, the dysregulation of cell death programs like apoptosis represent a central role in the development of cancer types. ${ }^{22}$ Apoptotic cell death can be induced via an intrinsic and an extrinsic pathway. ${ }^{23}$ The extrinsic apoptotic pathway requires binding of pro-apoptotic ligands to so called death receptors, leading to the recruitment of Fas-associated death domain and caspases- 8 and -10 to form the death-inducing signaling complex. 4,23 Subsequently, caspases- 8 and -10 are activated and induce caspase cascade, thereby effector caspases-3, -6 and -7 are activated. These effector caspases enable the execution of apoptosis. ${ }^{23}$ Caspases represent cysteine proteases, mediating DNA fragmentation as well as degradation and cross-linking of proteins. Consequently, chromatin condensation and shrinkage of the core membrane - which represent the process of so called pyknosis - in the end lead to the formation of apoptotic bodies. These apoptotic bodies are detected from phagocytic cells like macrophages by the expression of specific ligands on their surface and are subsequently phagocytized. ${ }^{24}$

Activation of the intrinsic pathway is regulated by so called B-Cell Lymphoma-2 (BCL-2) proteins, which can be differentiated into pro- as well as anti-apoptotic proteins. ${ }^{4,25}$ The main anti-apoptotic proteins are represented by BCL-2, Myeloid Cell Leukemia sequence 1 (MCL-1) and B-Cell Lymphoma-Extra Large (BCL- $\mathrm{X}_{\mathrm{L}}$ ). By directly binding to and sequestration of pro-apoptotic $B C L-2$ proteins, they can block their pro-apoptotic function and apoptotic cell death cannot be initiated. The pro-apoptotic BCL-2 proteins can be distinguished into pro-apoptotic effector proteins like BCL-2 associated $X$ protein (BAX) and BCL-2-antagonist/killer (BAK) and pro-apoptotic $\mathrm{BCL}-2$ homology domain $3(\mathrm{BH} 3)$ only proteins. ${ }^{4,25,26}$ Within the group of BH3-only proteins, a distinction of activator proteins like BIM or PUMA and sensitizer proteins like NOXA is possible. Activator $\mathrm{BH} 3-$ only proteins directly activate the effector proteins, whereas sensitizer $\mathrm{BH} 3$-only proteins bind to the anti-apoptotic BCL-2 proteins to block their binding groove and prevent them from binding pro-apoptotic BCL-2 proteins. ${ }^{25}$ 
In a healthy cell, there is a balance between pro- and anti-apoptotic BCL-2 proteins that allows them to stay alive. Apoptotic stimuli like DNA damage or oncogene activation lead to an upregulation or activation of $\mathrm{BH} 3$ only proteins and a downregulation of anti-apoptotic BCL-2 proteins. Thus, the balance shifts to pro-apoptotic proteins.

These can activate the effector proteins BAX and BAK via conformational changes, leading to pore formation in the outer mitochondrial membrane. Subsequently this results in mitochondrial outer membrane permeabilization (MOMP) including a loss of mitochondrial membrane potential (MMP) and consequently, cytochrome $C$ is released into the cytosol. ${ }^{4,25}$ Cytochrome $C$ then interacts with apoptotic peptidase activating factor 1 (Apaf-1) and procaspase- 9 to form the protein complex named apoptosome, facilitating the proteolytic cleavage and thus activation of caspase- 9 and subsequently effector caspases- 3 and $-7 .{ }^{4}$ Accordingly, apoptosis will be executed (Figure 2). ${ }^{4,25,26}$

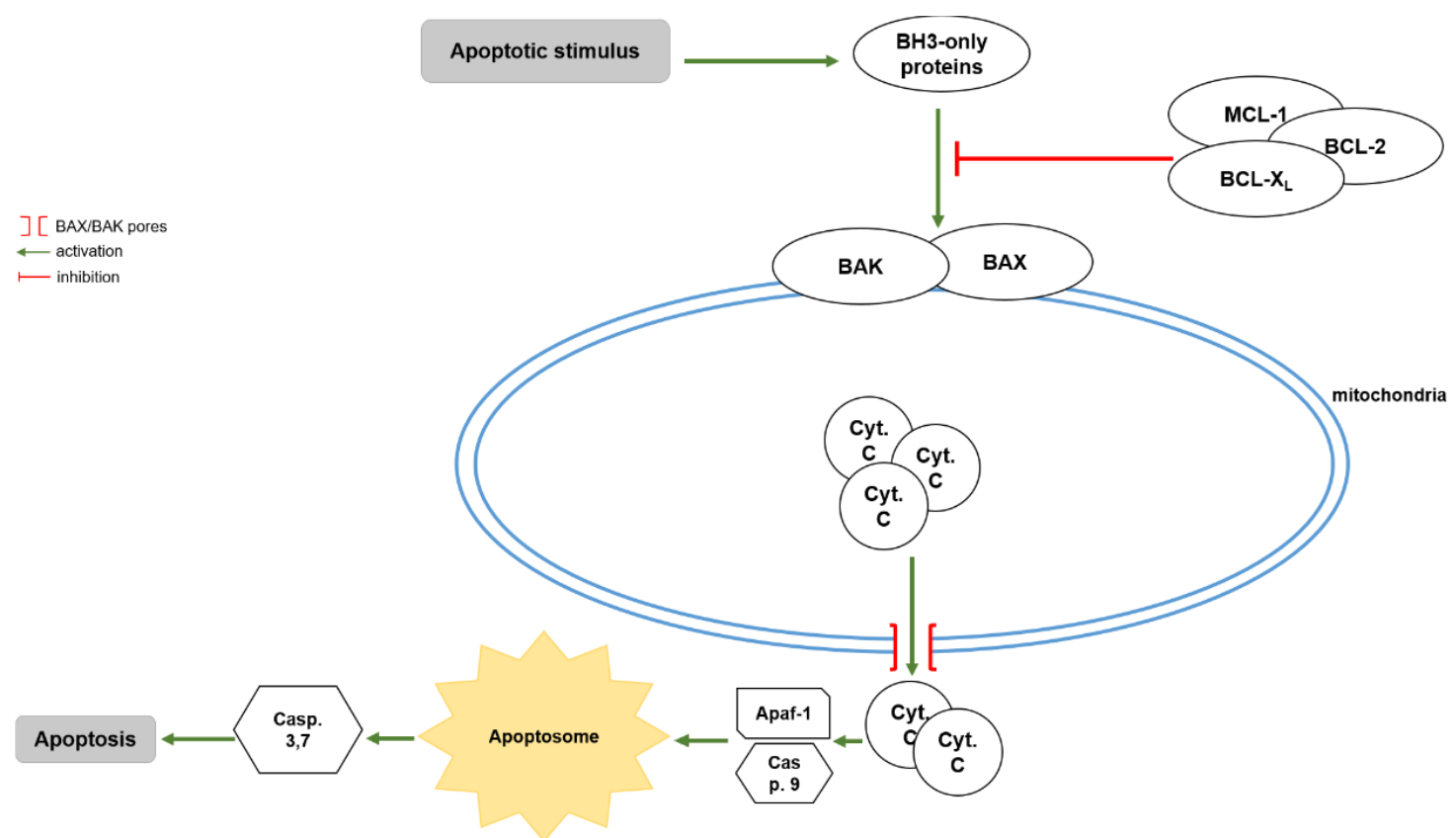

Figure 2: The intrinsic apoptotic pathway.

Upon an apoptotic stimulus, BH3-only proteins are upregulated and activated. Consequently, BAX and BAK are activated and pores are formed in the mitochondrial outer membrane. Cytochrome $C(C y t . C)$ is released out of the mitochondria and recruits Apaf- 1 as well as Caspase (Casp.) 9 to form the apoptosome. This activates effector caspases-3 and -7 , so that apoptosis can occur. 
Correspondingly, there are two different possibilities to block apoptosis and ensure tumor cell survival. On the one hand, those cells could reduce the expression of $\mathrm{BH} 3$-only proteins or pro-apoptotic $\mathrm{BCL}-2$ effector proteins and on the other hand, overexpress anti-apoptotic BCL-2 proteins.

The latter is present in so called primed tumor cells. ${ }^{25}$ This means, an apoptotic stimulus already led to an upregulation of $\mathrm{BH} 3$-only proteins and normally, they would undergo apoptotic cell death. But the overexpression of anti-apoptotic BCL-2 proteins enables the increased binding and inhibition of the pro-apoptotic $\mathrm{BH} 3-o n l y$ proteins and so, the activation of BAX and BAK to accomplish apoptosis can be prevented. Thus, these cells survive as long as there is an excess of anti-apoptotic BCL-2 proteins. With so-called BH3 mimetics (see Chapter 1.3), the function of anti-apoptotic BCL-2 proteins can be inhibited and primed cells can undergo apoptotic cell death. ${ }^{25}$ 


\subsection{BH3 mimetics}

\subsubsection{Steps towards the development of selective $\mathrm{BH} 3$ mimetics}

$\mathrm{BH} 3$ mimetics function as small molecule inhibitors of anti-apoptotic BCL-2 proteins by directly binding to their hydrophobic binding groove. ${ }^{27}$ So, the binding groove is blocked and their normal function, which is binding and inhibiting the pro-apoptotic BCL-2 proteins, cannot be performed anymore. ${ }^{26}$ Consequently, $\mathrm{BH} 3$ mimetics can displace already bound pro-apoptotic $\mathrm{BCL}-2$ proteins in primed cells or prevent anti-apoptotic proteins from binding newly expressed pro-apoptotic proteins in unprimed cells. ${ }^{26,27}$ Thus, they enable the induction of apoptosis by unbound and uninhibited pro-apoptotic BCL-2 proteins. Besides attempts to induce apoptosis by targeting the mRNA and influencing the translation of BCL-2 proteins, approaches followed to directly target the expressed proteins. The first compound doing so is named Obatoclax. Because it represents a pan-inhibitor of anti-apoptotic BCL-2 proteins and induces apoptosis independent of BAX/BAK, it entailed unintended side effects. ${ }^{27,28} \mathrm{An}$ ensuing approach included a more selective inhibitor of anti-apoptotic BCL-2 proteins: ABT-737. This strongly binds to and inhibits BCL-2, BCL-XL and BCL-W and induces BAX/BAK dependent apoptosis. Unfavorable pharmacokinetic characteristics averted the investigation in clinical trials. To overcome this problem, Navitoclax (ABT-263) was developed. As for ABT-737, Navitoclax also effectively induces cell death in e.g. chronic lymphocytic leukemia (CLL) cells that are BCL-2 dependent as well as in platelets that are BCL-XL dependent. Cell death induction in platelets led to a limitation of their clinical use because of arising thrombocytopenia. ${ }^{27}$

\subsubsection{Selective BCL-2 inhibitors: ABT-199 and S55746}

By developing the selective BCL-2 inhibitor Venetoclax (ABT-199) (Figure 3), $B C L-X_{L}$ inhibition is omitted and thus thrombocytopenia is prevented, however 
cell death will be induced in BCL-2 dependent cells. In several clinical trials the side effects were minor and consist in for instance nausea, diarrhea or neutropenia. ${ }^{4,27}$ All in all, this led to Food and Drug Administration (FDA) approvals for Venetoclax for the treatment of patients with relapsed or refractory CLL with 17p deletion in 2016 and in combination with hypomethylating agents like azacytidine and chemotherapeutics like daunorubicin, or low dose Ara- $C$ for patients with newly diagnosed AML that are 75 years or older or patients that are unable to receive intensive chemotherapy in $2018 .{ }^{29,30}$ Multiple clinical trials with Venetoclax are currently ongoing. 31

Another orally bioavailable selective BCL-2 inhibitor named BCL201 (S55746) (Figure 3) was designed. Several studies have reported that BCL201 induce BAX/BAK dependent apoptosis in hematological cancer cells as well as in primary samples from CLL and Mantle Cell Lymphoma (MCL) patients. Furthermore, examinations in tumor xenograft models in vivo showed dose-dependent anti-tumor activity while being well tolerated. ${ }^{32}$ Two phase I clinical trials with this drug as a single agent were completed: First, in patients with CLL and B-Cell Non-Hodgkin Lymphoma dose escalation of S55746 was investigated and was stopped during dose escalation (NCT02920697). Second, in patients with Follicular Lymphoma and MCL the combination of S55746 with Idelalisib was examined and revealed promising results while being well tolerated (NCT02603445). ${ }^{33}$

\subsubsection{Selective BCL- $X_{L}$ inhibitor: $A-1331852$}

WEHI-539 represents the first selective BCL-XL inhibitor and turned out to have a comparably low cellular potency. This was followed by the design of - among others - A-1331852 (Figure 3) with a higher cellular potency. ${ }^{27}$ It represents an orally bioavailable compound inducing BAX/BAK dependent apoptosis. ${ }^{34}$ There $^{2}$ are no clinical trials with this compound yet. ${ }^{35}$ 


\subsubsection{Selective MCL-1 inhibitor: $\mathbf{S 6 3 8 4 5}$}

MCL-1 also plays an important role as an anti-apoptotic BCL-2 protein. Therefore, S63845 as an orally bioavailable selective MCL-1 inhibitor (Figure 3) was developed. It induces BAX/BAK dependent apoptosis, especially in MCL-1 dependent cell lines like selected lymphoma cell lines. ${ }^{27}$ S63845 itself is not investigated in clinical trials so far, ${ }^{36}$ but the derivate $\mathbf{S} 64315$ is investigated in phase-I clinical trials in patients with AML or Myelodysplastic syndrome (NCT02979366), Lymphoma or Multiple Myeloma (NCT02992483) and in combination with Venetoclax in patients with AML (NCT03672695). ${ }^{37}$ Additionally, MCL-1 inhibitors AMG 176 and AZD5991 are currently examined in clinical trials alone and in combination with ABT-199 in patients with hematological malignancies. 38,39

These selective $\mathrm{BH} 3$ mimetics were explored in different studies but were not directly compared with each other in AML cell lines yet. Hence, it is not defined so far, which of these BCL-2 proteins are relevant targets in each subgroup of AML.

Pro-apoptotic BCL-2 proteins

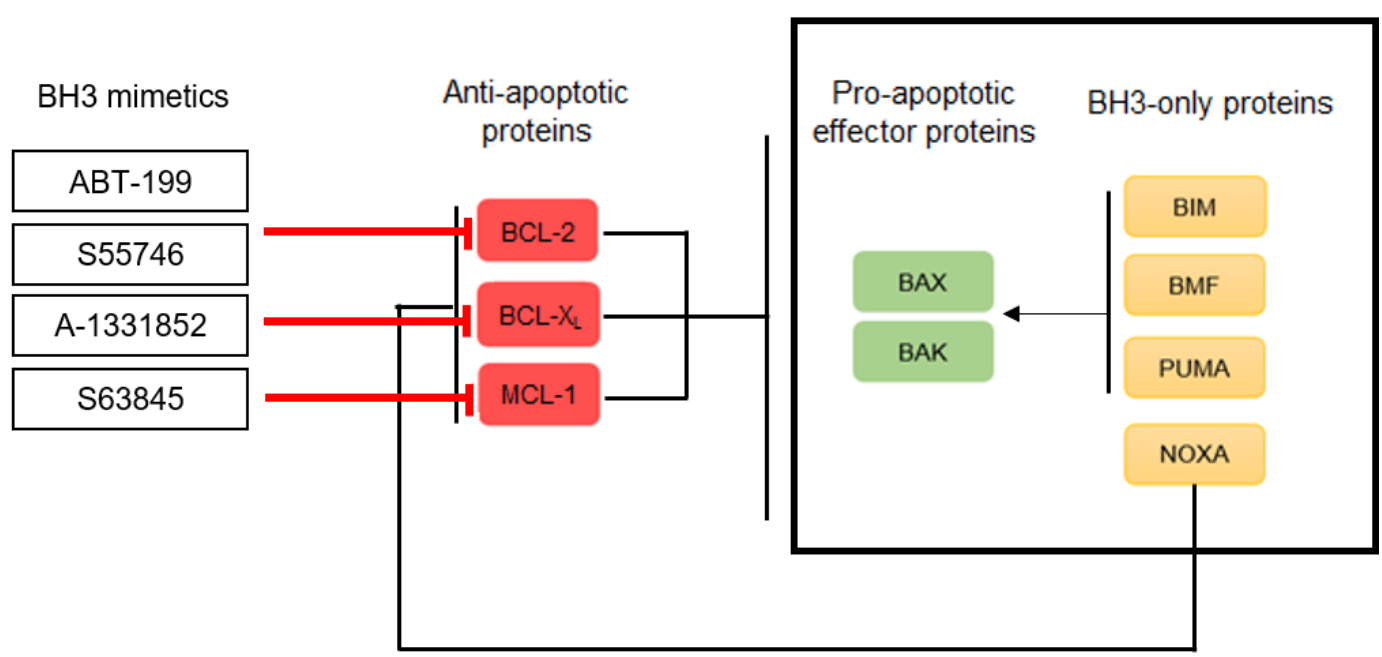

Figure 3: Intervention of $\mathrm{BH} 3$ mimetics in the interactions of $\mathrm{BCL}-2$ proteins.

$\mathrm{BH} 3$ mimetics are selective inhibitors of anti-apoptotic BCL-2 proteins. ABT-199 and 555746 inhibit the function of BCL-2, A-1331852 inhibits BCL- $X_{L}$ and S63845 inhibits MCL-1. The main function of these anti-apoptotic $B C L-2$ proteins is the inhibition of pro-apoptotic $B C L-2$ proteins to prevent apoptosis. $B H 3$-only proteins enable the direct or indirect activation of $\mathrm{BAX}$ and BAK either by binding to them or by binding to anti-apoptotic BCL-2 proteins to prevent them from inhibiting BAX and BAK. Figure adapted from ${ }^{25}$. 


\section{Aim of the study}

The aim of this study was to provide a basis for $\mathrm{BH} 3$ mimetics as a novel therapeutic strategy in AML. Therefore, we aimed to identify which of the anti-apoptotic BCL-2 proteins are relevant targets in AML cell lines by directly comparing $\mathrm{BH} 3$ mimetics selectively targeting the different anti-apoptotic BCL-2 proteins. To this end, we used ABT-199 and S55746 as BCL-2 inhibitors, S63845 as MCL-1 inhibitor and A-1331852 as BCL-X inhibitor and compared these $\mathrm{BH} 3$ mimetics side-by-side. Further, we explored whether sensitivity to $\mathrm{BH} 3$ mimetics may correlate with the expression of distinct BCL-2 proteins. To obtain a better understanding of the molecular function of $\mathrm{BH} 3$ mimetics in $\mathrm{AML}$, we examined the underlying molecular mechanisms of $\mathrm{BH} 3$ mimetics induced cell death in AML. To evaluate the translational relevance of our study, we investigated the antileukemic effects of $\mathrm{BH} 3$ mimetics in primary blasts derived from treatment-naive AML patients. 


\section{Materials and Methods}

\subsection{Materials}

\subsubsection{List of cell culture material}

Table 4: List of cell culture material.

\begin{tabular}{|c|c|}
\hline Reagent & Supplier \\
\hline \multirow[t]{2}{*}{ Alpha-Minimum essential medium (MEM) } & Life Technologies, \\
\hline & Darmstadt, Germany \\
\hline \multirow[t]{2}{*}{ Dimethyl sulfoxide (DMSO) } & Sigma-Aldrich, \\
\hline & Deisenhofen, Germany \\
\hline \multirow[t]{2}{*}{ Dulbecco's phosphate buffered saline (DPBS) } & Life Technologies, \\
\hline & Darmstadt, Germany \\
\hline \multirow[t]{2}{*}{ Fetal calf serum (FCS) } & Life Technologies, \\
\hline & Darmstadt, Germany \\
\hline \multirow[t]{2}{*}{ Fms-like tyrosine kinase 3 (FLT3) Ligand } & PeproTech, Rocky Hill, NJ, \\
\hline & USA \\
\hline Granulocyte-macrophage colony-stimulating & Life Technologies, \\
\hline factor (GM-CSF) & Darmstadt, Germany \\
\hline \multirow[t]{2}{*}{ Interleukin-3 (IL-3) } & Life Technologies, \\
\hline & Darmstadt, Germany \\
\hline Iscove's modified Dulbecco's medium (IMDM) & Life Technologies, \\
\hline with GlutaMAX supplement & Darmstadt, Germany \\
\hline MEM non-essential amino acids solution & Life Technologies, \\
\hline$(100 x)$ & Darmstadt, Germany \\
\hline \multirow[t]{2}{*}{ Methocult H4435 Enriched } & Stemcell Technologies, \\
\hline & Vancouver, Canada \\
\hline \multirow[t]{2}{*}{ Penicillin/Streptomycin (10000 U/ml) } & Life Technologies, \\
\hline & Darmstadt, Germany \\
\hline \multirow[t]{2}{*}{ Rh- stem cell factor (rh-SCF) } & Life Technologies, \\
\hline & Darmstadt, Germany \\
\hline
\end{tabular}


RPMI 1640 GlutaMAX-I Medium

Sodium pyruvate (100 mM)

Trypan blue solution, $0.4 \%$ in EDTA

$\beta$-Mercaptoethanol
Life Technologies,

Darmstadt, Germany

Life Technologies,

Darmstadt, Germany

Life Technologies,

Darmstadt, Germany

Life Technologies,

Darmstadt, Germany 


\subsubsection{List of cell lines}

Table 5: List of cell lines.

\begin{tabular}{|c|c|c|c|c|}
\hline Cell line & $\begin{array}{l}\text { FAB } \\
\text { classification }\end{array}$ & Specification & Medium & Supplier \\
\hline HL-60 & M2 & myeloid & RPMI 1640 & DSMZ \\
\hline KASUMI-1 & M2 & myeloid & RPMI 1640 & DSMZ \\
\hline KG-1 & - & myeloid & RPMI 1640 & DSMZ \\
\hline ML-2 & M4 & $\begin{array}{l}\text { Myelo- } \\
\text { monocytic }\end{array}$ & RPMI 1640 & $\begin{array}{l}\text { T. Oellerich, } \\
\text { Goethe } \\
\text { University, } \\
\text { Frankfurt, } \\
\text { Germany. }\end{array}$ \\
\hline MOLM-13 & M5a & myeloid & RPMI 1640 & DSMZ \\
\hline $\begin{array}{l}\text { MONO- } \\
\text { MAC-6 }\end{array}$ & M5 & monocytic & RPMI 1640 & DSMZ \\
\hline MV4-11 & M5 & monocytic & RPMI 1640 & DSMZ \\
\hline NB4 & M3 & promyelocytic & RPMI 1640 & DSMZ \\
\hline OCI-AML3 & M4 & myeloid & $\alpha-M E M$ & DSMZ \\
\hline PLB-985 & M4 & myeloid & RPMI 1640 & $\begin{array}{l}\text { T. Oellerich, } \\
\text { Goethe } \\
\text { University, } \\
\text { Frankfurt, } \\
\text { Germany. }\end{array}$ \\
\hline THP-1 & M5 & monocytic & RPMI 1640 & $\begin{array}{l}\text { T. Oellerich, } \\
\text { Goethe } \\
\text { University, } \\
\text { Frankfurt, } \\
\text { Germany. }\end{array}$ \\
\hline
\end{tabular}




\subsubsection{List of primary samples}

Primary AML samples were received as either bone marrow (BM) or peripheral blood derived (PB) samples. These were obtained from AML patients at initial diagnosis before the initiation of therapy under written informed consents from patients. The hematological biobank and the tumor documentation of the UCT Frankfurt (Germany) provided mononuclear cells (MNCs) and clinical data.

Table 6: List of primary samples.

\begin{tabular}{|c|c|c|c|c|c|c|}
\hline $\begin{array}{l}\text { Patient } \\
\#\end{array}$ & $\begin{array}{l}\text { Type of } \\
\text { material }\end{array}$ & $\begin{array}{l}\text { Subtype } \\
\text { [FAB] }\end{array}$ & $\begin{array}{l}\text { Subtype } \\
\text { [WHO] }\end{array}$ & $\begin{array}{l}\text { Age/ } \\
\text { Sex }\end{array}$ & Cytogenetic & $\begin{array}{l}\text { Genetic } \\
\text { alteration }\end{array}$ \\
\hline 45 & BM & - & NOS & $\begin{array}{l}33 \\
M\end{array}$ & $46, X Y$ & $\begin{array}{l}\text { KMT2A(ML } \\
\text { L)-PTD } \\
\text { (Vari- } \\
\text { ante9e3), } \\
\text { FLT3-ITD } \\
\text { (2 frag- } \\
\text { ments) }\end{array}$ \\
\hline 48 & BM & M4 & $\begin{array}{l}\text { AML with } \\
\text { myelo- } \\
\text { dysplasia } \\
\text { related } \\
\text { changes, } \\
\text { devel- } \\
\text { oped } \\
\text { from CML }\end{array}$ & $\begin{array}{l}58 \\
F\end{array}$ & $46, X X$ & $\begin{array}{l}\text { DNMT3A, } \\
\text { NRAS }\end{array}$ \\
\hline 55 & PB & - & $\begin{array}{l}\text { sec. AML } \\
\text { after } \\
\text { MDS }\end{array}$ & $\begin{array}{l}79 \\
F\end{array}$ & $\begin{array}{l}46, X X, \text { del } \\
\text { (13)(q13q21) }\end{array}$ & FLT3-ITD \\
\hline
\end{tabular}


56

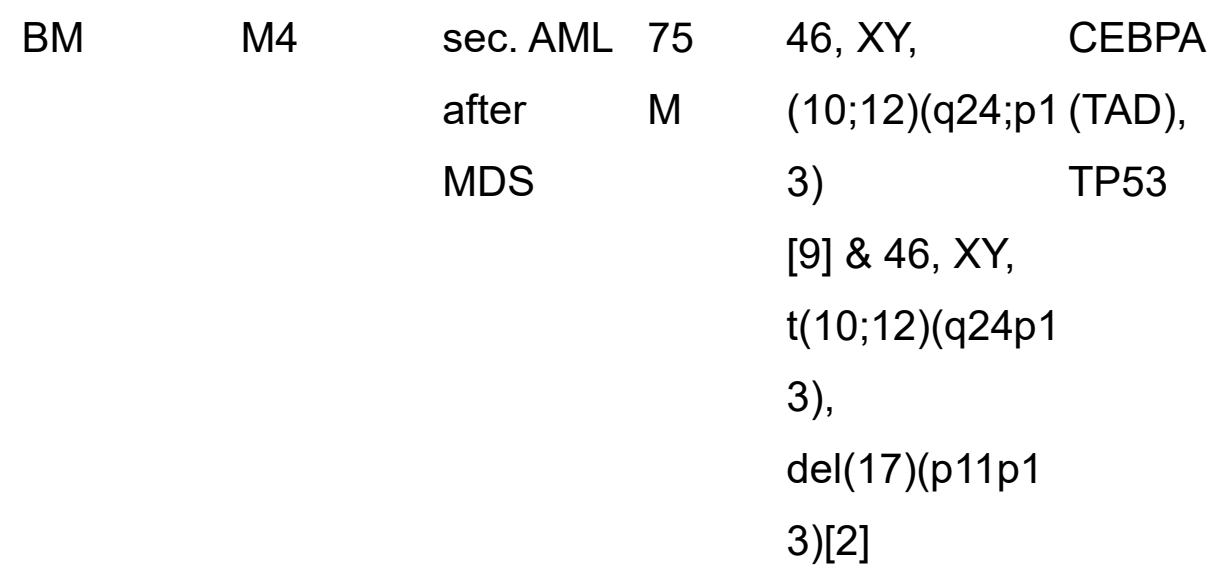

Human G-CSF-mobilized CD34+ hematopoietic progenitor cells (HPCs) from healthy donors were kindly provided by Prof. H. Bönig, Institute for Transfusion Medicine and Immunohematology, Frankfurt, Germany.

\subsubsection{List of inhibitors}

Table 7: List of inhibitors.

\begin{tabular}{llll}
\hline Inhibitor & Target & Solvent & Supplier \\
\hline A-1331852 & BCL-XL & DMSO & $\begin{array}{l}\text { Selleck Chemicals, } \\
\text { Houston, TX, USA }\end{array}$ \\
ABT-199 & BCL-2 & DMSO & $\begin{array}{l}\text { Selleck Chemicals, } \\
\text { Houston, TX, USA }\end{array}$ \\
S55746 & BCL-2 & DMSO & Servier, Suresnes, France \\
S63845 & MCL-1 & DMSO & Appexbio \\
zVAD.fmk & Caspases & DMSO & Selleck Chemicals, \\
(zVAD) & & & Houston, TX, USA \\
\hline
\end{tabular}




\subsubsection{List of buffers}

Table 8: List of buffers.

\begin{tabular}{|c|c|}
\hline Buffer & Ingredients \\
\hline \multirow[t]{4}{*}{ Antibody dilution buffer } & $0.9 \% \mathrm{NaCl}$ \\
\hline & $5 \mathrm{mM}$ EDTA \\
\hline & $1 \mathrm{mg} / \mathrm{ml} \mathrm{BSA}$ \\
\hline & $10 \mathrm{mM}$ TrisHCl pH 7.5 \\
\hline \multirow[t]{7}{*}{ Lysis Buffer } & $30 \mathrm{mM}$ TrisHCl \\
\hline & $150 \mathrm{mM} \mathrm{NaCl}$ \\
\hline & $10 \%$ Glycerol \\
\hline & $0.5 \mathrm{mM}$ PMSF \\
\hline & 2 mM DTT \\
\hline & $1 \%$ Triton X-100 \\
\hline & $1 \times \mathrm{PIC}$ \\
\hline Phosphate buffer saline & $400 \mathrm{~g} \mathrm{NaCl}$ \\
\hline \multirow[t]{5}{*}{ (PBS, 10x, pH 7.4) } & $10 \mathrm{~g} \mathrm{KCl}$ \\
\hline & $10 \mathrm{~g} \mathrm{KH}_{2} \mathrm{PO}_{4}$ \\
\hline & $72 \mathrm{~g} \mathrm{Na}_{2} \mathrm{HPO}_{4}$ \\
\hline & 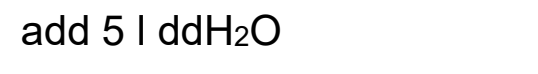 \\
\hline & adjust with $\mathrm{NaOH}$ to $\mathrm{pH} 7.4$ \\
\hline \multirow[t]{2}{*}{ PBS-T } & 1x PBS \\
\hline & $0.1 \%$ Tween 20 \\
\hline \multirow[t]{5}{*}{ SDS loading dye (6x) } & 360 mM TrisBase pH 6.8 \\
\hline & $30 \%$ Glycerol \\
\hline & $120 \mathrm{mg} / \mathrm{ml} \mathrm{SDS}$ \\
\hline & 93 mg/ml DTT \\
\hline & $12 \mathrm{mg} / \mathrm{ml}$ bromophenol blue \\
\hline
\end{tabular}


Blotting buffer (1x)

Running buffer (5x)

Annexin $\mathrm{V}$ binding buffer ( $\mathrm{pH} 7.4)$

3-[(3-Cholamidopropyl)

dimethylammonio]-1-

propanesulfonate(CHAPS) buffer
$11.6 \mathrm{~g}$ TrisBase

$5.8 \mathrm{~g}$ Glycine

$7.5 \mathrm{ml} \mathrm{10 \%} \mathrm{SDS}$

$400 \mathrm{ml}$ Methanol

add $2 \mathrm{I} \mathrm{ddH}_{2} \mathrm{O}$

$30.2 \mathrm{~g}$ TrisBase

$188 \mathrm{~g}$ Glycine

$100 \mathrm{ml} 10 \%$ SDS

add $2 \mathrm{I} \mathrm{ddH} \mathrm{H}_{2} \mathrm{O}$

10 mM HEPES

$150 \mathrm{mM} \mathrm{NaCl}$

$5 \mathrm{mM} \mathrm{KCl}$

$1 \mathrm{mM} \mathrm{MgCl} 2$

$1.8 \mathrm{mM} \mathrm{CaCl} 2$

adjust with $\mathrm{NaOH}$ to $\mathrm{pH} 7.4$

$4.35 \mathrm{~g} \mathrm{NaCl}$

$20 \mathrm{mM}$ TrisHCl pH 8

1\% CHAPS (or 0.5\% TritX)

$1 \times \mathrm{PIC}$

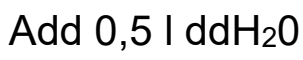

0,2 M TEA pH 8,2 


\subsubsection{List of antibodies}

\subsubsection{Primary antibodies for Western blotting}

Table 9: Primary antibodies for Western blotting.

\begin{tabular}{llll}
\hline $\begin{array}{l}\text { Target } \\
\text { protein }\end{array}$ & Dilution & $\begin{array}{l}\text { Specie } \\
\text { s }\end{array}$ & Supplier \\
\hline BAK & 1.1000 & rabbit & BD Biosciences, Heidelberg, Germany \\
BAX & $1: 1000$ & mouse & Cell Signaling, Beverly, MA, USA \\
BCL-2 & $1: 50$ & mouse & Dako, Carpinteria, California, USA \\
BCL-XL & $1: 1000$ & rabbit & Cell Signaling, Beverly, MA, USA \\
BIM & $1: 500$ & rabbit & Cell Signaling, Beverly, MA, USA \\
Caspase-3 & $1: 1000$ & rabbit & Cell Signaling, Beverly, MA, USA \\
Caspase-8 & $1: 1000$ & mouse & Enzo Life Sciences, Farmindale, NY, USA \\
Caspase-9 & $1: 1000$ & rabbit & Cell Signaling, Beverly, MA, USA \\
cleaved & $1: 1000$ & mouse & Cell Signaling, Beverly, MA, USA \\
PARP & & & \\
GAPDH & $1: 5000$ & mouse & BioTrend (HyTest), Turku, Finland \\
MCL-1 & $1: 1000$ & rabbit & Enzo Life Sciences, Farmindale, NY, USA \\
NOXA & $1: 1000$ & mouse & Enzo Life Sciences, Farmindale, NY, USA \\
Vinculin & $1: 2000$ & mouse & Sigma Aldrich /Merck \\
B-Actin & $1: 10000$ & mouse & Sigma Aldrich, Deisenhofen, Germany
\end{tabular}

All primary antibodies were diluted in antibody dilution buffer. 


\subsubsection{Secondary antibodies for Western blotting}

Table 10: Secondary antibodies for Western blotting.

\begin{tabular}{lllll}
\hline Target species & Dilution & Conjugation & Species & Supplier \\
\hline Mouse & $1: 5000$ & Peroxidase & Goat & $\begin{array}{l}\text { Santa Cruz } \\
\text { Biotechnology, Santa } \\
\end{array}$ \\
& $1: 5000$ & Peroxidase & Goat & $\begin{array}{l}\text { Cruz, CA, USA } \\
\text { Santa Cruz } \\
\text { Biotechnology, Santa }\end{array}$ \\
& & & & $\begin{array}{l}\text { Cruz, CA, USA } \\
\text { Rabbit }\end{array}$ \\
& $1: 5000$ & Peroxidase & Goat & $\begin{array}{l}\text { Santa Cruz } \\
\text { Biotechnology, Santa } \\
\text { Rat }\end{array}$ \\
& & & & Cruz, CA, USA \\
\hline
\end{tabular}

All secondary antibodies were diluted in 5\% milk in PBS-T.

\subsubsection{Primary antibodies for immunoprecipitation (IP)}

Table 11: Primary antibodies for IP.

\begin{tabular}{llll}
\hline Target protein & Amount & Species & Supplier \\
\hline BCL-2 & $2 \mu l$ per sample & hamster & BD Biosciences, \\
& & & Heidelberg, Germany \\
BCL-XL & $2 \mu l$ per sample & rabbit & Abcam, Cambridge, \\
& & & UK \\
MCL-1 & $2 \mu l$ per sample & mouse & BD Biosciences, \\
& & & Heidelberg, Germany \\
\hline
\end{tabular}




\subsubsection{Secondary antibodies for IP}

Table 12: Secondary antibodies for IP.

\begin{tabular}{llll}
\hline Target protein & Dilution & Species & Supplier \\
\hline BCL-2 & $1: 50$ & mouse & $\begin{array}{l}\text { Dako (Agilent), Santa } \\
\text { Clara, CA, USA }\end{array}$ \\
BCL-XL & $1: 1000$ & rabbit & $\begin{array}{l}\text { Cell Signaling, Beverly, } \\
\text { MA, USA }\end{array}$ \\
MCL-1 & $1: 1000$ & rabbit & $\begin{array}{l}\text { Enzo Life Sciences, } \\
\text { Farmindale, NY, USA }\end{array}$ \\
BIM & $1: 500$ & rabbit & $\begin{array}{l}\text { Cell Signaling, Beverly, } \\
\text { MA, USA }\end{array}$ \\
NOXA & $1: 1000$ & mouse & Enzo Life Sciences, \\
& & & Farmindale, NY, USA \\
B-Actin & $1: 10000$ & mouse & Sigma Aldrich, \\
& & & Deisenhofen, Germany \\
\hline
\end{tabular}

\subsubsection{Antibodies for fluorescence-activated cell sorting (FACS) measurement}

Table 13: Antibodies for FACS measurement.

\begin{tabular}{lll}
\hline Antibody & Amount & Supplier \\
\hline Fluorescein isothiocyanate & $0.1 \mu$ l per $100 \mu$ l Annexin & University of \\
(FITC) Annexin V & binding buffer & Leicester \\
& & \\
CD45-APC & $0.5 \mu$ l per $100 \mu$ l Annexin & eBioScience, \\
& binding buffer & San Diego, \\
& & USA \\
\hline
\end{tabular}




\subsubsection{List of small interfering (si) RNA}

Table 14: List of siRNA.

\begin{tabular}{llll}
\hline Protein & Construct & Catalog No. & Final concentration \\
\hline none & $\mathrm{ns}$ & $\mathrm{s} 4390843$ & $\begin{array}{l}\text { equal to targeting } \\
\text { siRNA }\end{array}$ \\
& & & $100 \mathrm{nM}$ \\
MCL-1 & $\# 1$ & $\mathrm{~s} 8583$ & $100 \mathrm{nM}$ \\
& $\# 2$ & $\mathrm{~s} 8585$ & $100 \mathrm{nM}$ \\
BAX & $\# 1$ & $\mathrm{~s} 1888$ & $100 \mathrm{nM}$ \\
& $\# 3$ & $\mathrm{~s} 1890$ & $100 \mathrm{nM}$ \\
BAK & $\# 1$ & $\mathrm{~s} 1880$ & $100 \mathrm{nM}$ \\
& $\# 2$ & $\mathrm{~s} 1881$ & $100 \mathrm{nM}$ \\
BIM & \#1 & $\mathrm{s} 195012$ & $100 \mathrm{nM}$ \\
\hline
\end{tabular}

All siRNAs were purchased from Thermo Scientific, Roskilde, Denmark. 


\subsubsection{Kits and Ready-to-use solutions}

Table 15: Kits and Ready-to-use solutions

\begin{tabular}{ll}
\hline Kit/Solution & Supplier \\
\hline FACS Clean Solution & BD Biosciences, \\
FACS Rinse Solution & Heidelberg, Germany \\
& BD Biosciences, \\
FACS Flow sheath fluid & Heidelberg, Germany \\
& BD Biosciences, \\
FACS Shutdown Solution & Heidelberg, Germany \\
& BD Biosciences, \\
Neon Transfection System & Heidelberg, Germany \\
& Invitrogen, Karlsruhe, \\
PageRuler Plus Prestained Protein Ladder & Germany \\
& Thermo Scientific, Roskilde, \\
Pierce BCA protein assay & Denmark \\
& Thermo Scientific, Roskilde, \\
Pierce enhanced chemiluminescence (ECL) & Thermo Scientific, Roskilde, \\
Western Blotting Substrate & Denmark \\
\hline
\end{tabular}




\subsubsection{General chemicals}

Table 16: General chemicals.

\begin{tabular}{ll}
\hline Chemical & Supplier \\
\hline 2-(4-(2-Hydroxyethyl)-1-piperazinyl)- & Thermo Scientific, Roskilde, \\
ethansulfonsäure (HEPES) & Denmark \\
Acrylamid mix, 30\% & Carl Roth, Karlsruhe, Germany \\
Ammonium persulfate (APS) & Carl Roth, Karlsruhe, Germany \\
Bovine serum albumin (BSA) & Carl Roth, Karlsruhe, Germany \\
Bromophenol Blue & Carl Roth, Karlsruhe, Germany \\
Calcium chloride & Carl Roth, Karlsruhe, Germany \\
CellTiter-Glo (CTG) reagent & Promega, Wisconsin, USA \\
CHAPS & Sigma-Aldrich, Deisenhofen, \\
& Germany \\
Cytarabine & AG Cinatl, Frankfurt, Germany \\
dimethyl pimelimidate (DMP) & Sigma-Aldrich, Deisenhofen, \\
Dithiothreitol (DTT) & Germany \\
Dyna protein G beads & Millipore, Darmstadt, Germany \\
Ethanol & Thermo Scientific, Roskilde, \\
Ethylenediaminetetraacetic acid (EDTA) & Carl Roth, Karlsruhe, Germany \\
Glycine & Carl Roth, Karlsruhe, Germany \\
Hydrochloric acid (HCI) & Carl Roth, Karlsruhe, Germany \\
Insulin & Sigma-Aldrich, Deisenhofen, \\
Isopropanol & Germany \\
Methanol & Carl Roth, Karlsruhe, Germany \\
Milk powder & Carl Roth, Karlsruhe, Germany \\
Phenylmethylsulfonylfluoride (PMSF) & Carl Roth, Karlsruhe, Germany \\
Propidium iodide (PI) & Carl Roth, Karlsruhe, Germany \\
& Gigma-Aldrich, Deisenhofen, \\
&
\end{tabular}


Protease inhibitor cocktail (PIC)

Sodium dodecyl sulfate (SDS)

Sodium fluoride

Sodium hydroxide $(\mathrm{NaOH})$

Sodium hydroxide $(\mathrm{NaOH})$

Sodium orthovanadate

TEA

Tetramethylethylenediamine (TEMED)

Tetramethylrhodamine methylester

(TMRM)

TrisBase

Tris $\mathrm{HCl}$

Triton X-100 detergent

Tween 20

$\beta$-Glycerophosphate

$\beta$-Mercaptoethanol
Roche Diagnostics, Mannheim, Germany

Carl Roth, Karlsuhe, Germany

Sigma-Aldrich, Deisenhofen, Germany

Carl Roth, Karlsruhe, Germany

Carl Roth, Karlsuhe, Germany

Sigma-Aldrich, Deisenhofen, Germany

Sigma-Aldrich, Deisenhofen, Germany

Carl Roth, Karlsuhe, Germany

Sigma-Aldrich, Deisenhofen, Germany

Carl Roth, Karlsruhe, Germany Carl Roth, Karlsruhe, Germany

Carl Roth, Karlsuhe, Germany

Carl Roth, Karlsuhe, Germany

Sigma-Aldrich, Deisenhofen, Germany

Life Technologies, Darmstadt, Germany 


\subsubsection{Consumable materials}

Table 17: Consumable materials.

\begin{tabular}{|c|c|}
\hline Material & Supplier \\
\hline Cell Culture dishes (100 mm) & $\begin{array}{l}\text { Greiner Bio-One, Frickenhausen, } \\
\text { Germany }\end{array}$ \\
\hline Cell culture flasks $\left(25 \mathrm{~cm}^{2}, 75 \mathrm{~cm}^{2}\right)$ & $\begin{array}{l}\text { Greiner Bio-One, Frickenhausen, } \\
\text { Germany }\end{array}$ \\
\hline Centrifuge Tubes (15 ml, $50 \mathrm{ml})$ & $\begin{array}{l}\text { Greiner Bio-One, Frickenhausen, } \\
\text { Germany }\end{array}$ \\
\hline Combitips & Eppendorf, Hamburg, Germany \\
\hline Cryogenic vials & Starlab, Hamburg, Germany \\
\hline Dishes with grid (35 mm) & $\begin{array}{l}\text { Greiner Bio-One, Frickenhausen, } \\
\text { Germany }\end{array}$ \\
\hline Filter tips $(10 \mu \mathrm{l}, 200 \mu \mathrm{l}, 1000 \mu \mathrm{l})$ & Starlab, Hamburg, Germany \\
\hline Hybond ECL nitrocellulose membrane & $\begin{array}{l}\text { GE Healthcare, Buckinghamshire, } \\
\text { UK }\end{array}$ \\
\hline Hyperfilm ECL & $\begin{array}{l}\text { GE Healthcare, Buckinghamshire, } \\
\text { UK }\end{array}$ \\
\hline $\begin{array}{l}\text { Microcentrifuge tubes }(0,5 \mathrm{ml}, 1,5 \mathrm{ml}, 2 \\
\mathrm{ml})\end{array}$ & Starlab, Hamburg, Germany \\
\hline Mr. Frosty ${ }^{\mathrm{TM}}$ freezing container & $\begin{array}{l}\text { Thermo Scientific, Roskilde, } \\
\text { Denmark }\end{array}$ \\
\hline Nitril gloves, sterile, powder-free & Starlab, Hamburg, Germany \\
\hline Round-bottom tubes (FACS-Tubes) & $\begin{array}{l}\text { BD Biosciences, Heidelberg, } \\
\text { Germany }\end{array}$ \\
\hline $\begin{array}{l}\text { Sterile pipette }(5 \mathrm{ml}, 10 \mathrm{ml}, 25 \mathrm{ml}, 50 \\
\mathrm{ml})\end{array}$ & $\begin{array}{l}\text { Greiner Bio-One, Frickenhausen, } \\
\text { Germany }\end{array}$ \\
\hline $\begin{array}{l}\text { Tissue culture plates (6-, 96-well plates; } \\
\text { white, uncoloured) }\end{array}$ & $\begin{array}{l}\text { Greiner Bio-One, Frickenhausen, } \\
\text { Germany }\end{array}$ \\
\hline Whatman paper (2,5 mm) & $\begin{array}{l}\text { Thermo Scientific, Roskilde, } \\
\text { Denmark }\end{array}$ \\
\hline
\end{tabular}




\subsubsection{Equipment}

Table 18: Equipment.

\begin{tabular}{|c|c|}
\hline Equipment & Supplier \\
\hline ARE heating magnetic stirrer & VELP Scientifica, Usmate, Italy \\
\hline Centrifuge MIKRO $200 \mathrm{R}$ & $\begin{array}{l}\text { Hettich, Baden-Baden, } \\
\text { Germany }\end{array}$ \\
\hline Centrifuge ROTANTA $460 \mathrm{R}$ & $\begin{array}{l}\text { Hettich, Baden-Baden, } \\
\text { Germany }\end{array}$ \\
\hline Centrifuge ROTIXA 50 RS & $\begin{array}{l}\text { Hettich, Baden-Baden, } \\
\text { Germany }\end{array}$ \\
\hline CO2 Incubator & SANYO, Wehr, Germany \\
\hline Easypet & Eppendorf, Hamburg, Germany \\
\hline Eletronic analytical balance EW & Kern, Balingen, Germany \\
\hline Eletronic precision balance 770 & Kern, Balingen, Germany \\
\hline FACS Canto II & $\begin{array}{l}\text { BD Biosciences, Heidelberg, } \\
\text { Germany }\end{array}$ \\
\hline Microscope CKX41 & Olympus, Hamburg, Germany \\
\hline $\begin{array}{l}\text { Mini-PROTEAN Tetra Cell electrophoresis } \\
\text { system }\end{array}$ & Bio-Rad, Munich, Germany \\
\hline Neubauer counting chamber & Carl Roth, Karlsruhe, Germany \\
\hline $\begin{array}{l}\text { PerfectBlue Dual Gel Twin L } \\
\text { electrophoresis system }\end{array}$ & PEQLAB, Erlangen, Germany \\
\hline pH meter inoLab pH7310 & WTW, Weilheim, Germany \\
\hline $\begin{array}{l}\text { Pipette Research Plus } \\
(2.5 \mu \mathrm{l}, 10 \mu \mathrm{l}, 20 \mu \mathrm{l}, 100 \mu \mathrm{l}, 200 \mu \mathrm{l}, 1000 \mu \mathrm{l})\end{array}$ & Eppendorf, Hamburg, Germany \\
\hline Power Pac HC high-current power supply & Bio-Rad, Munich, Germany \\
\hline Rocking shaker & MS-L, Wiesloch, Germany \\
\hline Roller Mixer & Ratek, Victoria, Australia \\
\hline Rotating wheel & Stuart, Staffordshire, UK \\
\hline SANYO incubator MIR-262 & $\begin{array}{l}\text { New Brunswick Scientific, } \\
\text { Edison, NJ, USA }\end{array}$ \\
\hline
\end{tabular}


Tecan Infinite M200 plate reader

Thermomixer comfort

Trans-Blot SD semi-dry transfer cell

V-150 autoclave

Vortex mixer ZX classic

Water bath SWB20
Tecan, Crailsheim, Germany Eppendorf, Hamburg, Germany

Bio-Rad, Munich, Germany

SysTec, Bergheim-Glessen,

Germany

VELP Scientifica, Usmate, Italy

Medingen, Arnsdorf, Germany

\subsubsection{Software}

Table 19: Software.

\begin{tabular}{lll}
\hline Software & Version & Supplier \\
\hline Microsoft Office & 2013 & Microsoft GmbH, Germany \\
EndNote & X9.1 & Clarivate Analytics, Philadelphia, USA \\
ImageJ & $1.52 \mathrm{e}$ & National Institutes of Health, USA \\
GraphPad Prism & 8 & GraphPad Software, San Diego, \\
& & California, USA \\
Magellan Data Analysis & 7.2 & Tecan, Crailsheim, Germany \\
Tecan i-control & 1.10 & Tecan, Crailsheim, Germany \\
FACSDiva & 6.1 .3 & BD Biosciences, Heidelberg, Germany \\
\hline
\end{tabular}




\subsection{Methods}

\subsubsection{Cell culture}

OCI-AML3 cells were cultured in $80 \%$ a-MEM medium supplemented with $20 \%$ FCS, $1 \%$ penicillin/streptomycin and $1 \%$ sodium pyruvate, KASUMI-1 cells were cultivated in RPMI 1640 GlutaMAX-I medium supplemented with 20\% FCS, 1\% penicillin/streptomycin and $1 \%$ sodium pyruvate, and MONO-MAC- 6 cells were maintained in RPMI 1640 GlutaMAX-I medium with 10\% FCS, 1\% non-essential amino acids, $1 \%$ sodium pyruvate and $10 \mu \mathrm{g} / \mathrm{ml}$ Insulin. All remaining AML cell lines were cultured in RPMI GlutaMAX-I medium with 10\% FCS, 1\% penicillin/streptomycin and $1 \%$ sodium pyruvate. All cell lines were incubated at $37{ }^{\circ} \mathrm{C}$ with $5 \% \mathrm{CO}_{2}$ and split every two to three days at individual ratios (1:5 for HL-60, 1:2 for KASUMI-1 and 1:3 for all other cell lines). Passaging was performed by adding the corresponding volume of cell suspension into a new cell culture flask containing appropriate amount of fresh growth medium. Each cell line was verified by DSMZ and routinely checked for mycoplasma contamination.

\subsubsection{Primary samples}

Primary AML samples - with written informed consent from patients - were kindly provided from the hematological biobank of UCT Frankfurt/Germany. The study protocol was approved by the local ethics committee (No. SH-05-2014). With density gradient centrifugation using Ficoll-isopaque (Amersham Bioscience, Freiburg, Germany) they extracted MNCs, which were transported as cell pellets in $1 \mathrm{ml}$ PBS.

After collecting the samples, we first centrifugated them at $1400 \mathrm{rpm}$ for 4 minutes (min) at room temperature (RT). PBS was discarded and cells were carefully resuspended in IMDM with GlutaMAX-II supplemented with 10\% FCS, 1\% penicillin/streptomycin, $1 \%$ Sodium pyruvate, $1 \%$ non-essential amino acid, $8 \mathrm{ng} / \mathrm{ml} \mathrm{IL-3,} 20 \mathrm{ng} / \mathrm{ml}$ rh- SCF, $20 \mathrm{ng} / \mathrm{ml} \mathrm{GM}$-CSF and $50 \mu \mathrm{M} \beta$-Mercaptoethanol. Subsequently, primary AML cells were seeded into 96-well plates and treated. HPCs were obtained in a frozen condition. Thus, they first must be thawed by 
warming them in the water bath until they got a slightly viscous consistence and immediately after this, they were transferred in a $15 \mathrm{ml}$ tube with IMDM culture medium enriched with $20 \% \mathrm{FCS}, 1 \%$ penicillin/streptomycin, $50 \mathrm{ng} / \mathrm{ml}$ rh- SCF, $50 \mathrm{ng} / \mathrm{ml} \mathrm{IL-3,} 100 \mathrm{ng} / \mathrm{ml}$ FLT3-Ligand and $20 \mathrm{ng} / \mathrm{ml}$ GM-CSF. Subsequently, centrifugation at $1000 \mathrm{rpm}$ for $5 \mathrm{~min}$ at RT, resuspension in culture medium, seeding and treating followed.

\subsubsection{Cell counting}

To ensure equal conditions for every experiment, $A M L$ cell lines as well as primary samples were counted before seeding, so that the density of the different cell lines within the experiments was normalized. Therefore, cell culture flasks were carefully shaken to reach homogeneity and then $20 \mu$ of the cell suspension were mixed with $60 \mu \mathrm{l}$ of $0.4 \%$ Trypan blue solution (ratio $1: 4$ ). This solution facilitates the distinction of living cells from dead ones because it is able to pass the membrane of dead cells - in contrast to living cells - and let them appear blue. An appropriate amount of this cell dilution was transferred to the Neubauer counting chamber, so that living cells in each closed square can be counted. Thereby, the following formula applies:

$$
\text { number of cells [cells } / \mathrm{ml}] \hat{=} \text { counted cells } \times 10^{4} \text {. }
$$

To reach the appropriate density (for measurement of cell death, determination of caspase dependency and loss of mitochondrial membrane potential by FACS: $2 \times 10^{5}$ cells $/ \mathrm{ml}$, for CellTiter-Glo: $1 \times 10^{5}$ cells $/ \mathrm{ml}$, for cell death measurement of primary samples: $1 \times 10^{6}$ cells $/ \mathrm{ml}$ and for transient knockdown: $2 \times 10^{6} \mathrm{cells} / \mathrm{ml}$ ) an adequate volume of cell suspension was centrifugated at $1200 \mathrm{rpm}$ for $5 \mathrm{~min}$ at RT and after removing supernatant, the cell pellet was resuspended carefully in corresponding volume of fresh pre-warmed growth medium. 


\subsubsection{Freezing and thawing}

For storing cells, $2 \times 10^{6}$ cells were stored in a cryogenic vial. Therefore, an appropriate volume of cell suspension from the culture flasks were taken and after centrifugation at $1200 \mathrm{rpm}$ for $5 \mathrm{~min}$ at RT, supernatant was removed, and cell pellet was resuspended in freezing medium containing 10\% DMSO and $90 \%$ FCS. For less damage during cooling down, vials are stored in Mr. Frosty freezing containers filled with isopropanol at $-80^{\circ} \mathrm{C}$ overnight and at the next day, they were transferred to a nitrogen tank for long term storage at $-196^{\circ} \mathrm{C}$. Thawing was accomplished by warming vials in the water bath until their content was liquid again and immediately mixing this with pre-warmed culture medium in a $15 \mathrm{ml}$ tube. After centrifugation at $1200 \mathrm{rpm}$ for $5 \mathrm{~min}$ at RT, supernatant was removed, and the cell pellet was resuspended with $10 \mathrm{ml}$ culture medium (containing 20\% FCS) and transferred to a $25 \mathrm{~cm}^{2}$ culture flask.

\subsubsection{Cell pellets}

To guarantee that different Western blots for the investigation of basal protein expression levels of different cell lines deliver similar results, cell pellets were made in a standardized way. Thereby, cells were seeded in a density of $2 \times 10^{5} \mathrm{cells} / \mathrm{ml}$ in $30 \mathrm{ml}$ and cultured for $48 \mathrm{~h}$. Afterwards, the whole volume of the culture flask was transferred into a $50 \mathrm{ml}$ tube and centrifugated at $1800 \mathrm{rpm}$ for $5 \mathrm{~min}$ at $4{ }^{\circ} \mathrm{C}$. This was followed by discarding consumed culture medium, resuspending cell pellet in $3 \mathrm{ml}$ cooled PBS-T as a washing step and transferring $1 \mathrm{ml}$ each into $1.5 \mathrm{ml}$ microcentrifuge tubes to centrifugate again at $1800 \mathrm{rpm}$ for $5 \mathrm{~min}$ at $4{ }^{\circ} \mathrm{C}$. Supernatant was removed and cell pellets were either frozen at $-25^{\circ} \mathrm{C}$ or directly processed for Western blot analysis. 


\subsubsection{CellTiter-Glo viability assay}

The sensitivity of the eleven AML cell lines towards ABT-199, A-1331852, S63845 and S55746 was screened with CTG Luminescent Cell Viability Assay. Cells were seeded in a density of $1 \times 10^{5} \mathrm{cells} / \mathrm{ml}$ in a 96-well plate. The treatments were pipetted into the wells in serial dilution with horizontally increasing concentrations $(0.001,0.003,0.01,0.03,0.1,0.3,1,3$ and $10 \mu \mathrm{M})$. Cells were seeded and immediately treated with the different $\mathrm{BH} 3$ mimetics. After $72 \mathrm{~h}$ treatment $5 \mu \mathrm{l}$ of CTG reagent was added to each well and luminescence was measured with plate reader after ten minutes incubation at RT. Results were normalized to the control sample, which was set to $100 \%$ viability.

\subsubsection{Cell death analysis with Annexin V-FITC staining}

For analyzing cell death FACS measurement was used with Annexin V-FITC staining. Annexin V-FITC was applied for estimating phosphatidylserine (PS) exposure, that increases upon induction of apoptosis. Cells were seeded in an appropriate density into a 96-well plate and treated with $\mathrm{BH} 3$ mimetics for indicated time points. AML cells were incubated with different $\mathrm{BH} 3$ mimetics for indicated timepoints. After this $100 \mu \mathrm{l}$ of each well were incubated with $100 \mu \mathrm{l}$ of Annexin $\mathrm{V}$ binding buffer containing $0.1 \mu \mathrm{l}$ FITC Annexin V-FITC for ten minutes in the dark. Afterwards cell death was measured with flow cytometry. 


\subsubsection{Cell death analysis of primary samples}

Primary AML patient samples or HPCs were seeded in a density of $1 \times 10^{6}$ cells $/ \mathrm{ml}$. HPCs were treated with dilution series containing concentrations $0.001 \mu \mathrm{M}, 0.01 \mu \mathrm{M}, 0.1 \mu \mathrm{M}, 1 \mu \mathrm{M}$ and $10 \mu \mathrm{M}$ and primary $\mathrm{AML}$ patient samples were treated analogous to the different cell lines. After $20 \mathrm{~h}$ incubation $100 \mu \mathrm{l}$ of the primary MNCs derived from AML patients were incubated for 20 min at RT with $100 \mu$ Annexin V binding buffer supplemented with $0.1 \mu$ Annexin V-FITC and $0.5 \mu$ anti-human CD45-APC antibody and subsequently analysed by flow cytometry. Cell death of AML blasts was identified by CD45/side scatter (SSC) gating. ${ }^{40}$ HPCs were incubated and measured equivalent to the AML cell lines.

\subsubsection{Clonogenic assay}

For analysing the toxicity of $\mathrm{BH} 3$ mimetics on normal HPCs, their impact on colony-forming ability of HPCs was investigated. At first human methylcellulose enriched medium (Methocult $\mathrm{H} 4435$ enriched) containing recombinant cytokines especially SCF, GM-CSF, G-CSF, IL-3, IL-6 and erythropoietin was prepared according to manufacturer's instructions: Once thawed, the medium was shaken vigorously for one to two minutes, afterwards, it was aliquoted.

Treatment of $\mathrm{CD} 34^{+}$cells was executed according to the treatment of primary AML samples (see 3.2.8). After $9 \mathrm{~h}$ (BH3 mimetics) or $24 \mathrm{~h}$ (Cytarabine) treatment, $20 \mu \mathrm{l}$ of each well of the 96 -well plate were taken to analyse apoptosis (3.2.7) and centrifugated at $1200 \mathrm{rpm}$ for $5 \mathrm{~min}$ at RT. Cell pellet was resuspended in $666 \mu$ l culture medium to obtain approximately $3 \times 10^{4}$ cells $/ \mathrm{ml}$. $400 \mu \mathrm{l}$ of treated HPCs were transferred into $4 \mathrm{ml}$ aliquots of Methocult in $15 \mathrm{ml}$ tubes. Vortexing these tubes enables homogeneity of the cells within the Methocult. Transferring 1,1 $\mathrm{ml}$ into $35 \mathrm{~mm}$ dishes with grid ensures that approximately 3000 HPCs per dish were cultured. Dishes were placed at $37{ }^{\circ} \mathrm{C}$ in $5 \% \mathrm{CO}_{2}$ for 10-12 days. Afterwards, colonies containing more than 50 cells were analysed with microscopy for different lineages - colony forming unit - granulocyte, macro- 
phage, megakaryocyte (CFU-GEMM), colony forming unit - granulocyte, macrophage (CFU-GM) and burst forming unit - erythroid (BFU-E) - and counted on days $10-12$.

\subsubsection{Determination of loss of mitochondrial membrane potential (MMP)}

To measure changes in mitochondrial membrane potential we made use of Tetramethylrhodamine methylester (TMRM) that accumulates in intact mitochondria because of their negative relative charge associated with the proton pump of the respiratory chain. Upon induction of apoptosis, mitochondrial outer membrane permeabilization occurs, thus there is a loss of MMP and TMRM accumulation decreases. This staining can be assessed by flow cytometry. Selected AML cell lines were seeded in a density of $2 \times 10^{5} \mathrm{cells} / \mathrm{ml}$ in a 6 -well plate and treated the day after with $1 \mu \mathrm{M}$ ABT-199 or $1 \mu \mathrm{M}$ S63845. After incubation for indicated time points ( $1 \mathrm{~h}, 2 \mathrm{~h}, 4 \mathrm{~h}, 8 \mathrm{~h}, 24 \mathrm{~h}) 100 \mu \mathrm{l}$ cell suspension were incubated with $100 \mu$ l of TMRM staining solution ( $50 \mathrm{nM}$ ) for $10 \mathrm{~min}$ at $37^{\circ} \mathrm{C}$ in $5 \% \mathrm{CO}_{2}$. Changes in the accumulation of TMRM in mitochondria upon a loss of MMP was detected with flow cytometry. The remaining volume of the 6-well plate was used for Western blot analysis.

\subsubsection{Examination of caspase dependence}

Cells were seeded in a density of $2 \times 10^{5} \mathrm{cells} / \mathrm{ml}$ in a 96 -well plate and treated at the same time with $1 \mu \mathrm{M}$ ABT-199 or $1 \mu \mathrm{M}$ S63845 in the absence or presence of $50 \mu \mathrm{M} z \mathrm{VAD}$.fmk. After $8 \mathrm{~h}$ incubation cell death was measured with Annexin V-FITC staining and flow cytometry. 


\subsubsection{Western blot Analysis}

For Western blot analysis protein concentration of cell pellets must be determined starting with protein extraction. Therefore, cell pellets were resuspended in lysis buffer and incubated for $30 \mathrm{~min}$ on ice. This was followed by centrifugation at $14000 \mathrm{rpm}$ for $25 \mathrm{~min}$ at $4{ }^{\circ} \mathrm{C}$. Supernatants were transferred into new tubes and protein concentration was determined using Bicinchoninic acid (BCA) assay. Therefore, $1 \mu \mathrm{l}$ of protein sample and $10 \mu \mathrm{l}$ of BCA standard were incubated for $30 \mathrm{~min}$ at $37^{\circ} \mathrm{C}$ with $200 \mu \mathrm{l}$ of $\mathrm{BCA}$ reagent. The absorbance at $560 \mathrm{~nm}$ was measured by TECAN reader with Magellan software. After protein concentrations were calculated, samples for electrophoresis were prepared: To $50-100 \mu \mathrm{g}$ protein lysate $6 x$ SDS loading buffer was added in a dilution ratio $1: 6$ with $\mathrm{dd}_{2} \mathrm{O}$. Then samples were denaturized by heating at $96{ }^{\circ} \mathrm{C}$ for $5 \mathrm{~min}$. Proteins were separated based on their molecular weight by gel electrophoresis using $13.5 \%$ SDS page (resolving gel contained $250 \mathrm{mM}$ Tris $\mathrm{HCl}(\mathrm{pH} 8.8$ ), $0.1 \%$ SDS, $0.1 \%$ APS, $0.04 \%$ TEMED and $13.5 \%$ polyacrylamide; stacking gel contained $125 \mathrm{mM}$ TrisHCl (pH 6.8), $0.1 \%$ SDS, $0.1 \%$ APS, $0.04 \%$ TEMED and $5 \%$ of polyacrylamide). This was facilitated using $1 \mathrm{x}$ running buffer at constant voltage of $100 \mathrm{~V}$. When samples reached the stacking gel the voltage was increased to $140 \mathrm{~V}$. Afterwards, as part of the so-called blotting, proteins were transferred onto a hybond ECL nitrocellulose membrane within $1.5 \mathrm{~h}$ using a semi-dry blotting system. Therefore, membranes and gels were drenched with $1 \mathrm{x}$ blotting buffer and placed between two layers of Whatman paper on each side. After botting, unspecific binding sites were blocked by incubating membranes for at least $1 \mathrm{~h}$ at RT with $5 \%$ milk in PBS-T. Subsequently, membranes were incubated with primary antibodies at $4{ }^{\circ} \mathrm{C}$ overnight. The day after, membranes were washed three times with PBST for 10 min and then incubated with secondary antibodies for at least $1 \mathrm{~h}$ at RT. For protein detection, membranes were washed again three times with PBST for 10 min before ECL solution was applied. Prepared membranes and X-Ray films were positioned on X-ray developer cassettes and incubated for seconds up to $1.5 \mathrm{~h}$. Films were developed using Roentoroll developing and fixation solutions. Quantification of band intensities was performed using Image J 3.1Iv. 


\subsubsection{Immunoprecipitation}

For investigations of binding patterns of the main anti-apoptotic BCL-2 proteins co-immunoprecipitation (IP) was carried out. At the indicated time point of treatment cell pellets were made and subsequently protein extraction and quantification were performed as described before. Lysis was carried out with $500 \mu \mathrm{l} 1 \%$ CHAPS buffer. For immobilizing antibodies $20 \mu \mathrm{l}$ Dyna Protein $\mathrm{G}$ beads per IP were incubated with $2 \mu$ of the following antibodies on a rotating wheel for $1 \mathrm{~h}$ at $4{ }^{\circ} \mathrm{C}$ : mouse anti-MCL-1 (BD Biosciences, 559027), hamster anti-BCL-2 (BD Bioscience, 551051) and rabbit anti-BCL-XL (Abcam, ab32370). Cross-linking steps included washing beads with $1 \mathrm{ml} \mathrm{0,2} \mathrm{M}$ TEA buffer incubation with $1 \mathrm{ml} 20 \mathrm{mM}$ DMP in 0,2 M TEA for $30 \mathrm{~min}$ at RT on a roller mixer and after this incubation with $1 \mathrm{ml} 50 \mathrm{mM}$ Tris (pH 7.4) for $15 \mathrm{~min}$ at RT on a roller mixer. MCL-1, BCL-2 and BCL-XL immunoprecipitations were performed with at least $0.5 \mathrm{mg}$ protein lysate, that was incubated with cross-linked beads overnight on a rotating wheel at $4{ }^{\circ} \mathrm{C}$ before washing off the precipitate with CHAPS buffer. The resulting precipitate was analyzed by Western Blotting and the membranes probed with antibodies against mouse anti-NOXA (Enzo, ALX-804-408), rabbit anti-BIM (Cell Signaling, 2819S), rabbit anti-MCL-1 (Enzo, ADI-AAP-240F), rabbit anti-BCL-XL (Cell Signaling, 2762S) and mouse anti-BCL-2 (Dako (Agilent), M088701-2) to detect interactions. 


\subsubsection{RNA interference}

Genetic silencing was performed using Neon Transfection System. Therefore, cells were seeded in a density of $2 \times 10^{6} \mathrm{cells} / \mathrm{ml}$ in a 6-well plate. SiRNA was introduced into the cells by electroporation steps (1200 V, $20 \mathrm{~ms}$, pulse no. 2) using $100 \mathrm{nM}$ siRNA for MCL-1 with $24 \mathrm{~h}$ of transient knockdown prior to cell death measurement by Annexin V-FITC staining and FACS analysis. Knockdown efficacy was verified by Western blot analysis.

\subsubsection{Statistics}

The $E_{50}$ values were calculated with nonlinear regression algorithms in GraphPad Prism software. Statistical significance was verified by using t-test in Excel (two-samples, two-tailed distribution, unequal variance) and was defined as significant at $p<0.05\left(^{*}\right)$, moderately significant at $p<0.01\left(^{* *}\right)$ and highly significant at $p<0.001{ }^{\left({ }^{* *}\right)}$. 


\section{Results}

The following results were published in the journal Cell Death and Disease in 2019.41

\subsection{MCL-1 as well as BCL-2 inhibition decreases viability of AML cells}

To generally examine the potency of selective $\mathrm{BH} 3$ mimetics for the treatment of AML, eleven AML cell lines were screened for sensitivity to ABT-199, S55746, A-1331852 and S63845. Therefore, cell viability was measured with CellTiter-Glo viability assay $72 \mathrm{~h}$ after treatment. Four out of eleven cell lines (MOLM-13, MV4-11, ML-2 and KASUMI-1) responded to the BCL-2 inhibitors ABT-199 (Figure 4A) and S55746 (Figure 4B) with half maximal effective concentration $\left(E_{50}\right)$ values in the higher nanomolar range (Table 4). A comparison of ABT-199 and 555746 reveals that ABT-199 shows lower $\mathrm{EC}_{50}$ values and thus a higher potency. Only KASUMI-1 cells showed a decreased viability upon BCL- $X_{L}$ inhibition with a half-maximal effect at a concentration of $1.77 \mu \mathrm{M}$ (Figure 4C). All cell lines showed decreasing viability upon treatment with the MCL-1 inhibitor S63845 (Figure 4D). MV4-11, MOLM-13, KASUMI-1, NB4 and MONO-MAC-6 cells were most sensitive with an inhibition of $50 \%$ at nanomolar concentrations, and $\mathrm{HL}-60$ and OCl-AML3 cells were less sensitive with $\mathrm{EC}_{50}$ values in the micromolar range. Remarkably, all those cell lines that were highly sensitive to the treatment with ABT-199 also highly responded to the treatment with $\mathbf{5 6 3 8 4 5 .}$ In addition to the screening results, there is a statistically significant difference between $\mathrm{EC}_{50}$ values from $\mathrm{S} 63845$ and ABT-199 (Figure 5) that confirm the importance of MCL-1 inhibition for the treatment of AML.

Taken together, MCL-1 in comparison to BCL-2 and BCL-XL stands out as the most promising target for the treatment of AML. Response to $\mathrm{BH} 3$ mimetics appeared to be independent of the different AML subtypes, although the group size was too small for statistical analysis. 
A

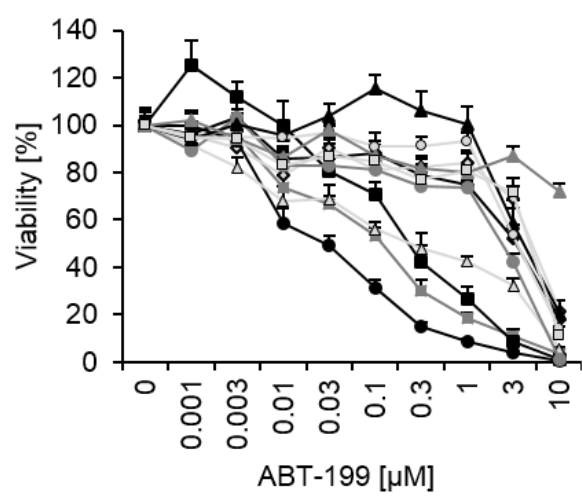

C

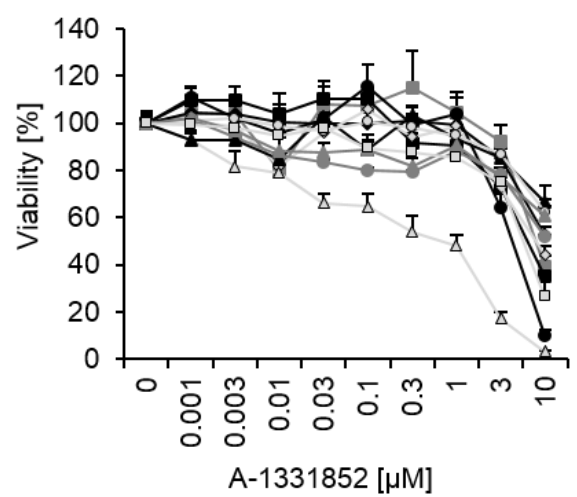

B

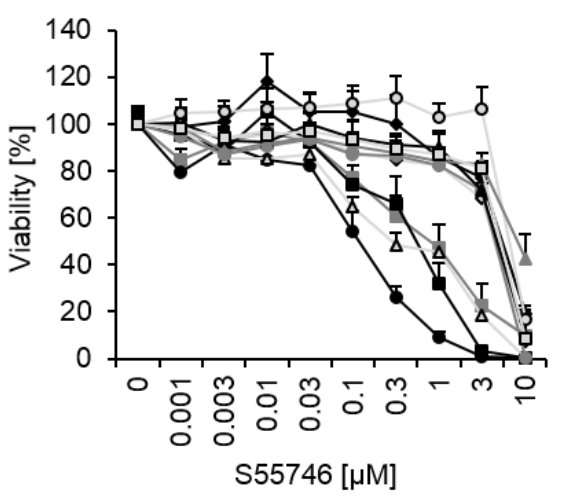

D

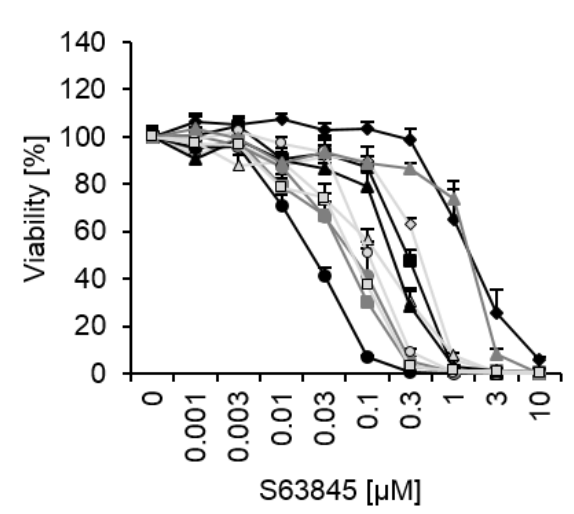

$\rightarrow-$ MOLM-13

$\rightarrow-M L-2$

$\rightarrow \mathrm{HL}-60$

$\leadsto$ KG-1

$\rightarrow-M V 4-11$

$\triangle$ KASUMI-1

$\rightarrow$ NB4

$\leftarrow$ PLB985

- THP-1

$\rightarrow$ OCI-AML3

- MONO-MAC-6

Figure 4: MCL-1 constitutes the most promising anti-apoptotic therapeutic target in AML.

Eleven AML cell lines were treated with increasing concentrations of (A) ABT-199, (B) S55746, (C) A-1331852 or (D) S63845 for $72 \mathrm{~h}$. Cell viability was measured using CellTiter-Glo viability assay. Mean and SEM of at least three independent experiments performed in duplicate or triplicate are shown. 
Table 20: $\mathrm{EC}_{50}$ values of $\mathrm{AML}$ cell lines to $\mathrm{BH} 3$ mimetics.

$\mathrm{EC}_{50}$ values were calculated by non-linear regression analysis using GraphPad prism.

\begin{tabular}{llllll}
\hline & Subtype & \multicolumn{3}{c}{ EC $_{50}[\mu \mathrm{M}]$} \\
\cline { 3 - 6 } Cell line & [FAB] & ABT-199 & S55746 & A-1331852 & S63845 \\
\hline MOLM-13 & M5a & 0.08 & 0.74 & $>10$ & 0.05 \\
ML-2 & M4 & 0.11 & 0.62 & 6.79 & 0.31 \\
HL-60 & M2 & 3 & 4.19 & $>10$ & 1.98 \\
KG-1 & - & 4 & 4.08 & $>10$ & 0.49 \\
MV4-11 & M5 & 0.01 & 0.16 & 3.35 & 0.02 \\
KASUMI-1 & M2 & 0.77 & 0.81 & 1.77 & 0.15 \\
NB4 & M3 & 2.92 & 4.11 & $>10$ & 0.06 \\
PLB985 & M4 & 3.05 & 3.94 & $>10$ & 0.22 \\
THP-1 & M5 & 3.15 & $>10$ & $>10$ & 0.10 \\
MONO-MAC-6 & M5 & 4.07 & 4.20 & 5.64 & 0.07 \\
OCI-AML3 & M4 & $>10$ & $>10$ & $>10$ & 1.53 \\
\hline
\end{tabular}

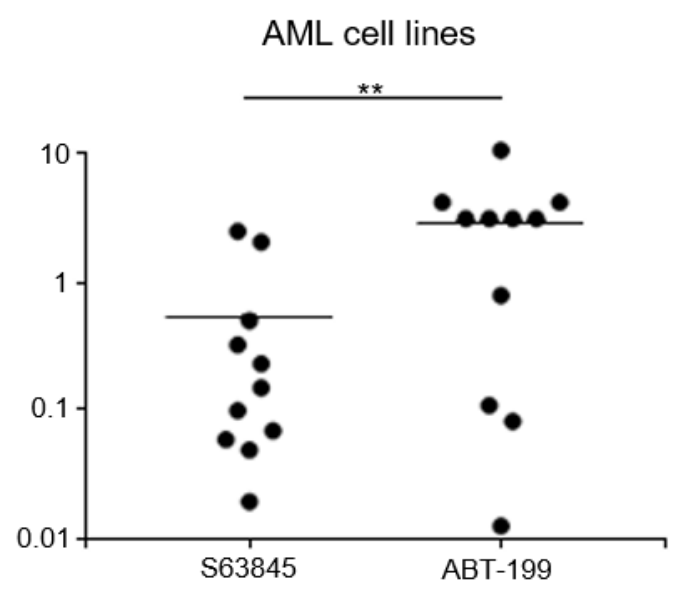

Figure 5: Comparison of $\mathrm{EC}_{50}$ values from $\mathrm{S} 63845$ with those from ABT-199.

Eleven AML cell lines were treated with S63845 or ABT-199, cell death was measured with CellTiter-Glo (see figure 4) and EC $_{50}$ values were calculated (see table 4) and plotted using GraphPad prism. Mean data points of at least three independent experiments performed in triplicate are shown. $p<0.01\left({ }^{* *}\right)$ 
To confirm the results, which were obtained by CellTiter-Glo viability assay, FACS measurement was used with Annexin V staining for quantification of PS exposure in selected cell lines. As expected MV4-11, MOLM-13, ML-2 and KASUMI-1 cells responded most to the treatment with ABT-199 (Figure 6A). The results for the treatment with S55746 were similar to those for ABT-199: MV4-11, MOLM-13, ML-2 and KASUMI-1 cells showed highest sensitivity, KG-1 cells a slight response, OCI-AML3 and HL-60 cells resistance (Figure 6B). S55746 showed according to CellTiter-Glo results a lower potency than ABT-199. KASUMI-1 cells showed a moderate sensitivity to A-1331852 (Figure 6C). MV4-11, MOLM-13 and ML-2 cells displayed a high response to $\mathrm{S} 63845$ as well (Figure 6D). Additionally, MONO-MAC- 6 cells were highly sensitive to the MCL- 1 inhibitor, while they were resistant to ABT-199 like OCI-AML3 and HL-60 cells. In contrast, KG-1 cells showed only a slight response to ABT-199. Taken together, these results are in accordance with those obtained by CellTiter-Glo measurement. 
A

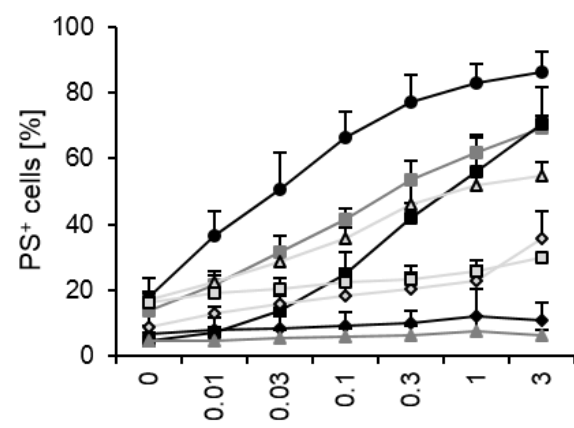

ABT-199 $[\mu \mathrm{M}]$

C

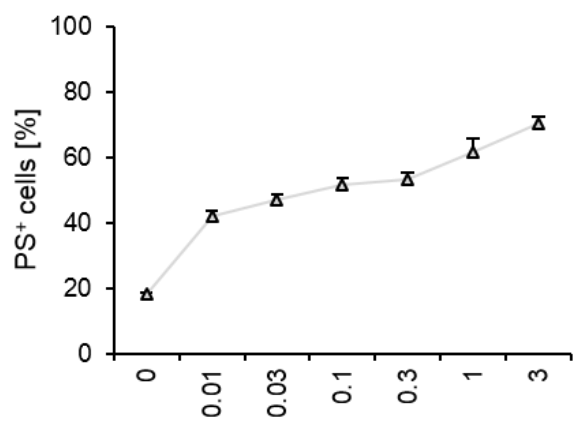

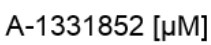

B

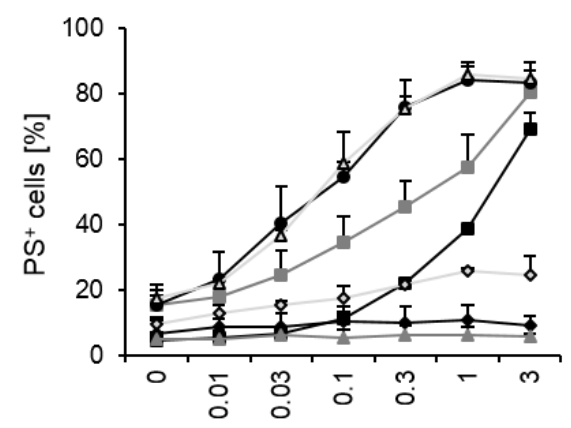

S55746 $[\mu \mathrm{M}]$

D

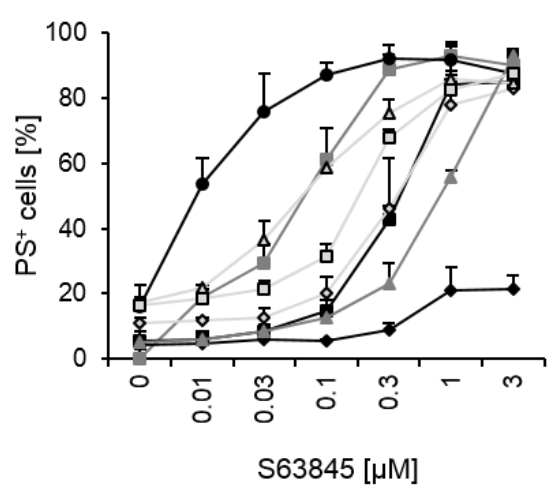

- - MOLM-13

$\rightarrow-M L-2$

$\rightarrow-\mathrm{HL}-60$

$\therefore$ KG-1

$\rightarrow$ MV4-11

$\triangle$ KASUMI-1

$\rightarrow$ OCI-AML3

$\square-M O N O-M A C-6$

Figure 6: Results of CellTiter-Glo viability assay can be confirmed by flow cytometry.

Selected AML cell lines were treated with indicated concentrations of (A) ABT-199, (B) S55746, (C) A1331852 or (D) S63845 for $24 \mathrm{~h}$ before PS exposure (PS ${ }^{+}$) was determined using Annexin V-FITC staining and flow cytometry. Mean and SD of at least three independent experiments performed in triplicate are shown. 


\subsection{The sensitivity of AML cell lines towards $B H 3$ mimetics does not correlate with the basal expression levels of BCL- 2 proteins}

The heterogeneity in susceptibility between the AML cell lines could be explained by diverse BCL-2 protein expression levels. To examine this, Western blotting was performed. Cell lines were arranged on the gel according to their sensitivity towards S63845. If there were a correlation, those cell lines that responded most to the respective $\mathrm{BH} 3$ mimetic would have the highest or lowest (in case of an inverse correlation) expression levels. BCL-2 expression levels are approximately similar between the different cell lines and thus, did not correlate with sensitivity to ABT-199 (Figure 7A). Also, MCL-1 expression does not appear to correlate with sensitivity to S63845, as MONO-MAC-6, THP-1, PLB985, ML-2, HL-60 and OCI-AML3 cells showed higher expression than the remaining cell lines. All cell lines express BCL-XL. KASUMI-1 cells, which were the only cell line that responded to $B C L-X_{L}$ inhibition at all, did not show the highest expression of $B C L-X_{L}$. This indicates, that the expression levels of $B C L-X_{L}$ were not related to sensitivity towards A-1331852. Moreover, there was no correlation between $B C L-X_{L}$ expression levels and sensitivity neither towards ABT-199 nor towards S63845. Additionally, linear regression analysis finally excludes a correlation between BCL-2 expression levels and susceptibility to $\mathrm{BH} 3$ mimetics (Figure 7C-E). Considering the pro-apoptotic effector proteins BAX and BAK, Western blots showed that they were expressed in all eleven cell lines (Figure 7B), which makes a correlation implausible. Similar results can be seen for $\mathrm{BH} 3$ only proteins BIM and NOXA, so the difference in sensitivity towards $\mathrm{BH} 3$ mimetics cannot be explained by different BCL-2 protein expression levels. 
A

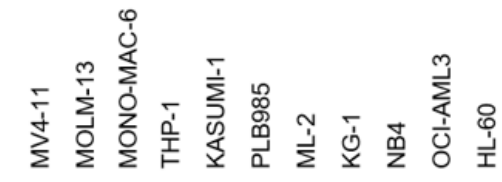

BCL-2

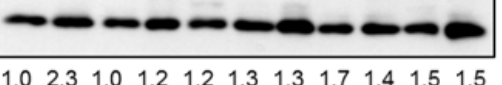

$B C L-x_{L}$

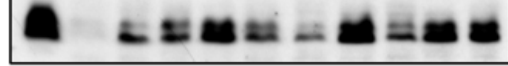

$\begin{array}{lllllllllll}2.1 & 0.5 & 1.0 & 1.5 & 1.8 & 1.3 & 0.9 & 3.5 & 1.6 & 1.7 & 1.5\end{array}$

MCL-1

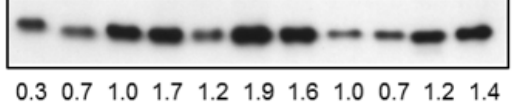

b-actin

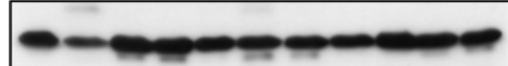

C

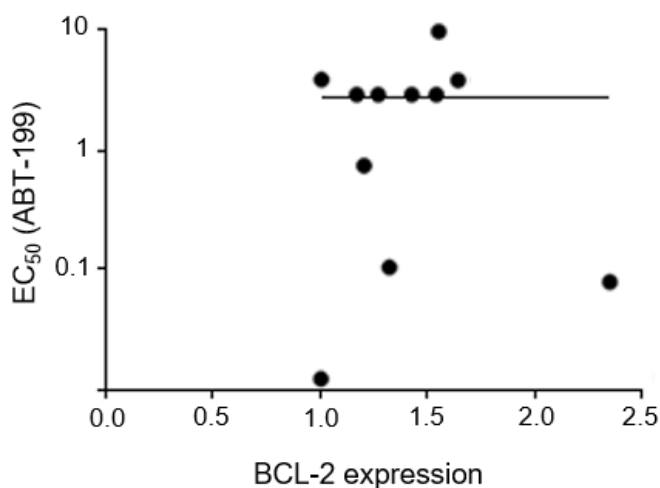

E

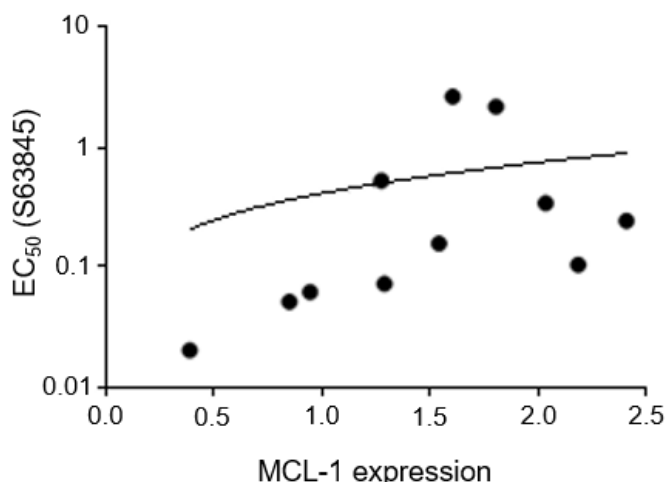

B
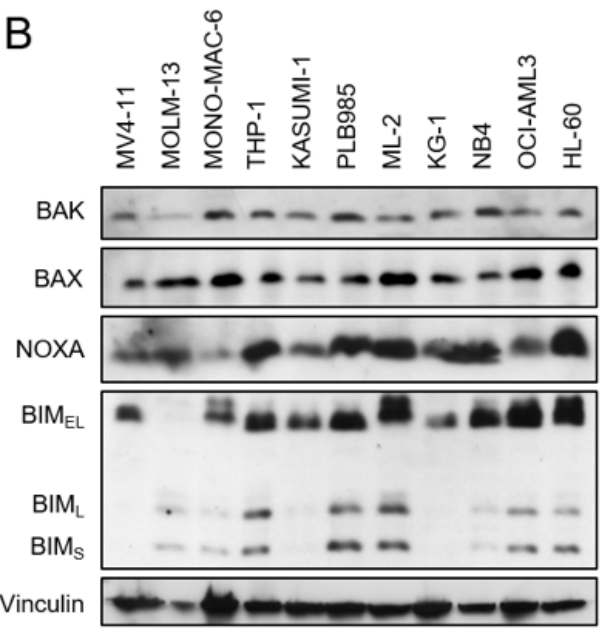

D
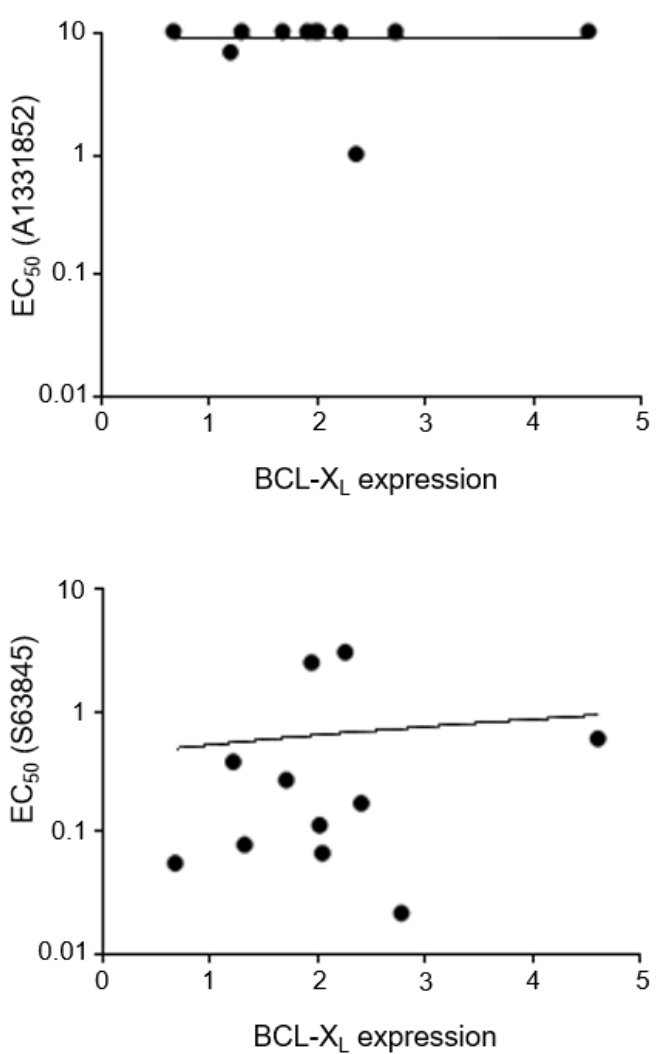

Figure 7: BCL-2 protein expression levels do not predict susceptibility to $\mathrm{BH} 3$ mimetics.

Basal expression levels of the main (A) anti- or (B) pro-apoptotic BCL-2 proteins in AML cells were investigated using Western blot analysis. Vinculin or $\beta$-Actin served as loading control. Representative blots of at least two independent experiments are shown. Numbers below the blots reflect the Quantification of band intensities using Image $J$ determined with three independent experiments normed to the loading control. Expression of (C) BCL-2 was quantified and correlated with $E_{50}$ of ABT-199, (D) BCL-XL with $E_{50}$ of A-1331852 and (E) MCL-1 or BCL-XL with EC 50 of $S 63845$ using GraphPad Prism. 


\subsection{MCL-1 expression is essential for the survival of AML cell lines}

All cell lines responded to the inhibition of MCL-1 by $\mathrm{S} 63845$ treatment. This indicates, that survival of AML cells depends on MCL-1. To investigate this hypothesis, MCL-1 expression was genetically silenced using siRNA and cell death was measured with flow cytometry after $24 \mathrm{~h}$ of transient knockdown. Therefore, representative cell lines were selected, namely MOLM-13 cells as a cell line that responded to BCL-2 as well as MCL-1 inhibition, MONO-MAC-6 cells as a cell line that only perished upon MCL-1 inhibition, and KASUMI-1 cells that showed a decreased viability upon the three BH3 mimetics. Knockdown of MCL-1 induced PS exposure after $24 \mathrm{~h}$ as a sign for apoptosis in all three cell lines (Figure 8A). This implies that MCL-1 has an essential function, which prevents pro-apoptotic BCL-2 proteins from being activated and inducing apoptotic cell death. When MCL-1 is not expressed, pro-apoptotic BCL-2 proteins can be activated, and apoptotic cell death can occur. Moreover, this indicates on-target activity of S63845. Knockdown efficacy was verified by assessing MCL-1 expression by Western blotting (Figure 8B). 
A
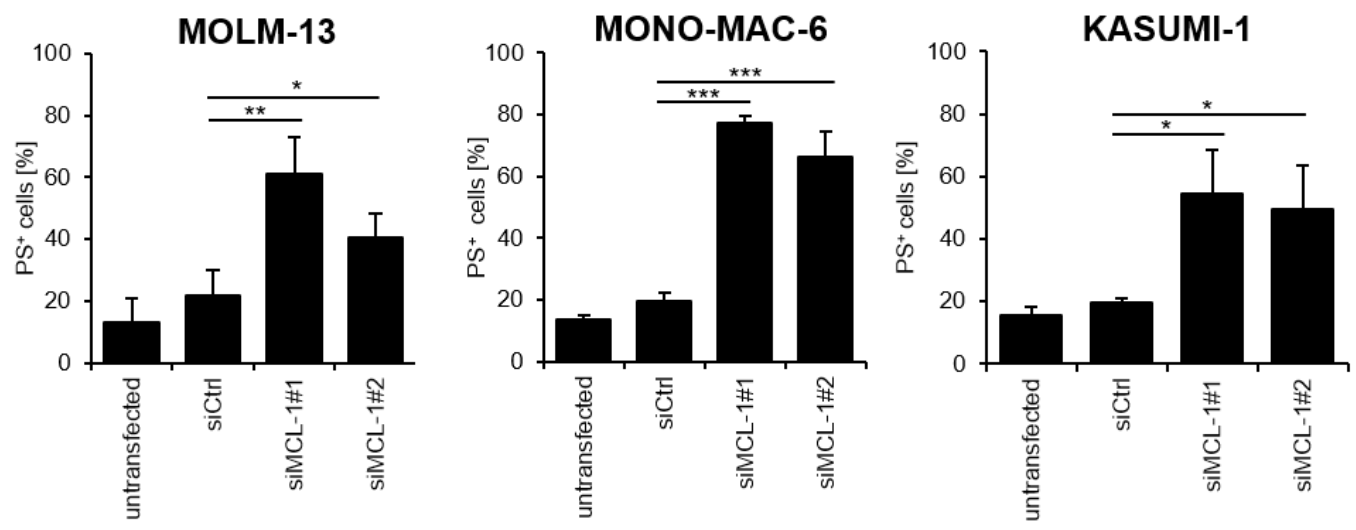

B

MOLM-13

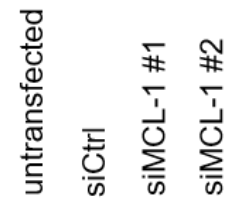

MCL-1

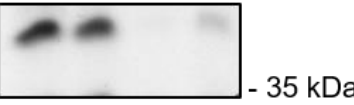

$\beta$-actin

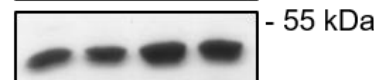

MONO-MAC-6

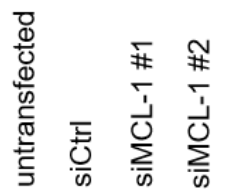

MCL-1

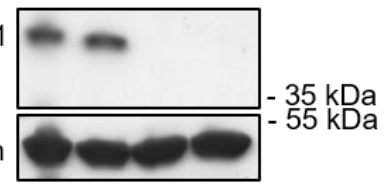

KASUMI-1

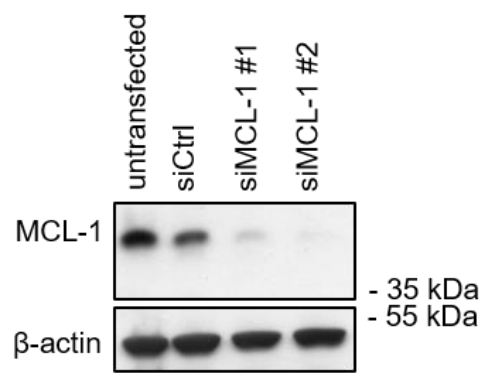

Figure 8: AML cell lines depend on MCL-1 for their survival.

Selected AML cell lines were transiently transfected with non-targeting control siRNA (siCtrl) or siRNA against MCL-1. (A) After $24 \mathrm{~h}$ of transient knockdown cell death was determined by flow cytometric analysis with Annexin V-FITC staining. Mean and SD of three independent experiments performed in triplicate are shown. $\left.p<0.05{ }^{*}\right), p<0.01\left(^{* \star}\right), p<0.001\left(^{* \star *}\right)$. (B) Knockdown efficacy was verified by assessing MCL-1 expression by Western blotting with B-Actin serving as loading control. 


\subsection{BH3 mimetics induce cell death primarily via caspase-dependent intrinsic apoptosis}

To further investigate the molecular mechanisms behind their cell death induction, MOLM-13 and MONO-MAC-6 cells were selected. KASUMI-1 cells were neglected, because this is the only cell line that responded to the $B C L-X L$ inhibition and thus, this is not representative for AML cells.

First, the kinetic of cell death induction was examined by treating cells with $1 \mu \mathrm{M}$ ABT-199 and $1 \mu \mathrm{M}$ S63845 and measuring PS exposure by flow cytometry at indicated time points. Thereby, the MCL-1 inhibitor turned out to be more quickly and more efficient in apoptosis induction, because PS exposure occurred earlier and stronger compared to ABT-199 (Figure 9). After $2 \mathrm{~h}$ treatment with $\$ 63845$ in average $42 \%$ of MONO-MAC- 6 cells exposed PS, after $4 \mathrm{~h}$ treatment with S63845 in average $47 \%$ of MOLM-13 cell exposed PS (Figure 9B) and only in average $29 \%$ of MOLM-13 cells exposed PS after $4 \mathrm{~h}$ treatment with ABT-199 (Figure 9A).
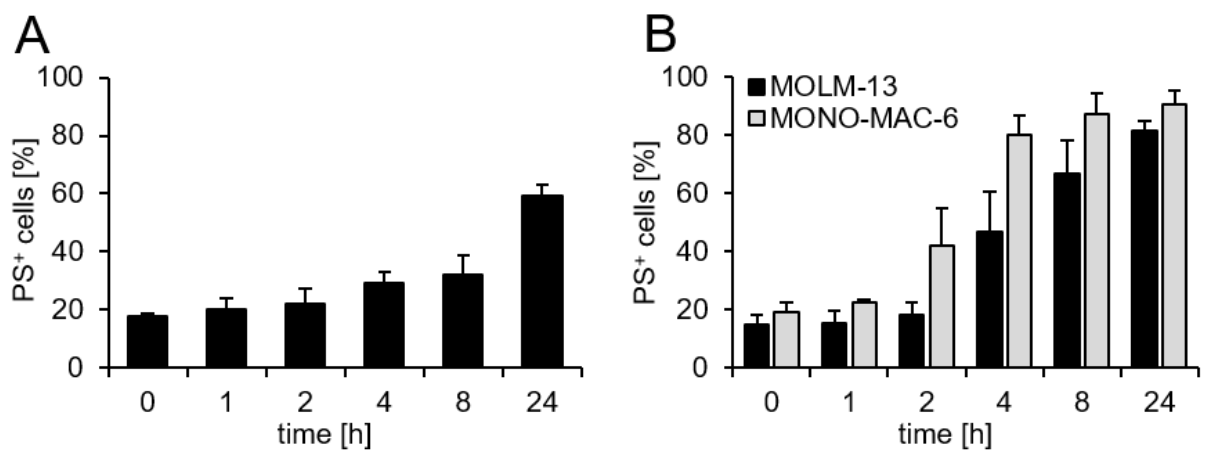

Figure 9: $\mathrm{BH} 3$ mimetics induce cell death in a time-dependent manner.

MOLM-13 cells were treated with $1 \mu \mathrm{M}$ ABT-199 (A) or $1 \mu \mathrm{M}$ S63845 and MONO-MAC-6 cells were treated with $1 \mu \mathrm{M}$ S63845 (B) for indicated time points. Cell death was determined by Annexin V-FITC staining and flow cytometry. Mean and SD of three independent experiments performed in triplicate are shown. 
The BCL-2 proteins regulate apoptosis at the mitochondrial membranes. Mitochondrial participation was proven with TMRM staining, a cationic dye that accumulates in intact mitochondria and allows a statement about the mitochondrial membrane potential. Mitochondrial outer membrane permeabilization (MOMP) as a sign for intrinsic apoptosis is accompanied by a loss of mitochondrial membrane potential, which can be detected by a decreased TMRM signal. Loss of MMP occurred after $4 \mathrm{~h}$ of treatment with ABT-199 or S63845 (Figure 10).

A

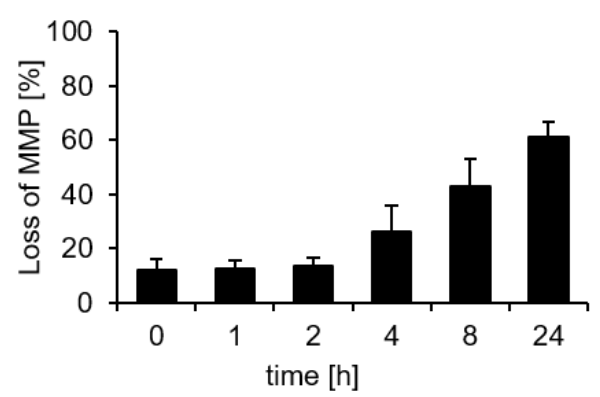

B

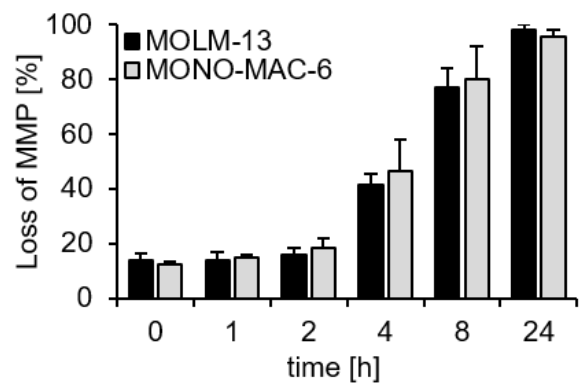

Figure 10: $\mathrm{BH} 3$ mimetics induced cell death comprises MOMP with loss of mitochondrial membrane potential.

MOLM-13 was treated with $1 \mu \mathrm{M}$ ABT-199 (A) or $1 \mu \mathrm{M}$ S63845 and MONO-MAC-6 cells were treated with $1 \mu \mathrm{M}$ S63845 (B) for indicated timepoints. Loss of mitochondrial membrane potential (MMP) was measured by flow cytometry using the fluorescent dye TMRM. Mean and SD of three independent experiments performed in triplicate are shown.

Furthermore, to assess caspase- 3 cleavage and activation as a hallmark of intrinsic apoptosis Western blotting was performed. In line with the kinetics of PS exposure, caspase- 3 was cleaved after only $1 \mathrm{~h}$ of treatment with both ABT-199 and S63845 (Figure 11). Indeed, the cleavage products of caspase-3 after MCL-1 inhibition were more pronounced than after BCL-2 inhibition. 
A

MOLM-13

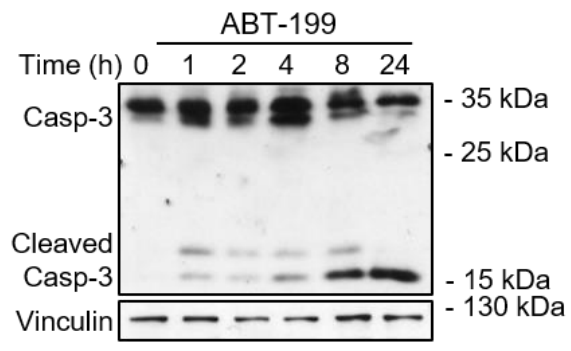

B

\begin{tabular}{l|l} 
MOLM-13 MONO-MAC-6 \\
\hline
\end{tabular}

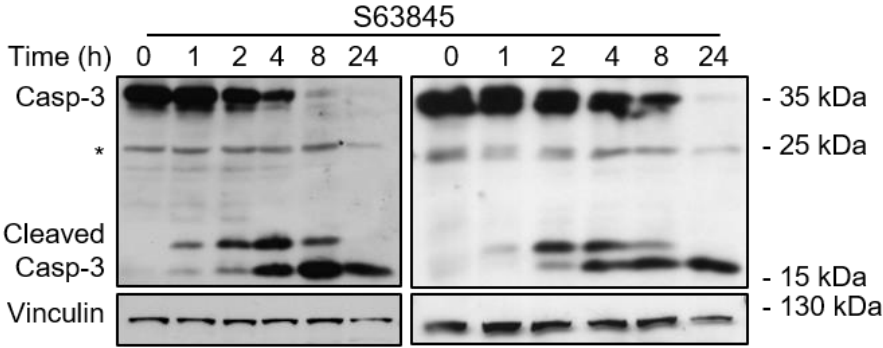

Figure 11: The cleavage and activation of caspase-3 is necessary for $\mathrm{BH} 3$ mimetics to induce cell death. MOLM-13 was treated with $1 \mu \mathrm{M}$ ABT-199 (A) or $1 \mu \mathrm{M}$ S63845 and MONO-MAC-6 cells were treated with $1 \mu \mathrm{M}$ S63845 (B) for indicated timepoints. Caspase-3 activation was analyzed by Western blotting with Vinculin serving as loading control. ${ }^{*}$ mark unspecific bands.

Perturbations of mitochondria can also result in caspase-independent cell death. To investigate whether $\mathrm{BH} 3$ mimetics can also induce caspase-independent cell death in AML, we inhibited caspases with the pan-caspase inhibitor zVAD.fmk. Addition of zVAD.fmk resulted in a significant decrease of cell death at $4 \mathrm{~h}$ (Figure 12). This implies that $\mathrm{BH} 3$ mimetics induced cell death primarily cannot occur caspase-independent and thus, takes place via caspase-dependent intrinsic apoptosis.

A

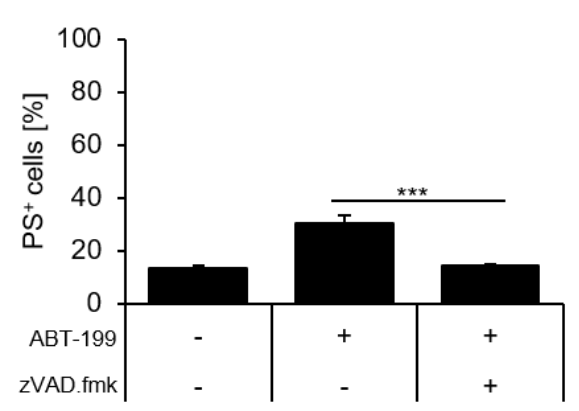

B

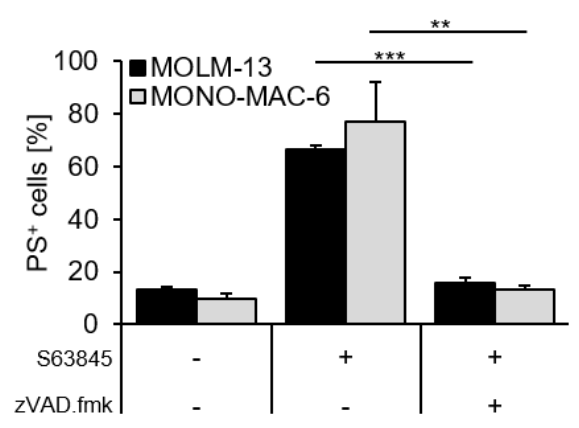

Figure 12: $\mathrm{BH} 3$ mimetics induced cell death is caspase dependent.

In the presence or absence of pan-caspase inhibitor zVAD.fmk MOLM-13 cells were treated for $4 \mathrm{~h}$ with $1 \mu \mathrm{M}$ ABT-199 (A) or $1 \mu \mathrm{M}$ S63845 and MONO-MAC-6 cells were treated with $1 \mu \mathrm{M}$ S63845 (B) before cell death was measured by Annexin V-FITC staining and flow cytometry. Mean and SD of three independent experiments performed in triplicate are shown. $\left.\left.p<0.01{ }^{(* *}\right), p<0.001{ }^{* * *}\right)$ 


\subsection{5 displaces BIMs and NOXA from MCL-1}

Next, we questioned how $\mathrm{BH} 3$ mimetics activate the intrinsic apoptotic pathway. To answer this question, we examined the binding patterns of the main anti-apoptotic BCL-2 proteins with Co-IP. Therefore, we treated MONO-MAC-6 cells for $2 \mathrm{~h}$ with $1 \mu \mathrm{M}$ S63845 before lysis and IP. We saw NOXA and BIM to be highly bound to MCL-1 in untreated cells (Figure 13). After treatment with $\$ 63845$ NOXA and BIMs were not bound anymore, indicating that $\mathbf{S 6 3 8 4 5}$ displaced them from MCL-1.

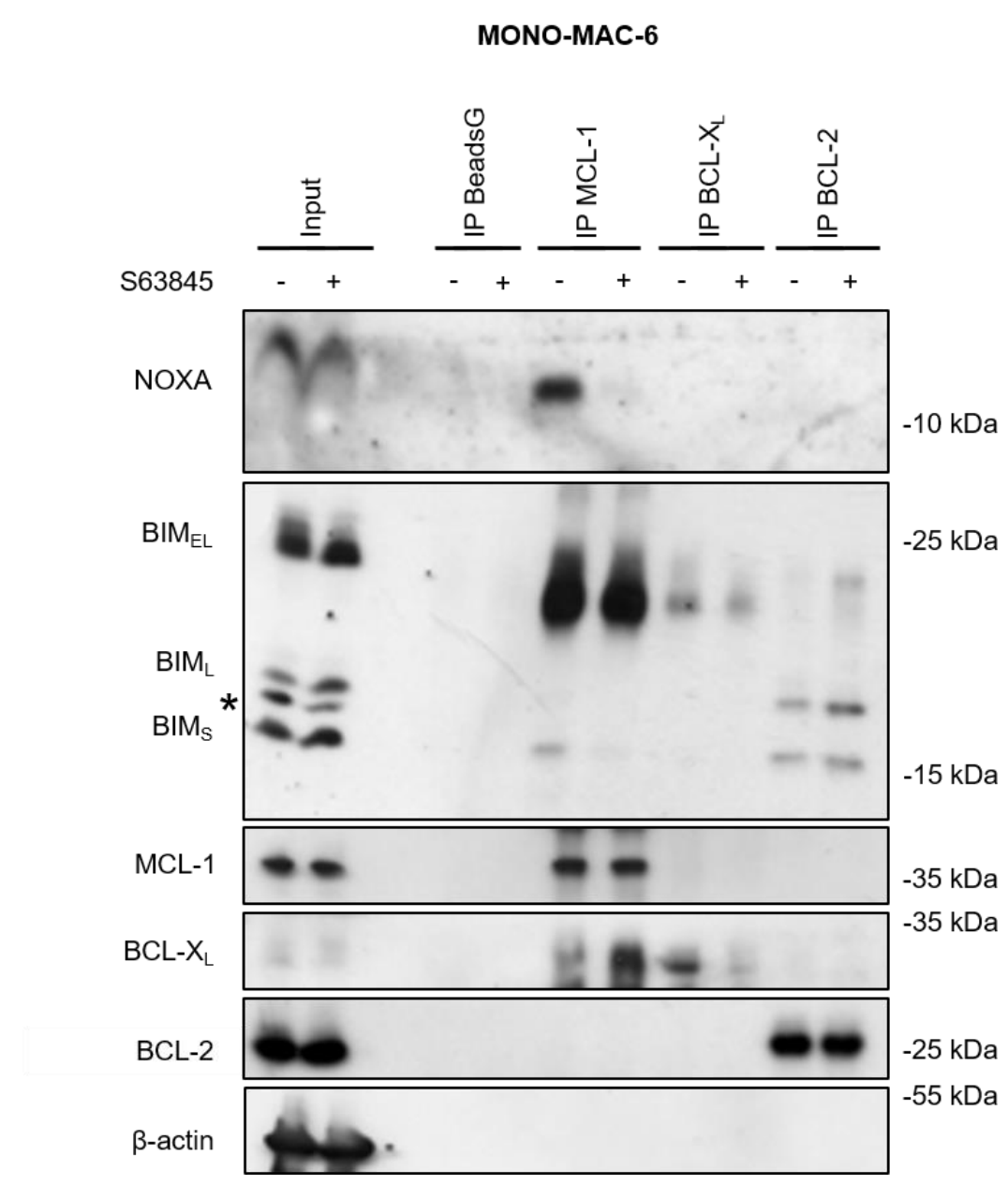

Figure 13: S63845 displaces BIMs and NOXA from MCL-1.

MONO-MAC-6 cells were treated with $1 \mu \mathrm{M}$ S63845 for $2 \mathrm{~h}$ and MCL-1, BCL-XL and BCL-2 were immunoprecipitated. The precipitate was analyzed for NOXA and BIM binding patterns and for MCL-1, $B C L-X_{L}$ and BCL-2 basal expression levels by Western blotting. $\beta$-actin served as loading control. * mark unspecific bands. 


\subsection{Primary AML samples show a wide range of responses to BH3 mimetics}

To verify their translational relevance, $\mathrm{BH} 3$ mimetics were tested in primary AML samples for $20 \mathrm{~h}$ before cell death was measured with Annexin $\mathrm{V}$ staining and flow cytometry. On the one hand, there are samples that were moderately sensitive for all the four BH3 mimetics, like sample \#56 (Figure 14). On the other hand, there were samples which did not respond to any $\mathrm{BH} 3$ mimetics or only were susceptible to selected compounds. These results were confirmed by heterogeneous $\mathrm{EC}_{50}$ values (Table 5) and reflected the screening results of the AML cell lines. Altogether, responses differed from patient to patient but there are anti-leukemic effects of $\mathrm{BH} 3$ mimetics on primary AML blasts. 
A

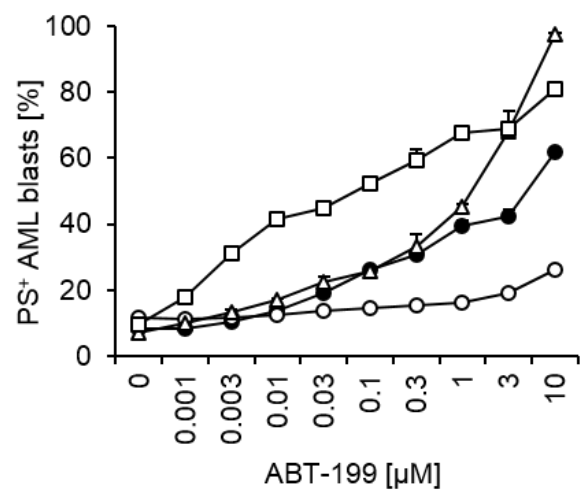

C

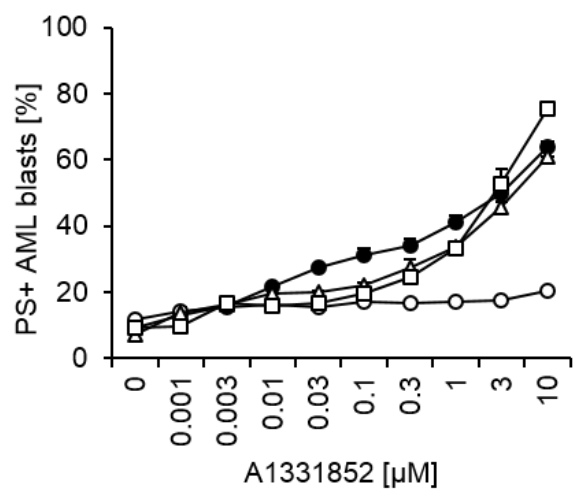

B

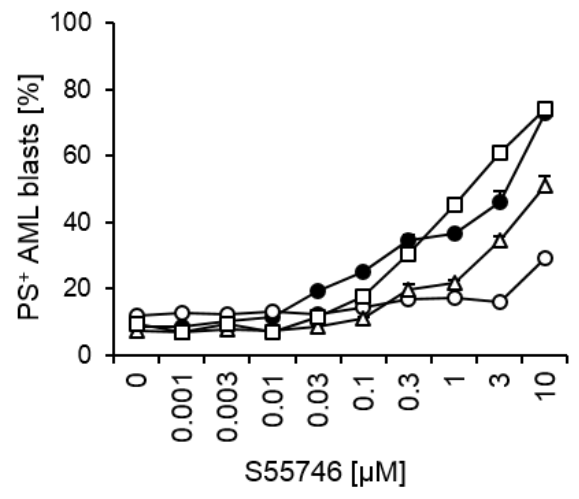

D

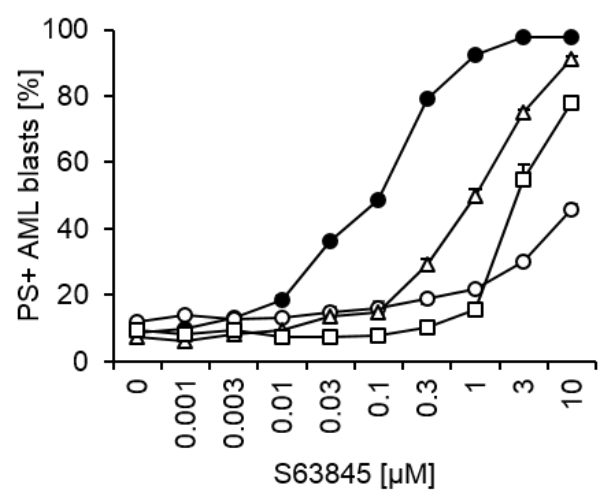

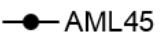

$\rightarrow$ AML48

$\triangle-$ AML55

$\rightarrow$-AML56

Figure 14: Primary AML samples show heterogeneous sensitivity towards $\mathrm{BH} 3$ mimetics.

Primary AML samples were treated with indicated concentrations of ABT-199 (A), S55746 (B), A-1331852

(C) or S63845 (D) for 20 h. Cell death was measured by flow cytometric analysis with Annexin V-FITC staining. AML blast cells were identified by CD45/SSC gating. Mean and SD of each experiment performed in duplicate or triplicate is shown.

Table 21: $E_{50}$ values of Primary AML samples to $B H 3$ mimetics.

$\mathrm{EC}_{50}$ values were calculated by non-linear regression analysis using GraphPad prism.

\begin{tabular}{llllll}
\hline Primary AML & Blasts & \multicolumn{4}{c}{$\mathrm{EC}_{50}[\boldsymbol{\mu M}]$} \\
\cline { 3 - 6 }$\#$ & {$[\%]$} & ABT-199 & $\mathbf{S 5 5 7 4 6}$ & $\mathbf{A - 1 3 3 1 8 5 2}$ & $\mathbf{S 6 3 8 4 5}$ \\
\hline$\# 45$ & 74 & $>10$ & $>10$ & $>10$ & 0.09 \\
$\# 48$ & 40 & $>10$ & $>10$ & $>10$ & $>10$ \\
$\# 55$ & 25 & 2.22 & 6.41 & 8.99 & 1.13 \\
$\# 56$ & 25 & 0.05 & 1.33 & 4 & 2.51 \\
\hline
\end{tabular}




\subsection{BH3 mimetics show moderate to high toxicity in normal $\mathrm{CD}^{+} 4^{+}$cells while their clonogenic growth is differently impacted}

For the evaluation of toxicity of $\mathrm{BH} 3$ mimetics on normal hematopoietic $\mathrm{CD} 34^{+}$ progenitor cells we examined their impact on cell death induction and colony formation. Therefore, cells were treated with indicated concentrations of $\mathrm{BH} 3$ mimetics and cytarabine (Ara-C) - as a standard-of-care chemotherapeutic - for $20 \mathrm{~h}$ and cell death was measured with Annexin V-FITC staining and flow cytometry. After $9 \mathrm{~h}$ treatment with $\mathrm{BH} 3$ mimetics and after $24 \mathrm{~h}$ treatment with cytarabine $20 \mu \mathrm{l}$ were taken out of each well to perform a colony formation assay. FACS measurements show that S63845 induced cell death at a concentration of $1 \mu \mathrm{M}$, which is comparable with the toxicity of cytarabine (Figure 15A). In contrast, ABT-199, S55746 and A-1331852 induced cell death at nanomolar concentrations. Considering the colony formation, A-1331852 reduced the formation of CFU-GEMM in a concentration dependent manner. (Figure 15C) The formation of CFU-GM (Figure 15B) and BFU-E (Figure 15D) was not influenced by BCL-XL inhibition. ABT-199 caused a slight reduction of CFU-GEMM formation, but did not impact the formation of BFU-E or CFU-GM. Upon S63845 and S55746 treatment the formation of CFU-GM and BFU-E was increased and the formation of CFU-GEMM was not changed compared to the control. Cytarabine did not significantly alter the formation of any of the colonies. All in all, S63845 possesses a beneficial toxicity profile compared to ABT-199, S55746 and A-1331852 and a similar toxicity compared to Cytarabine. 


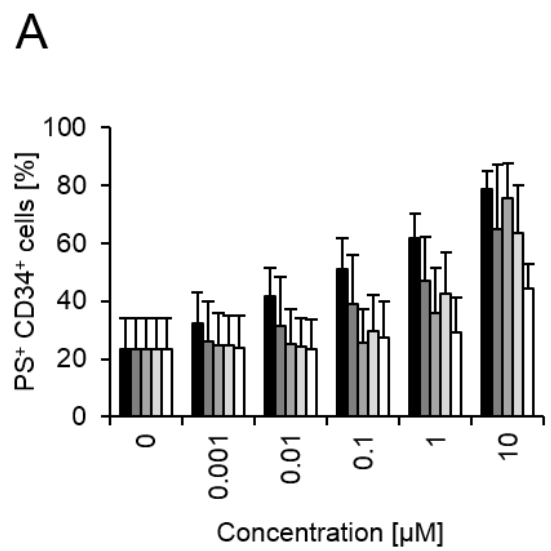

-A1331852

Concentration $[\mu \mathrm{M}]$

口ABT-199

口\$63845

B

C

D

口S55746
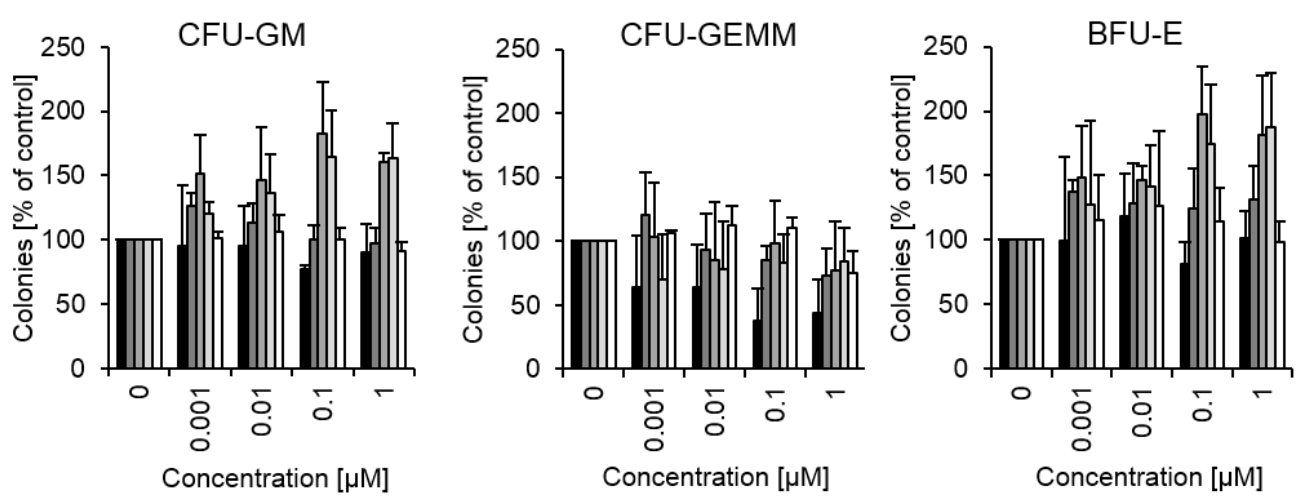

口Cytarabine

Figure 15: In comparison to BCL-2 and BCL- $X \mathrm{~L}$ inhibitors, the MCL-1 inhibitor shows less induction of cell death and less inhibition of colony formation of $\mathrm{CD} 34^{+}$cells.

(A) HPCs were treated with indicated concentrations of $\mathrm{BH} 3$ mimetics or standard chemotherapeutic agent cytarabine (Ara-C) for $20 \mathrm{~h}$ before cell death was measured with Annexin V-FITC staining and FACS. Mean and SD of four independent experiments performed in duplicate or triplicate are shown. (B-D) After $9 \mathrm{~h}$ treatment with $\mathrm{BH} 3$ mimetics or $24 \mathrm{~h}$ treatment with Ara-C, drugs were removed and colony forming assay was performed. Amount of (B) CFU-GM, (C) CFU-GEMM or (D) BFU-E normalized to control samples counted after 10-12 days are shown. Mean and SD of three independent experiments performed in duplicate or triplicate are shown. 
In summary, comparison of $\mathrm{BH} 3$ mimetics show heterogeneous response in eleven AML cell lines as well as in primary AML samples. The heterogeneity of sensitivity could not be explained by different BCL-2 protein expression levels. Thereby, MCL-1 and thereafter BCL-2 represent promising targets for the treatment of AML by inducing caspase-dependent intrinsic apoptosis in several cell lines. Moreover, S63845 turned out to displace BH3-only proteins BIMs and NOXA from MCL-1 to induce cell death. Furthermore, genetic silencing demonstrated the importance of MCL-1 for the survival of AML cell lines. Concerning their toxicity in normal hematopoietic progenitor cells, experiments with CD34 ${ }^{+}$ cells showed moderate cell death induction and no inhibitory effect on colony formation upon treatment with the MCL-1 inhibitor $\mathbf{5 3 8 4 5}$ in comparison to the other $\mathrm{BH} 3$ mimetics. Consequently, $\mathrm{S} 63845$ exhibits a favorable toxicity profile when compared to ABT-199, S55746 as well as A-1331852. 


\section{Discussion}

Despite improvements in the last years, cure rates of - especially elderly - AML patients are still unsatisfactory. Consequently, the development of novel therapeutic strategies is urgently needed. In this regard, $\mathrm{BH} 3$ mimetics represent promising treatment options, reflected by the FDA approvals for ABT-199 and multiple ongoing clinical trials with different other $\mathrm{BH} 3$ mimetics.

Therefore, in this study, we used several $\mathrm{BH} 3$ mimetics to induce cell death in a panel of AML cell lines and primary AML samples. ABT-199 as well as S55746 was used to inhibit BCL-2, S63845 to inhibit MCL-1 and A-1331852 to inhibit BCL-XL.

\subsection{MCL-1 is a key therapeutic target for AML treatment}

One major finding of this thesis is that MCL-1 represents a more promising therapeutic target when compared to BCL-2, while BCL- $X_{L}$ is largely irrelevant as a target for the treatment of AML.

On the one hand, this was demonstrated by screening results: all eleven investigated AML cell lines were sensitive towards S63845. Thereby, MV4-11 and MOLM-13 cells were most sensitive, reflected by $\mathrm{EC}_{50}$ values at nanomolar ranges, and $\mathrm{HL}-60$ and $\mathrm{OCl}-\mathrm{AML} 3$ cells were less sensitive with $\mathrm{EC}_{50}$ values at micromolar or high nanomolar ranges. These findings are in consistency with results of Kotschy et al. ${ }^{42}$ In contrast, the BCL-2 inhibitors ABT-199 and S55746 induced cell death in four out of eleven cell lines with significantly higher $\mathrm{EC}_{50}$ values. Consequently, MCL-1 signifies a more promising target than BCL-2. Concerning the role of other anti-apoptotic BCL-2 proteins, reports in literature already showed that $A M L$ cell lines are resistant to $B C L-X L$ inhibition ${ }^{43,44}$. Consistent with these, we observed only one out of eleven $A M L$ cell lines showing a moderate response to the $B C L-X_{L}$ inhibitor $A-1331852$ with an $E_{50}$ value at micromolar ranges. Therefore, $B C L-X L$ does not seem to be an important therapeutic target for single agent treatment of $\mathrm{AML}$, which is why we decided not to continue investigations on the $B C L-X_{L}$ inhibitor. 
Several studies reported that MCL-1 acts as a resistance factor for the treatment with $\mathrm{ABT}-199^{43,45-47}$ and vice versa $\mathrm{BCL}-2$ for the treatment with MCL-1 inhibitors. ${ }^{43,46}$ This resistance can be distinguished in intrinsic resistance (like OCI-AML3 cells own $)^{45,47}$ and acquired resistance upon prolonged treatment with ABT-199. 47 However, BCL-X $\mathrm{X}_{\mathrm{L}}$ seems to play an important role in the emergence of resistance to ABT-199, too. Lin et al. investigated the resistance mechanism upon chronic exposure to ABT-199. Their results show that the cells' dependencies shift from BCL-2 to $M C L-1$ and/or $B C L-X_{L}$ by transcriptional upregulation and thus, an increased protein expression of MCL-1 and/or BCL-XL. ${ }^{47}$ Therefore, it is advantageous to combine a BCL-2 inhibitor with a MCL-1 inhibitor ${ }^{43,44,46,47}$ and even better also a BCL- $X_{L}$ inhibitor $^{47}$ to overcome that resistance mechanism. Therefore, it might be rational to investigate A-1331852 in combination with other $\mathrm{BH} 3$ mimetics.

On the other hand, the importance of $\mathrm{MCL}-1$ as a therapeutic target is impressively verified by MCL-1 knockdown experiments. In addition to the pharmacological approach, we pursued a genetic strategy showing a dramatic increase of apoptotic cell death in several AML cell lines in comparison to control cells. Thus, MCL-1 expression is essential for AML cell lines to survive. In line with these results were findings of Glaser et al., who achieved the curation of mice suffering from AML with a knockdown of MCL-1 but not BCL-2. ${ }^{48}$ Also in agreement with our findings, Soderquist et al. could demonstrate that most AML cell lines are MCL-1 dependent, only some of them BCL-2 dependent and none of them BCL-XL dependent. ${ }^{49}$ All in all, these results support our findings of the superior role of MCL-1 in AML compared to BCL-2, which cannot be attributed to the inhibitors potency, because both show sub-nanomolar affinities. ${ }^{42,50}$

Screening of primary AML samples revealed a heterogeneous response towards the several $\mathrm{BH} 3$ mimetics in our study as well as in previous studies. ${ }^{42,51,52}$ Three out of four samples responded to the MCL-1 inhibitor while only two out of four showed a tendency to increased cell death after treatment with BCL-2 or BCL-X inhibitors. Kotschy et al. also found a heterogeneous response of primary AML samples towards the MCL- 1 inhibitor $\$ 63845$ with approximately $20 \%$ of samples that were highly sensitive. ${ }^{42}$ Sensitivity to $S 55746$ and A-1331852 were at most 
moderate in all tested samples. Reports in literature showed that in comparison to the other $\mathrm{BH} 3$ mimetics $\mathrm{A}-1331852$ shows the lowest activity in primary AML samples. ${ }^{43,44}$ The $\mathrm{EC}_{50}$ values for ABT-199 in primary AML samples confirm this heterogeneity, with values from $<10 \mathrm{nM}$ to $>1 \mu \mathrm{M}$, which was also described in literature. 51

This confirms the major role of MCL-1 as a target for the treatment of AML. Therefore, the translational relevance of $\mathbf{S 6 3 8 4 5}$ seems to be more promising than that of ABT-199, S55746 or A-1331852.

Interestingly, we found cell lines (MV4-11, MOLM-13, KASUMI-1, ML-2) as well as primary AML samples (\#55, \#56) that responded to both $\mathrm{S} 63845$ and ABT-199. Accordingly, by inhibiting either MCL-1 or BCL-2, the respective other one is not able to compensate the loss of function of MCL-1 or BCL-2 and thus, AML cells die via apoptosis. Consequently, they may be functionally non-redundant, and both are essential to prevent apoptosis.

Remarkably, MCL-1 represents the most relevant therapeutic target for the treatment of AML compared to BCL-2 and BCL- $X_{L}$, while the latter is largely irrelevant as a target for single agent treatment. ${ }^{43,49}$ Nevertheless, $B C L-X_{L}$ is described to perform an important role as a resistance factor for the treatment of AML with ABT-199. ${ }^{47,53}$ Thus, in these chemo-resistant diseases the combination with a BCL-XL inhibitor might be useful. 


\subsection{ABT-199 is more potent than S55746 while having the same mode of action}

While S55746 is a pretty new designed BCL-2 inhibitor, ABT-199 is already investigated in several studies and an established treatment strategy as well, with an FDA approval for the treatment of CLL or small lymphocytic lymphoma (SLL) and as a combination treatment with chemotherapeutics in AML. Therefore, we decided to compare these two BCL-2 inhibitors to offer an alternative therapeutic compound.

Screening of AML cell lines revealed that both, ABT-199 as well as S55746, induced cell death in the same four cell lines (MOLM-13, ML-2, MV4-11, KASUMI-1) indicating that they have the same mode of action. Additionally, we found out that both induce cell death via the intrinsic apoptotic pathway. For S55746 as well as ABT-199 we could ascertain PS exposure, loss of MMP, cleavage of caspase-3 and caspase dependency as hallmarks of intrinsic apoptosis. This concurs well with previous findings from Souers et al. in ALL cell lines ${ }^{50}$ and Niu et al. in AML cell lines ${ }^{45}$ for the treatment with ABT-199 and from Casara et al. in CLL cells upon treatment with $\mathrm{S55746.}{ }^{32}$

Moreover, our investigations exposed that ABT-199 is more potent than S55746, which is represented by lower $\mathrm{EC}_{50}$ values after treatment of cell lines as well as primary AML samples. Similar results were described in a former study demonstrating $\mathrm{IC}_{50}$ values for $\mathrm{ABT}-199$ in a range from $<0.01 \mu \mathrm{M}$ to $>1 \mu \mathrm{M}$. ${ }^{51}$ Furthermore, ABT-199 turned out to have a higher potency than S55746 in acute lymphoid leukemia (ALL) cell line RS4;11 reflected by lower $\mathrm{IC}_{50}$ values. ${ }^{32}$ Because of its higher potency, we decided to continue investigations only with ABT-199 in assumption that the results we would obtain for ABT-199 would also apply to S55746. According to previous findings, their selectivity profile is largely identical in $\mathrm{AML}^{44}, \mathrm{ALL}$ and small cell lung cancer cell lines and both rapidly induce cell death via the intrinsic apoptotic pathway. ${ }^{32,51}$ 


\subsection{BCL-2 protein expression levels could not serve as a prediction marker of sensitivity towards $\mathrm{BH} 3$ mimetics}

Heterogeneity of responses to $\mathrm{BH} 3$ mimetics emphasizes the need to develop biomarkers to predict sensitivity to optimize therapies. An approach could be the investigation of BCL-2 expression levels, with the hypothesis that there could be a correlation between these and the susceptibility to $\mathrm{BH} 3$ mimetics.

Our examinations of BCL-2 protein expression levels in AML cell lines did not show any correlation between the basal expression neither of anti- nor of proapoptotic BCL-2 proteins and the sensitivity to BH3 mimetics: a correlation could neither be found between MCL-1 nor BCL-X $\mathrm{L}$ protein expression levels and sensitivity to the MCL-1 inhibitor. In contrast to this, it has been described that $B C L-X_{L}$ expression levels inversely correlate with the susceptibility to S63845. ${ }^{42,49}$ This may be due to different considerations: While Kotschy et al. investigated mRNA expression, we examined basal protein expression. ${ }^{42}$ Furthermore, we could not verify the earlier publicized correlation between BCL-2 protein levels and sensitivity towards ABT-199.49,51,52,54 In addition to these, an inverse correlation between BCL-XL protein expression ${ }^{51,52}$ as well as MRNA levels and between PUMA and BIM mRNA levels and the sensitivity towards ABT-199 is described, whereas BAX mRNA levels positively correlate with response to ABT-199. High MCL-1 protein levels may indicate a resistance to ABT-199. ${ }^{52,54}$ A correlation between $B C L-X_{L}$ levels and sensitivity to the $B C L-X_{L}$ inhibitor A-1331852 could neither be shown.

Our investigations concerning a possible correlation between BCL-2 protein expression levels and the susceptibility to those four $\mathrm{BH} 3$ mimetics could neither confirm conclusions in literature nor facilitate the prediction of sensitivity to the respective $\mathrm{BH} 3$ mimetics. However, previous publications suggest further opportunities to forecast efficacy of the respective $\mathrm{BH} 3$ mimetic in AML cell lines that could also be investigated in our future studies. On the one hand, it was found that seven HOXA and HOXB genes and mutations of chromatin modifiers positively correlate with the sensitivity towards ABT-199. ${ }^{52}$ On the other hand, it has 
been previously shown that the presence of mutations of Isocitrate Dehydrogenases (IDH) 1 or 2 correlate with a high susceptibility to ABT-199 in AML cell lines as well as primary AML samples. ${ }^{52,55,56} \mathrm{IDH}$ is an enzyme that acts as a catalysator in the citrate acid cycle and is normally responsible for converting isocitrate to a-ketoglutarate, but its mutant converts a-ketoglutarate to (R)-2-hydroxyglutarate (2-HG). This molecule induces BCL-2 dependency by inhibiting complex IV of the mitochondrial respiratory chain and thus decreasing the threshold for apoptosis induction. Their importance result in both, their presence in about $15 \%$ of AML patients and in the possibility to treat patients with wild type IDH by targeting complex IV in combination with BCL-2.55,56 Unfortunately, all the samples we investigated did not carry IDH mutations, so we could not compare sensitive with resistant samples in this regard. However, with $\mathrm{EC}_{50}$ values in the higher nanomolar to micromolar range there is potential for higher sensitivities, which might be present in IDH mutated samples.

Taken together, multiple studies have investigated gene signatures associated with sensitivity to ABT-199. Notably, most of these studies are based on large numbers of primary samples, whereas our study mainly investigated cell lines. The number of primary samples included in our study was too low to investigate patterns associated with sensitivity.

BH3-profiling may serve as a functional biomarker independent of genetic markers, and thus simplify the assignment of treatments with different $\mathrm{BH} 3$ mimetics to $A M L$ patients. Previous publications indicate that $\mathrm{BH} 3$ profiling enables the prediction of responses to $\mathrm{BH} 3$ mimetics in primary AML samples. ${ }^{46,49,51}$ This is based on the three different ways to block apoptosis by cancer cells, as described in Chapter 1.2: Less expression of either BH3-only proteins (Class A block) or pro-apoptotic effector BCL-2 proteins (Class $B$ block) or overexpression of anti-apoptotic BCL-2 proteins (Class $\mathrm{C}$ block). $\mathrm{BH} 3$ profiling characterizes a method to identify the way of blocking apoptotic cell death. By adding a panel of sensitizer and activator $\mathrm{BH} 3$-only proteins to isolated mitochondria and measurement of cytochrome $C$ release as a hallmark of intrinsic apoptosis, this identification is possible. In case of a class A block, the addition of lacking activator 
BH3-only proteins like BID or BIM will cause MOMP including cytochrome C release ${ }^{24,25}$. If cytochrome $C$ release occurs upon both activator and sensitizer BH3-only protein addition, this would be characteristic for a class $\mathrm{C}$ block, because the survival of those cancer cells is dependent on the excessive inhibition of $\mathrm{BH} 3$-only proteins by overexpressed anti-apoptotic BCL-2 proteins. By adding those peptides, the balance would switch, and the primed cell would undergo apoptotic cell death. Cancer cells that survive by a class B block do not respond to any of the added proteins, because the essential effectors BAK and BAX are lacking. Because specific interactions between anti-apoptotic BCL-2 proteins and sensitizer BH3-only proteins are known, an identification of the leading anti-apoptotic BCL-2 protein is possible. ${ }^{25}$

Accordingly, Pan et al. could predict sensitivity of AML cell lines as well as primary AML samples to $A B T-199$ by using $B H 3$ profiling with $B A D$ peptide ${ }^{51}$.

To sum up, possible biomarkers are investigated more extensively for ABT-199 than for S63845. Sensitivity could be predicted in future by investigations of BCL-2 protein expression or mRNA levels, IDH 1/2 type, HOX gene expression and $\mathrm{BH} 3$ profiling. Sensitivity for $\mathrm{S} 63845$ might be predicted by investigation of $B C L-X_{L}$ mRNA examination. Nevertheless, it is useful to identify concrete biomarkers for sensitivity towards $\mathbf{S 6 3 8 4 5}$ because of its potency to induce cell death in AML cell lines and the heterogeneity of responses of the primary AML samples. 


\subsection{BH3 mimetics induced apoptosis occurs by the displace- ment of BH3-only proteins from anti-apoptotic BCL-2 pro- teins}

To further examine the molecular mechanisms behind the induction of apoptosis by $\mathrm{BH} 3$ mimetics we performed Co-IPs. With these experiments, we could compare the binding patterns of BCL-2 proteins before and after the treatment with each $\mathrm{BH} 3$ mimetic.

We could show that BIMs and NOXA are bound less to MCL-1 within a few hours upon treatment with S63845 in MONO-MAC-6 as well as MOLM-13 cells as demonstrated in our publication. ${ }^{41}$ On the one hand, this could be due to a displacement caused by $\mathbf{S 6 3 8 4 5}$, which is in line with previous studies ${ }^{57,58}$, but on the other hand, due to a prevention of new binding.

Nevertheless, our study indicates that MCL-1 facilitates AML cell survival by binding and sequestering BIMs and NOXA. This is in line with a former study reporting NOXA specifically interacting with MCL-1, while BIM interacts with BCL-2, BCL-XL, BCL-W, BCL-2A1 and particularly MCL-1 in mammalian cells. ${ }^{59}$ When the cells are treated with $\mathrm{S} 63845$ and these two $\mathrm{BH}$-only proteins are displaced, BIM can function as an activator of BAX and BAK again and apoptotic cell death can occur, while NOXA acts as a sensitizer protein. Consequently, NOXA binds to the binding groove of MCL-1 and prevents this anti-apoptotic protein from binding to, and so inhibiting pro-apoptotic BCL-2 proteins. In conclusion, pro-apoptotic $B C L-2$ proteins can execute the activation of the effector proteins BAX and BAK and apoptosis can be accomplished. It is also known that NOXA or BIM bound to MCL-1 cause conformational changes of MCL-1 and thereby influence the degradation of MCL-1 by the ubiquitin-proteasome system. The binding of BIM by MCL-1 prevents its ubiquitination, while the binding of NOXA encourages the ubiquitination and thus degradation of MCL-1. ${ }^{60-62}$

On the one hand, when NOXA is displaced from MCL-1 after treatment with S63845 it could cause the proteasomal degradation of MCL-1 and consequently in addition to its sensitizer function enhance apoptosis induction. On the other 
hand, it is shown that $\mathbf{S 6 3 8 4 5}$ stabilizes MCL-1 and increases MCL-1 protein levels ${ }^{57,62}$, which resembles the effects of BIM binding to MCL-1.

Furthermore, it has been published, that BIM was displaced from BCL-250 and increasingly bound to MCL-1 upon ABT-199 treatment ${ }^{45}$. Additionally, the sensitivity towards a combination of S63845 with ABT-199 is decreased upon BIM knockdown. ${ }^{63}$

Moreover, Niu et al. investigated the intrinsic resistance and showed that in AML cell lines as well as primary AML samples upon ABT-199 treatment on the one hand, BIM is less bound to BCL-2 and on the other hand, in resistant cells protein levels of MCL-1 as well as BIM/MCL-1 complexes are enhanced.

Altogether, these results indicate that BIM and NOXA play an important role in the mechanisms of $\mathrm{BH} 3$ mimetic induced cell death and resistance. 


\section{5 $\mathbf{5} 63845$ and $A B T-199$ are translational more relevant than S55746 and A-1331852}

To transfer the results of experiments in cell lines to a clinical context, the impact on viability of primary AML samples and normal nonmalignant cells constitutes an important aspect for the use as an anticancer compound. In order for BH3 mimetics to be useful anticancer therapeutics they have to be effective against cancer cells while sparing normal nonmalignant cells.

Concerning primary AML samples, we and others observed heterogeneous responses to the treatment with $\mathrm{BH} 3$ mimetics. ${ }^{42,51,52}$ Besides samples that show high sensitivity to only either ABT-199 or $\$ 63845$ or both, there were also samples that did not respond to neither S63845 nor ABT-199. ${ }^{41,42}$ For both ABT-19964 as well as $S 63845^{42}$ it is published that they are sparing healthy human $C D 34^{+}$progenitor cells.

In order to investigate the toxicity of $\mathrm{BH} 3$ mimetics on non-malignant cells, $\mathrm{CD} 34^{+}$ $\mathrm{HPC}$ were exposed to these compounds. When these cells were treated with $\mathrm{BH} 3$ mimetics, PS exposure occurred upon concentrations of $1 \mu \mathrm{M}$ and above for S63845 and S55746. This is comparable with the toxicity of standard of care chemotherapeutic cytarabine. In contrast, ABT-199 and especially A-1331852 induce cell death in normal stem cells with lower doses and thus, show a higher toxicity. Considering the minimal $\mathrm{EC}_{50}$ that was necessary for apoptosis induction in primary AML samples, a possible therapeutic window could be determined. The most sensitive primary AML sample towards $\mathbf{S} 63845$ exhibits an $\mathrm{EC}_{50}$ value of $0.09 \mu \mathrm{M}$, while in HPCs apoptosis induction slightly starts upon a concentration of $1 \mu \mathrm{M}$ represented by PS exposure. Accordingly, the treatment of AML with S63845 could be performed with an effective concentration of $0.09 \mu \mathrm{M}$ without causing cytotoxicity on HPCs. The impact of $\mathbf{S} 63845$ on clonogenic growth of CFU-GM, CFU-GEMM as well as BFU-E was comparable with Ara-C, that represents an established compound in the treatment of AML. Indeed, clonogenic growth of HPCs was not inhibited by relevant concentrations of S63845. Altogether, our findings are in line with previous reports ${ }^{42}$ and confirm the results from our experiments with AML cell lines. 
For ABT-199, the most sensitive primary sample responded to a concentration of $0.05 \mu \mathrm{M}$. Apparent PS exposure of HPCs occurred upon concentrations of $\geq 0.1 \mu \mathrm{M}$. Thus, there exists only a narrow therapeutic window for the treatment of AML with ABT-199 without relevant toxic side effects on normal progenitor cells. Clonogenic growth of CFU-GEMM but not BFU-E and CFU-GM was slightly inhibited in a dose dependent manner by the treatment of ABT-199. Consequently, the toxicity profile of $\mathbf{S} 63845$ is more convenient than the profile of ABT-199, which is also in line with our investigations on AML cell lines.

Already upon 0.001 $\mu \mathrm{M}$ A-1331852 PS exposure of HPCs is detectable, whereas the lowest $\mathrm{EC}_{50}$ value for the treatment of primary AML samples amounted $4 \mu \mathrm{M}$. Additionally, colony forming is affected most by this BCL-XL inhibitor, with an inhibition of growth of CFU-GEMM in a dose dependent manner. Consequently, the toxicity profile of A-1331852 confirms the low relevance of this inhibitor in comparison to especially $\mathbf{S 6 3 8 4 5 .}$

All in all, our experiments on normal nonmalignant cells could confirm the superior role of $\mathrm{S} 63845$ as a therapeutic target for the treatment of AML. This is because it is not causing cytotoxicity on HPCs at efficacious doses in comparison to the other $\mathrm{BH} 3$ mimetics. 


\subsection{Concluding remarks}

This study directly compared several $\mathrm{BH} 3$ mimetics inhibiting the main anti-apoptotic BCL-2 proteins in AML cell lines as well as in primary AML samples for the first time. We could clearly demonstrate that MCL-1 represents the most promising therapeutic target in AML compared to the other targets tested in this study. Furthermore, we could confirm that $\mathrm{BH} 3$ mimetics induce cell death by intrinsic apoptosis. Investigations regarding the underlying molecular mechanism of S63845 induced apoptosis revealed a displacement of BH3-only proteins from MCL-1.

However, there remain a few questions that require further investigations to be answered.

First, the heterogeneous response we observed in cell lines and primary AML samples emphasize the need to identify markers that allow the assignment of a $\mathrm{BH} 3$ mimetic to a cell line, a primary AML sample or a patient. As we were not able to confirm previous results which indicate that BCL-2 protein expression levels may predict sensitivities towards $\mathrm{BH} 3$ mimetics, former studies proposed further opportunities to evolve prediction markers. For example, $\mathrm{BH} 3$ profiling $46,49,51$, mRNA expression levels ${ }^{51}$ or gene mutations ${ }^{52,55,56}$ may be investigated in AML cell lines as well as primary AML samples as a continuation of this study.

Second, although we were able to show a displacement of NOXA and BIMs from $M C L-1$, recent work from our group revealed that cell death is only moderately reduced by knockdown of BIM or NOXA ${ }^{41}$. This indicates a minor role of BIM and NOXA regarding the molecular mechanism behind $\mathrm{BH} 3$ mimetics induced cell death. Therefore, $\mathrm{BH} 3$ mimetics may induce BAX/BAK insertion into the outer mitochondrial membrane and thus the formation of pores to let apoptosis take place. Consequently, the localization as well as insertion of BAX and BAK at the outer mitochondrial membrane could be examined to further identify the molecular mechanism of $\mathrm{BH} 3$ mimetics induced apoptosis.

Third, MCL-1 plays an important role as a resistance factor for the treatment with ABT-199, which is also a promising compound in AML. Furthermore, BCL- $X L$ is 
reported to play a central role as a resistance factor for the treatment with ABT-199 as well as $\mathbf{S 6 3 8 4 5}$ (see chapter 5.1). This indicates that a combination of the respective $\mathrm{BH} 3$ mimetics may overcome these resistances.

Fourth, we only investigated these BH3 mimetics in AML cell lines and primary AML samples. Therefore, in vivo models like xenograft mice models could further verify our results. As inhibitors of MCL-1 are reported to be well tolerated at efficacious doses in mice ${ }^{42}$, the results of the first clinical trials with MCL-1 inhibitors are eagerly awaited.

In conclusion, this study generates the basis for $\mathbf{S 6 3 8 4 5}$ as a promising novel therapeutic strategy for the treatment of AML. 


\section{Summary}

\subsection{Deutsche Zusammenfassung}

BH3-Mimetika sind neuartige Krebstherapeutika, die Apoptose induzieren, indem sie anti-apoptotische BCL-2 Proteine blockieren. Hochspezifische Inhibitoren der wichtigsten anti-apoptotischen Proteine BCL-2, BCL-XL und MCL-1 versprechen neue Möglichkeiten für die Behandlung von AML. Derzeit ist jedoch unklar, welches dieser anti-apoptotischen BCL-2-Proteine das vielversprechendste Ziel bei AML darstellt. Daher untersuchten wir die Wirkung von BH3-Mimetika, die entweder BCL-2 (ABT-199, S55746), BCL-XL (A-1331852) oder MCL-1 (S63845) inhibieren, auf elf AML-Zelllinien. Das Screening der Sensitivität ergab eine heterogene Empfindlichkeit gegenüber den verschiedenen BH3-Mimetika, wobei die höchste Sensitivität gegenüber der Inhibition von MCL-1 beobachtet werden konnte. Ausgewählte Zelllinien, die gegenüber den spezifischen BH3-Mimetika sensibel waren, zeigten die Zelltod-Induktion über den intrinsischen Weg der Apoptose, die durch Verlust des mitochondrialen Membranpotentials, Exposition von Phosphatidylserin und Aktivierung von Caspasen gekennzeichnet war. Darüber hinaus stellte sich heraus, dass S63845 BIMs und NOXA aus der Bindungstasche von $\mathrm{MCL}-1$ verdrängt, um den apoptotischen Zelltod zu induzieren. Außerdem konnte die translatorische Relevanz dieser Studie durch Experimente an primären AML-Blasten, die ähnlich sensibel gegenüber $\mathrm{BH}$ Mimetika waren wie die untersuchten Zelllinien, präsentiert werden. Des Weiteren bestätigt sich die klinische Relevanz des MCL-1 Inhibitors durch die geringe Zytotoxizität in Bezug auf hämatopoetische Stammzellen.

Zusammenfassend zeigen unsere Ergebnisse, dass die Hemmung von BCL-2 Proteinen, insbesondere von MCL-1, durch BH3-Mimetika eine vielversprechende Strategie bei der Behandlung von AML darstellt. 


\subsection{English summary}

$\mathrm{BH} 3$ mimetics are novel anticancer therapeutics that induce apoptosis by targeting anti-apoptotic BCL-2 proteins. Highly specific inhibitors of the main antiapoptotic proteins $B C L-2, B C L-X L$ and $M C L-1$ promise new opportunities for the treatment of AML. However, it is currently unclear which of these anti-apoptotic BCL-2 proteins represents the most promising target in AML. Therefore, we investigated the effect of BH3 mimetics targeting either BCL-2 (ABT-199, S55746), BCL-XL(A-1331852) or MCL-1 (S63845) on eleven AML cell lines. Drug sensitivity screening revealed heterogeneous sensitivity towards the different BH3 mimetics, with the best responses observed upon targeting of MCL-1. Selected cell lines that displayed sensitivity towards the specific $\mathrm{BH} 3$ mimetics underwent intrinsic apoptosis, which was characterized by loss of mitochondrial membrane potential, exposure of phosphatidylserine and activation of caspases. Furthermore, S63845 turned out to displace BIMs and NOXA from MCL-1 to induce apoptotic cell death. Importantly, the translational relevance of this study was demonstrated by experiments in primary AML blasts, which displayed similar sensitivity towards $\mathrm{BH} 3$ mimetics as the cell lines did. Additionally, experiments with nonmalignant cells could confirm the clinical relevance of the MCL-1 inhibitor. There we could show, that $\mathbf{S 6 3 8 4 5}$ does not cause cytotoxicity on HPCs at efficacious doses.

In conclusion, our findings reveal that the inhibition of BCL-2 proteins, especially MCL-1, by BH3 mimetics can be a promising strategy in AML treatment. 


\section{References}

1. Jagannathan-Bogdan M, Zon LI. Hematopoiesis. Development. 2013;140(12):24632467.

2. Rieger MA, Schroeder T. Hematopoiesis. Cold Spring Harb Perspect Biol. 2012;4(12).

3. Orkin SH, Zon LI. Hematopoiesis: an evolving paradigm for stem cell biology. Cell. 2008;132(4):631-644.

4. Cassier PA, Castets M, Belhabri A, Vey N. Targeting apoptosis in acute myeloid leukaemia. Br J Cancer. 2017;117(8):1089-1098.

5. NationalCancerInstitute. Cancer Stat Facts: Leukemia - Acute Myeloid Leukemia. Surveillance, Epidemiology, and End Results Program -SEER. . https://seer.cancer.gov/statfacts/html/amyl.html. . Published 2018. Accessed2019.

6. Deschler B, Lubbert M. Acute myeloid leukemia: epidemiology and etiology. Cancer. 2006;107(9):2099-2107.

7. Greenlee RT, Hill-Harmon MB, Murray T, Thun M. Cancer statistics, 2001. CA Cancer J Clin. 2001;51(1):15-36.

8. Lowenberg B, Downing JR, Burnett A. Acute myeloid leukemia. N Engl J Med. 1999;341(14):1051-1062.

9. Dohner $\mathrm{H}$, Estey $\mathrm{E}$, Grimwade $\mathrm{D}$, et al. Diagnosis and management of $\mathrm{AML}$ in adults: 2017 ELN recommendations from an international expert panel. Blood. 2017;129(4):424-447.

10. Behbehani GK, Finck R, Samusik N, et al. Profiling myelodysplastic syndromes by mass cytometry demonstrates abnormal progenitor cell phenotype and differentiation. Cytometry B Clin Cytom. 2020.

11. Reiter A, Schrappe M, Parwaresch R, et al. Non-Hodgkin's lymphomas of childhood and adolescence: results of a treatment stratified for biologic subtypes and stage--a report of the Berlin-Frankfurt-Munster Group. J Clin Oncol. 1995;13(2):359-372.

12. Dohner H, Estey EH, Amadori S, et al. Diagnosis and management of acute myeloid leukemia in adults: recommendations from an international expert panel, on behalf of the European LeukemiaNet. Blood. 2010;115(3):453-474.

13. Bennett JM, Catovsky D, Daniel MT, et al. Proposed revised criteria for the classification of acute myeloid leukemia. A report of the French-American-British Cooperative Group. Ann Intern Med. 1985;103(4):620-625.

14. Bennett JM, Catovsky D, Daniel MT, et al. Criteria for the diagnosis of acute leukemia of megakaryocyte lineage (M7). A report of the French-American-British Cooperative Group. Ann Intern Med. 1985;103(3):460-462.

15. Bennett JM, Catovsky D, Daniel MT, et al. Proposals for the classification of the acute leukaemias. French-American-British (FAB) co-operative group. Br J Haematol. 1976;33(4):451-458.

16. Bennett JM, Catovsky D, Daniel MT, et al. Proposal for the recognition of minimally differentiated acute myeloid leukaemia (AML-MO). Br J Haematol. 1991;78(3):325-329.

17. cancer.org. Acute Myeloid Leukemia (AML) Subtypes and Prognostic Factors. https://www.cancer.org/cancer/acute-myeloid-leukemia/detection-diagnosisstaging/how-classified.html\#references. Published 2018. Updated August 21, 2018. Accessed2020.

18. Arber DA, Orazi A, Hasserjian R, et al. The 2016 revision to the World Health Organization classification of myeloid neoplasms and acute leukemia. Blood. 2016;127(20):2391-2405.

19. Dohner H, Weisdorf DJ, Bloomfield CD. Acute Myeloid Leukemia. N Eng/ J Med. 2015;373(12):1136-1152. 
20. Roboz GJ. Current treatment of acute myeloid leukemia. Curr Opin Oncol. 2012;24(6):711-719.

21. Lennard AL, Jackson GH. Stem cell transplantation. BMJ. 2000;321(7258):433-437.

22. Hanahan D, Weinberg RA. Hallmarks of cancer: the next generation. Cell. 2011;144(5):646-674.

23. Ashkenazi A. Targeting the extrinsic apoptosis pathway in cancer. Cytokine Growth Factor Rev. 2008;19(3-4):325-331.

24. Elmore S. Apoptosis: a review of programmed cell death. Toxicol Pathol. 2007;35(4):495-516.

25. Letai AG. Diagnosing and exploiting cancer's addiction to blocks in apoptosis. Nat Rev Cancer. 2008;8(2):121-132.

26. Dai H, Meng XW, Kaufmann SH. Mitochondrial apoptosis and BH3 mimetics. F100ORes. 2016;5:2804.

27. Vogler M, Walter HS, Dyer MJS. Targeting anti-apoptotic BCL2 family proteins in haematological malignancies - from pathogenesis to treatment. Br J Haematol. 2017;178(3):364-379.

28. Vogler $M$, Weber $K$, Dinsdale $D$, et al. Different forms of cell death induced by putative BCL2 inhibitors. Cell Death Differ. 2009;16(7):1030-1039.

29. Administration F-FaD. FDA approves venetoclax in combination for AML in adults. . https://www.fda.gov/Drugs/InformationOnDrugs/ApprovedDrugs/ucm626499.htm. .

Published 2018. Accessed2019.

30. Administration F-FaD. FDA approves new drug for chronic lymphocytic leukemia in patients with a specific chromosomal abnormality. .

https://www.fda.gov/NewsEvents/Newsroom/PressAnnouncements/ucm495253.htm. Published 2016. Accessed2019.

31. Medicine USNLo. Studies found for ABT-199 - Clinical Trials. https://clinicaltrials.gov/ct2/results?cond $=\&$ term $=$ abt$199 \&$ cntry $=\&$ state $=\&$ city $=\&$ dist $=.$. Accessed 2019 .

32. Casara P, Davidson J, Claperon A, et al. S55746 is a novel orally active BCL-2 selective and potent inhibitor that impairs hematological tumor growth. Oncotarget. 2018;9(28):20075-20088.

33. Medicine USNLo. Studies found for S55746 - Clinical Trials. https://clinicaltrials.gov/ct2/results?cond=\&term=s55746\&cntry=\&state=\&city=\&dist=. Accessed2019.

34. Leverson JD, Phillips DC, Mitten MJ, et al. Exploiting selective BCL-2 family inhibitors to dissect cell survival dependencies and define improved strategies for cancer therapy. Sci Transl Med. 2015;7(279):279ra240.

35. Medicine USNLo. Studies found for A-1331852 - Clinical Trials. https://clinicaltrials.gov/ct2/results? cond=\&term=A$1331852 \&$ cntry $=\&$ state $=\&$ city $=\&$ dist $=$. Accessed 2019 .

36. Medicine USNLo. Studies found for $\mathbf{S 6 3 8 4 5}$ - Clinical Trials. https://clinicaltrials.gov/ct2/results?cond=\&term=s63845\&cntry=\&state=\&city=\&dist=. Accessed2019.

37. Medicine USNLo. Studies found for $\$ 64315$ - Clinical Trials. https://clinicaltrials.gov/ct2/results?cond=\&term=S64315+\&cntry=\&state=\&city=\&dist $=$. Accessed2019.

38. Medicine USNLo. Studies found for AMG 176 - Clinical Trials. .

39. Medicine USNLo. Studies found for AZD5991 - Clinical trials.

40. Lacombe F, Durrieu F, Briais A, et al. Flow cytometry CD45 gating for immunophenotyping of acute myeloid leukemia. Leukemia. 1997;11(11):1878-1886.

41. Ewald L, Dittmann J, Vogler M, Fulda S. Side-by-side comparison of BH3-mimetics identifies MCL-1 as a key therapeutic target in AML. Cell Death Dis. 2019;10(12):917. 
42. Kotschy A, Szlavik Z, Murray J, et al. The MCL1 inhibitor 563845 is tolerable and effective in diverse cancer models. Nature. 2016;538(7626):477-482.

43. Anstee NS, Bilardi RA, Ng AP, et al. Impact of elevated anti-apoptotic MCL-1 and BCL-2 on the development and treatment of MLL-AF9 AML in mice. Cell Death Differ. 2018.

44. Moujalled DM, Pomilio G, Ghiurau C, et al. Combining BH3-mimetics to target both $\mathrm{BCL}-2$ and $\mathrm{MCL1}$ has potent activity in pre-clinical models of acute myeloid leukemia. Leukemia. 2018.

45. Niu X, Zhao J, Ma J, et al. Binding of Released Bim to Mcl-1 is a Mechanism of Intrinsic Resistance to ABT-199 which can be Overcome by Combination with Daunorubicin or Cytarabine in AML Cells. Clin Cancer Res. 2016;22(17):4440-4451.

46. Ramsey HE, Fischer MA, Lee T, et al. A Novel MCL1 Inhibitor Combined with Venetoclax Rescues Venetoclax-Resistant Acute Myelogenous Leukemia. Cancer Discov. 2018;8(12):1566-1581.

47. Lin KH, Winter PS, Xie A, et al. Targeting MCL-1/BCL-XL Forestalls the Acquisition of Resistance to ABT-199 in Acute Myeloid Leukemia. Sci Rep. 2016;6:27696.

48. Glaser SP, Lee EF, Trounson E, et al. Anti-apoptotic Mcl-1 is essential for the development and sustained growth of acute myeloid leukemia. Genes Dev. 2012;26(2):120-125.

49. Soderquist RS, Crawford L, Liu E, et al. Systematic mapping of BCL-2 gene dependencies in cancer reveals molecular determinants of $\mathrm{BH} 3$ mimetic sensitivity. Nat Commun. 2018;9(1):3513.

50. Souers AJ, Leverson JD, Boghaert ER, et al. ABT-199, a potent and selective BCL-2 inhibitor, achieves antitumor activity while sparing platelets. Nat Med. 2013;19(2):202208.

51. Pan R, Hogdal LJ, Benito JM, et al. Selective BCL-2 inhibition by ABT-199 causes ontarget cell death in acute myeloid leukemia. Cancer Discov. 2014;4(3):362-375.

52. Kontro M, Kumar A, Majumder MM, et al. HOX gene expression predicts response to BCL-2 inhibition in acute myeloid leukemia. Leukemia. 2017;31(2):301-309.

53. Zhou W, Xu J, Gelston E, et al. Inhibition of Bcl-xL overcomes polyploidy resistance and leads to apoptotic cell death in acute myeloid leukemia cells. Oncotarget. 2015;6(25):21557-21571.

54. Jilg S, Reidel V, Muller-Thomas C, et al. Blockade of BCL-2 proteins efficiently induces apoptosis in progenitor cells of high-risk myelodysplastic syndromes patients. Leukemia. 2016;30(1):112-123.

55. Chan SM, Thomas D, Corces-Zimmerman MR, et al. Isocitrate dehydrogenase 1 and 2 mutations induce BCL-2 dependence in acute myeloid leukemia. Nat Med. 2015;21(2):178-184.

56. Pronier E, Levine RL. IDH1/2 mutations and BCL-2 dependence: an unexpected Chink in AML's armour. Cancer Cell. 2015;27(3):323-325.

57. Dengler MA, Teh CE, Thijssen R, et al. Potent efficacy of MCL-1 inhibitor-based therapies in preclinical models of mantle cell lymphoma. Oncogene. 2020;39(9):20092023.

58. Greaves $\mathrm{G}$, Milani M, Butterworth $\mathrm{M}$, et al. BH3-only proteins are dispensable for apoptosis induced by pharmacological inhibition of both MCL-1 and BCL-XL. Cell Death Differ. 2018.

59. Chen L, Willis SN, Wei A, et al. Differential targeting of prosurvival $\mathrm{BCl}-2$ proteins by their BH3-only ligands allows complementary apoptotic function. Mol Cell. 2005;17(3):393-403.

60. Gomez-Bougie P, Menoret E, Juin P, Dousset C, Pellat-Deceunynck C, Amiot M. Noxa controls Mule-dependent $\mathrm{Mcl}-1$ ubiquitination through the regulation of the Mcl1/USP9X interaction. Biochem Biophys Res Commun. 2011;413(3):460-464. 
61. Song T, Wang Z, Ji F, et al. Deactivation of Mcl-1 by Dual-Function Small-Molecule Inhibitors Targeting the Bcl-2 Homology 3 Domain and Facilitating Mcl-1 Ubiquitination. Angew Chem Int Ed Engl. 2016;55(46):14250-14256.

62. Guikema JE, Amiot M, Eldering E. Exploiting the pro-apoptotic function of NOXA as a therapeutic modality in cancer. Expert Opin Ther Targets. 2017;21(8):767-779.

63. Algarin EM, Diaz-Tejedor A, Mogollon $\mathrm{P}$, et al. Preclinical evaluation of the simultaneous inhibition of MCL-1 and BCL-2 with the combination of $\mathrm{S} 63845$ and venetoclax in multiple myeloma. Haematologica. 2020;105(3):e116-e120.

64. Liu F, Knight T, Su Y, et al. Venetoclax Synergistically Enhances the Anti-leukemic Activity of Vosaroxin Against Acute Myeloid Leukemia Cells Ex Vivo. Target Oncol. 2019;14(3):351-364. 


\section{Related publications}

The results of this study contributed essentially to a publication in the journal Cell Death \& Disease.

Complete citation:

Ewald L, Dittmann J, Vogler M, Fulda S. Side-by-side comparison of BH3mimetics identifies MCL-1 as a key therapeutic target in AML. Cell Death Dis. 019;10(12):917. 


\section{Curriculum vitae}

Larissa Ewald

E-Mail

larissa.ewald@gmx.de

Geburtsdatum

16.09.1995

Geburtsort

Frankfurt am Main, Deutschland

Akademischer Werdegang

Voraussichtlich Dez. 2020

Dritter Abschnitt der Ärztlichen Prüfung - M3

Nov. 2019 - Okt. 2020

Praktisches Jahr

Okt. 2019

Zweiter Abschnitt der Ärztlichen Prüfung - M2

(Note: 2)

Sept. 2015

Erster Abschnitt der Ärztlichen Prüfung

Physikum - M1 (Note: 1,0)

Okt. 2013

Beginn des Studiums der Humanmedizin an der Goethe- Universität Frankfurt am Main 
Praktisches Jahr

$29.06 .2020-18.10 .2020$

Innere Tertial

Nordwestkrankenhaus Frankfurt am Main

09.03.2020 - 28.06.2020

Chirurgie Tertial

04.05.2020 - 28.06.2020: Allgemeinchirurgie

Nordwestkrankenhaus Frankfurt am Main

09.03.2020 - 03.05.2020: Unfallchirurgie

BG Unfallklinik Frankfurt am Main

18.11.2019-08.03.2020

Wahl-Tertial - Orthopädie

BG Unfallklinik Frankfurt am Main

Promotion

Dez. 2019

Publikation im Journal 'Cell Death \&

Disease'

Ewald L, Dittmann J, Vogler M, Fulda S.

"Side-by-side comparison of BH3-mimetics

identifies MCL-1 as a key therapeutic target in AML"

15. - 16. Mai 2019

\section{$9^{\text {th }}$ Mildred Scheel Cancer Conference}

Poster Präsentation: 'Side-by-side

comparison of $\mathrm{BH} 3$ mimetics identifies MCL-1

as a key therapeutic target in AML' 
24. - 25. Sept. 2018

Nov. 2017 - Okt. 2018

\section{Symposium der Deutschen Krebshilfe}

Poster Präsentation: 'Evaluation of $\mathrm{BH} 3$ mimetics as a novel therapeutic strategy in acute myeloid leukemia'

Forschung im Rahmen einer

experimentellen Doktorarbeit im Institut für experimentelle Tumorforschung in der

Pädiatrie, Fr. Prof. Dr. Simone Fulda,

Frankfurt am Main

Thema: „Evaluation of $\mathrm{BH} 3$ mimetics as a novel therapeutic strategy in AML"

Stipendiatin im Mildred-Scheel-

Doktorandenprogramm der Deutschen

Krebshilfe

Famulaturen

21.02.-24.03.2019

30.09. -29.10 .2017$

01.02.-28.02.2017

26.07.-25-08.2016
Allgemeinmedizinische Gemeinschaftspraxis

„Röbel \& Kollegen“ Frankfurt am Main

Plastische und Ästhetische Chirurgie, Wiederherstellungs- und Handchirurgie des Markus Krankenhauses Frankfurt am Main

Zentrale Notaufnahme der BG Unfallklinik Frankfurt am Main

Unfallchirurgie \& orthopädische Chirurgie der BG Unfallklinik Frankfurt am Main 
Elisabethenschule (Gymnasium),

Frankfurt am Main

Abschluss: Allgemeine Hochschulreife $(1,4)$

Auszeichnung für die jahrgangsbeste

Abiturientin des Fachs Chemie: GDCh-

Abiturientenpreis

$2001-2005$

Engelbert-Humperdinck-Schule,

Frankfurt am Main

Nebenbeschäftigungen

Nov. 2015 - Dez. 2016

Studentischer Aushilfsjob

Kinderwunschzentrum, Offenbach

seit April 2015

Ehrenamtliche Mitarbeit bei 'Uni-hilft'

Frankfurt am Main

Feb. 2011 - Juni 2019

Ehrenamtliche Mitarbeit im

Fußballverein TSG51 
Zusatzqualifikationen

Praxisorientierte Kurse

24.07.2016

Chirurgischer Naht- und Knotenkurs

2016/17

Sonographie Kurs

(DEGUM - zertifizierter curricularer

Ultraschallkurs für Abdomen- und

Schilddrüsensonographie)

Sprachkenntnisse

Englisch (verhandlungssicher in Wort und

Schrift)

Latein (Latinum)

$\underline{\text { IT-Kenntnisse }}$

Betriebssysteme (Windows),

MS Office (Word, Excel, Power Point)

Laborsoftware (MagellanTM, ImageJTM,

DIVATM, Graph PadPrismTM)

Frankfurt am Main, 18.06.2020

Larissa Ewald 


\section{Danksagung}

Nach dieser aufregenden und lehrreichen, aber auch anstrengenden Zeit, möchte ich mich bei allen bedanken, die mich in dieser Zeit unterstützt haben.

Zuallererst möchte ich meiner Doktormutter Prof. Dr. Simone Fulda für die Möglichkeit meine Doktorarbeit in Ihrer AG absolvieren zu dürfen danken. Vielen Dank für die dauerhafte Unterstützung, die hilfreichen Diskussionen sowie das Ermöglichen der Teilnahme an Konferenzen und Symposien.

Ausdrücklichsten Dank möchte ich auch der Deutschen Krebshilfe für das Auszeichnen meiner Bemühungen sowie die volle Unterstützung mit dem Stipendium im Rahmen des Mildred-Scheel Doktorandenprogramms für Medizinstudierende aussprechen. Dadurch war es mir möglich, mich vollständig auf die Forschung und die Doktorarbeit zu konzentrieren.

Ein großes Danke auch an Dr. Meike Vogler und Jessica Dittmann, die mich nicht nur während des Jahres im Labor, sondern auch darüber hinaus jederzeit unterstützt und jede Frage konstruktiv und hilfreich beantwortet haben.

Vielen Dank auch an Christina Hugenberg, die uns Allen das Leben im Labor mit der Erledigung von und Hilfe bei bürokratischen Dingen sowie der Weitergabe von wichtigen Informationen sehr erleichtert.

Nicht zu vergessen der Dank an die gesamte AG Fulda für die tolle Zeit, die große Hilfe in allen möglichen - wissenschaftlichen oder persönlichen - Belangen, das Schließen neuer Freundschaften und das Motivieren in unmotivierten Zeiten. Danke insbesondere an Rebekka!

Zum Schluss möchte ich auch meiner Familie, meinen Freunden und Marvin dafür danken, dass ihr immer an mich geglaubt habt und glaubt, mich immer unterstützt und mir die Stärke gebt, die ich in schwachen Zeiten brauchen kann.

DANKE! 


\section{Schriftliche Erklärung}

Ich erkläre ehrenwörtlich, dass ich die dem Fachbereich Medizin der Johann Wolfgang Goethe-Universität Frankfurt am Main zur Promotionsprüfung eingereichte Dissertation mit dem Titel

\section{Evaluation of BH3 mimetics as a novel therapeutic strategy in acute myeloid leukemia}

in dem Institut für experimentelle Tumorforschung in der Pädiatrie unter Betreuung und Anleitung von Prof. Dr. Simone Fulda mit Unterstützung durch Dr. Meike Vogler ohne sonstige Hilfe selbst durchgeführt und bei der Abfassung der Arbeit keine anderen als die in der Dissertation angeführten Hilfsmittel benutzt habe. Darüber hinaus versichere ich, nicht die Hilfe einer kommerziellen Promotionsvermittlung in Anspruch genommen zu haben.

Ich habe bisher an keiner in- oder ausländischen Universität ein Gesuch um Zulassung zur Promotion eingereicht*. Die vorliegende Arbeit wurde bisher nicht als Dissertation eingereicht.

Vorliegende Ergebnisse der Arbeit wurden (oder werden) in folgendem Publikationsorgan veröffentlicht:

Ewald L, Dittmann J, Vogler M, Fulda S. Side-by-side comparison of BH3-mimetics identifies MCL-1 as a key therapeutic target in AML. Cell Death Dis. 2019;10(12):917. 